Supporting Information for the Paper Entitled:

\title{
Werner-Type Complexes of Uranium(III) and (IV)
}

Judith Riedhammer, ${ }^{\dagger}$ J. Rolando Aguilar-Calderón, ${ }^{\ddagger}, \S$ Matthias Miehlich, ${ }^{\dagger}$ Dominik P. Halter ${ }^{\dagger}$

Dominik Munz,$^{\dagger}$ Frank W. Heinemann, ${ }^{\dagger}$ Skye Fortier, ${ }^{\ddagger}$ Karsten Meyer, ${ }^{*},{ }^{\dagger}$ and Daniel J. Mindiola ${ }^{*} \dagger, \S$

$\dagger$ Inorganic Chemistry, Department of Chemistry and Pharmacy, Friedrich-AlexanderUniversity Erlangen-Nürnberg (FAU), 91058 Erlangen, Germany.

$¥$ Department of Chemistry and Biochemistry, University of Texas at El Paso, El Paso, Texas 79968, USA.

§ Department of Chemistry, University of Pennsylvania, Philadelphia, Pennsylvania 19104, USA.

\section{Supporting Information Table of Contents}

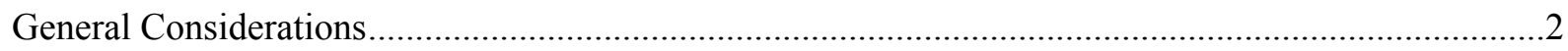

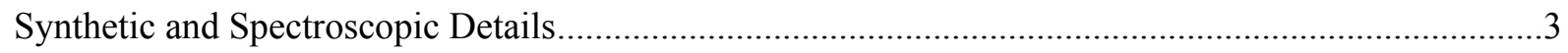

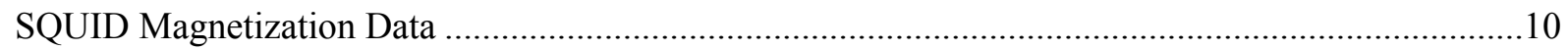

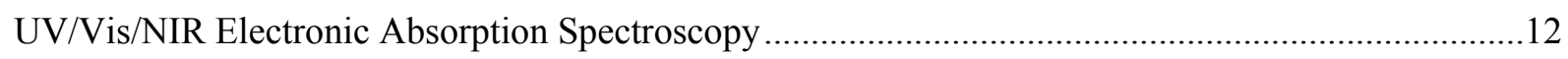

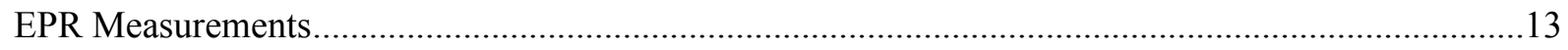

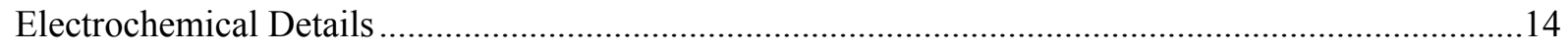

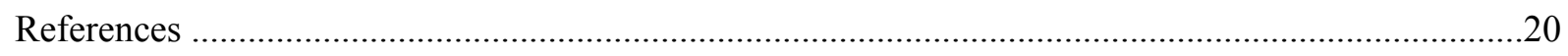

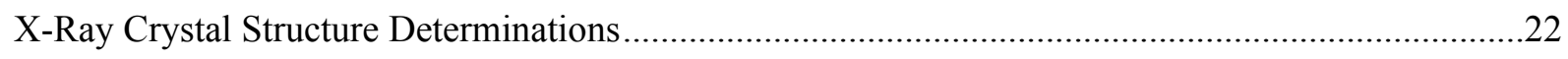

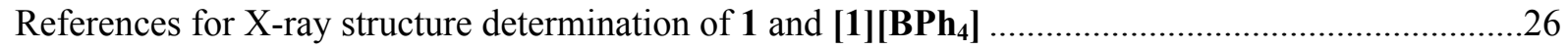

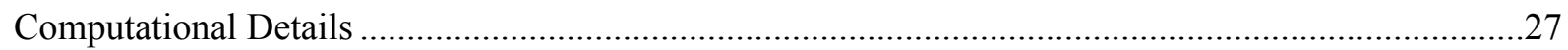

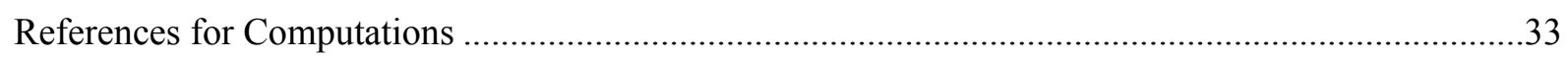




\section{General Considerations}

All air- and moisture-sensitive experiments were performed under a dry dinitrogen atmosphere, using standard Schlenk techniques or in an MBraun inert-gas glovebox containing an atmosphere of purified dinitrogen. The glovebox is equipped with a $-35{ }^{\circ} \mathrm{C}$ freezer. All glassware was dried by storage in an oven overnight $(>8 \mathrm{~h})$ at a temperature of $>150{ }^{\circ} \mathrm{C}$. Solvents were purified using a two-column, solid-state purification system (Glass Contour System, Irvine, CA), transferred to the glovebox without exposure to air, and stored over molecular sieves and sodium (where appropriate). NMR solvents were obtained packaged under argon and stored over activated molecular sieves and sodium (where appropriate) prior to use or were vacuum transferred from purple ketyl solutions over sodium. The precursor complexes $\left.\left[\mathrm{UI}_{3} \text { (dioxane }\right)_{1.5}\right]^{1}$ and $\left[\mathrm{UI}_{3}(\mathrm{THF})_{4}\right]^{2}$ were prepared according to literature procedures. ${ }^{1} \mathrm{Fc}\left[\mathrm{Al}\left\{\mathrm{OC}\left(\mathrm{CF}_{3}\right)_{3}\right\}_{4}\right]$ was prepared from the reaction of $\mathrm{Li}\left[\mathrm{Al}\left\{\mathrm{OC}\left(\mathrm{CF}_{3}\right)_{3}\right\}_{4}\right]^{3}$ with $\mathrm{FcCl}$ in $\mathrm{Et}_{2} \mathrm{O}$. All other reagents were acquired from commercial sources and used as received. ${ }^{1} \mathrm{H}$ NMR spectra were recorded on a JEOL ECX $270 \mathrm{MHz}$, JEOL ECZ $400 \mathrm{MHz}$ instrument, or a Bruker AVANCE III $400 \mathrm{MHz}$ spectrometer operating at frequencies of $269.714 \mathrm{MHz}$ and $400.178 \mathrm{MHz}$ for ${ }^{1} \mathrm{H}$ NMR spectra, and at a probe temperature of $25^{\circ} \mathrm{C}$; if not stated otherwise. Chemical shifts, $\delta$, are reported relative to residual ${ }^{1} \mathrm{H}$ NMR resonances of the solvent in ppm. ${ }^{4}$ ${ }^{19} \mathrm{~F}\left\{{ }^{1} \mathrm{H}\right\}$ NMR spectra were collected using a Bruker AVANCE III $400 \mathrm{MHz}$ spectrometer and are referenced to external $\alpha, \alpha, \alpha$-trifluorotoluene $\left(-63.72 \mathrm{ppm}\right.$ relative to $\mathrm{CFCl}_{3}$ at $0 \mathrm{ppm}$ ). Elemental analyses were obtained using Euro EA 3000 (Euro Vector) and EA 1108 (CarloErba) elemental analyzers in the Chair of Inorganic and General Chemistry at FAU. Electronic absorption spectra were recorded from 250 to $2200 \mathrm{~nm}$ (Shimadzu, UV-3600 or Zhengzhou Nanbei Instrument spectrophotometer) in the indicated solvent at room temperature. Magnetization data of micro-crystalline and powdered samples were recorded with a SQUID magnetometer (Quantum Design) at $10 \mathrm{kOe}$ as a function of temperature (2-300 K). Values of the magnetic susceptibility were corrected for the underlying diamagnetic increment $\left(\chi_{\text {dia }}=\right.$ $-505.18 \times 10^{-6} \mathrm{~cm}^{3} \mathrm{~mol}^{-1} \mathbf{1},-558.28 \times 10^{-6} \mathrm{~cm}^{3} \mathrm{~mol}^{-1}[\mathbf{1}]\left[\mathbf{P F}_{6}\right]$, by using tabulated Pascal constants, and the effect of the blank sample holders (gelatin capsule/straw). ${ }^{5}$ Data reproducibility was carefully checked on three independently synthesized and measured samples. Samples used for magnetization measurements were checked for chemical composition and purity by $\mathrm{CHN}$ elemental analysis and ${ }^{1} \mathrm{H}$ NMR spectroscopy. Electron Paramagnetic Resonance (EPR) spectra were recorded on a JEOL continuous wave spectrometer JES-FA200 equipped with an X-band Gunn oscillator bridge, a cylindrical mode cavity, and a helium cryostat. The sample was freshly dissolved in toluene in an approximately $40 \mathrm{mM}$ concentration in a quartz glass EPR tube. Analysis and simulation of the data was performed using the software "eview" and "esim" written by E. Bill (mail: ebill@gwdg.de, MPI for Chemical Energy Conversion, Mülheim an der Ruhr). Electrochemical experiments were carried out, using a three-electrode setup with rotating glassy carbon working electrode ( $3 \mathrm{~mm}$ diameter) and platinum rods as counter- and reference electrodes. The potentiostat was a Metrohm $\mu$ Autolab Type-III. The whole setup was placed inside a nitrogen equipped glovebox. All samples were measured in $0.1 \mathrm{M}$ electrolyte solutions of $\left[\mathrm{N}(n-\mathrm{Bu})_{4}\right]\left[\mathrm{PF}_{6}\right]$ (purchased from Sigma Aldrich and used without purification) in THF or DCM. Reported half-wave potentials were referenced to the $\mathrm{Fc}^{+} / \mathrm{Fc}$ redox couple by adding recrystallized and purified ferrocene to the sample solution.

Caution: Natural uranium is a radioactive $\alpha$-emitter; and thus, direct and prolonged exposure and inhalation must be prevented. Manipulations should be carried out with care in monitored fume hoods or in inert atmosphere gloveboxes in radiation-controlled laboratories equipped with appropriate radiation counting instruments. 


\section{Nomenclature: ${ }^{\mathrm{R} 1}$ nacnac ${ }^{\mathrm{R} 2}$, where $\mathrm{R} 1$ is backbone $\mathrm{C}$ - and $\mathrm{R} 2$ is $\mathrm{N}$-functionalization.}
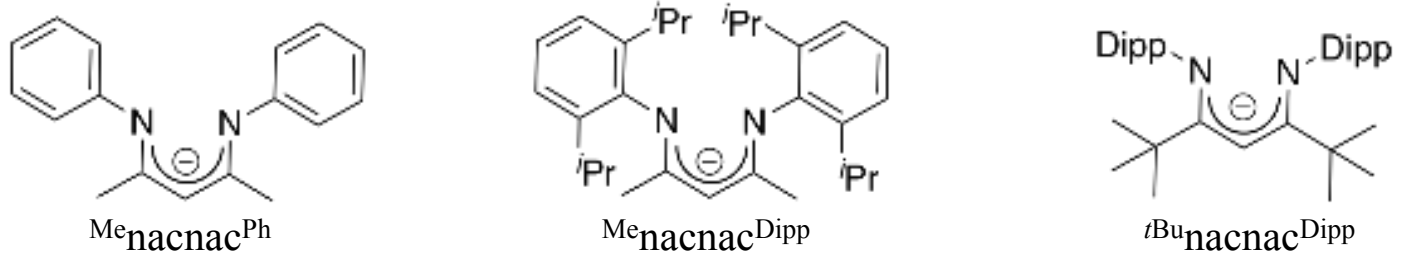

Synthetic and Spectroscopic Details

\section{Synthesis of $\mathrm{PhHNC}\left(\mathrm{CH}_{3}\right) \mathrm{CH}\left(\mathrm{CH}_{3}\right) \mathrm{CNPh}\left({ }^{\mathrm{Me}}\right.$ nacnac $\left.^{\mathrm{Ph}} \mathrm{H}\right){ }^{6}$}

Acetylacetone $(10.01 \mathrm{~g}, 0.100 \mathrm{~mol})$ was dissolved in aniline $(18.63 \mathrm{~g}, 0.200 \mathrm{~mol})$ and the solution was cooled down to $0{ }^{\circ} \mathrm{C}$. Hydrochloric acid $(8 \mathrm{~mL})$ was slowly added while stirring. After addition, the mixture was allowed to warm up to room temperature and was stirred for 16 $\mathrm{h}$, whereupon a brownish solid was formed. After completion of the reaction, methylene chloride $(\sim 60 \mathrm{~mL})$ was added to redissolve the solid. To the resulting solution aqueous $\mathrm{Na}_{2} \mathrm{CO}_{3}$ $(80 \mathrm{~mL})$ was added. The aqueous phase was separated from the organic phase and extracted with methylene chloride $(3 \times \sim 20 \mathrm{~mL})$. The organic phases were collected and dried over $\mathrm{MgSO}_{4}$. The solvent was concentrated under reduced pressure. The resulting yellow oil can be recrystallized from $\mathrm{MeOH}$ at $-35^{\circ} \mathrm{C}$ as small yellow plates. Yield: $11.80 \mathrm{~g}, 0.047 \mathrm{mmol}, 47 \%$. ${ }^{1} \mathbf{H}$ NMR (400 MHz, $\mathrm{CDCl}_{3}$ ): $\delta=12.81$ (br. s, 1H, N-H), 7.36 (m, 4H, $m$-ArH), 7.12 (m, 2H, p-ArH), $7.04(\mathrm{~m}, 4 \mathrm{H}, o-\mathrm{ArH}), 4.95(\mathrm{~s}, 1 \mathrm{H}, \alpha-\mathrm{CH}), 2.08\left(\mathrm{~s}, 6 \mathrm{H}, \beta-\mathrm{CH}_{3}\right) .{ }^{13} \mathbf{C}$ NMR $(270 \mathrm{MHz}$, $\left.\mathrm{CDCl}_{3}\right): \delta=159.5,145.8,128.9,123.3,122.7,97.5,20.9$. CHN Elemental analysis calculated for $\mathrm{C}_{17} \mathrm{H}_{18} \mathrm{~N}_{2}$ : N 11.19\%; C 81.56\%; H 7.25\%. Found: N $11.31 \%$; C 81.99\%; H 7.25\%.

\section{Synthesis of $[\mathrm{K}]\left[^{\mathrm{Me}}\right.$ nacnac $\left.^{\mathrm{Ph}}\right]$.}

A solution of KHMDS (0.402 g, $2.013 \mathrm{mmol})$ in $\mathrm{Et}_{2} \mathrm{O}(4 \mathrm{~mL})$ was added drowise to a solution of ${ }^{\mathrm{Me}}$ nacnac $^{\mathrm{Ph}} \mathbf{H}(0.501 \mathrm{~g}, 2.000 \mathrm{mmol})$ in $\mathrm{Et}_{2} \mathrm{O}(2 \mathrm{~mL})$. After stirring for $3.5 \mathrm{~h}$, the reaction mixture was cooled down to $-35^{\circ} \mathrm{C}$. The yellow solid was filtered off and washed with cold $\mathrm{Et}_{2} \mathrm{O}(3 \times 1.5 \mathrm{~mL})$. [K] [ $\left.{ }^{\mathrm{Me}} \mathbf{n a c n a c}^{\mathrm{Ph}}\right]$ was dried in vacuo yielding a yellow, fluffy powder. Yield: $0.565 \mathrm{~g}, 1.960 \mathrm{mmol}, 98 \%$. ${ }^{1} \mathbf{H}$ NMR $\left(270 \mathrm{MHz}, \mathrm{CD}_{3} \mathrm{CN}\right): \delta=7.11$ (br. m, $\left.4 \mathrm{H}, m-\mathrm{ArH}\right), 6.67$ (br. m, $6 \mathrm{H}, p$-ArH and $o$-ArH), 4.29 (br. s, $1 \mathrm{H}, \alpha-\mathrm{CH}$ ), 1.88 (br. s, $6 \mathrm{H}, \beta-\mathrm{CH}_{3}$ ) ppm. ${ }^{13} \mathbf{C} \mathbf{N M R}$ $\left(270 \mathrm{MHz},\left(\mathrm{CD}_{3}\right)_{2} \mathrm{SO}\right): \delta=160.6,156.4,127.9,122.2,117.0,89.6,24.2$.

\section{Synthesis of $\left[\mathrm{U}\left({ }^{\mathrm{Me}} \text { nacnac }^{\mathrm{Ph}}\right)_{3}\right] \mathbf{1}$.}

To a solution of $\mathrm{UI}_{3}(\text { diox })_{1,5}(0.173 \mathrm{~g}, 0.231 \mathrm{mmol})$ in THF $(4 \mathrm{~mL})$ was added [K] ${ }^{\mathrm{Me}}$ nacnac $\left.^{\mathbf{P h}}\right]$ $(0.203 \mathrm{mg}, 0.703 \mathrm{mmol})$ as a suspension in THF $(4 \mathrm{~mL})$. The reaction mixture was stirred for $2.5 \mathrm{~h}$. The solvent was removed and the resulting dark green solid was redissolved in toluene and filtered through a pad of celite. After the removal of toluene, the olive green solid was washed with cold pentane $(3 \times 1.5 \mathrm{~mL})$ and dried in vacuo. 1 can be recrystallized from a concentrated toluene solution at $-35^{\circ} \mathrm{C}$. Yield: $0.162 \mathrm{~g}, 0.164 \mathrm{mmol}, 71 \% .{ }^{1} \mathbf{H}$ NMR $(400 \mathrm{MHz}$, $\mathrm{C}_{6} \mathrm{D}_{6}$ ): $\delta=6.07(\mathrm{~s}), 5.72(\operatorname{tr}, J=7.4 \mathrm{~Hz}),-31.63(\mathrm{~s})$. CHN Elemental analysis calculated for $\mathrm{C}_{51} \mathrm{H}_{51} \mathrm{~N}_{6} \mathrm{U}$ : N 8.52\%; C 62.12\%; H 5.21\%. Found: N 8.42\%; C 61.86\%; H 5.26\%. 


\section{Synthesis of $\left[\mathrm{U}\left({ }^{\mathrm{Me}} \text { nacnac }^{\mathrm{Ph}}\right)_{3}\right]\left[\mathrm{PF}_{6}\right][1]\left[\mathrm{PF}_{6}\right]$.}

To a solution of $1(0.100 \mathrm{~g}, 0.101 \mathrm{mmol})$ in THF $(4 \mathrm{~mL})\left[\mathrm{CoCp}_{2}\right]\left[\mathrm{PF}_{6}\right](0.034 \mathrm{~g}, 0.101 \mathrm{mmol})$ was added as a suspension in THF $(4 \mathrm{~mL})$. The reaction mixture was stirred for $3 \mathrm{~h}$ during which time an orange solid precipitates. The reaction mixture was filtered though a medium

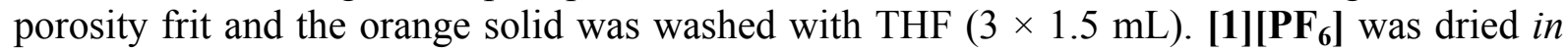
vacuo. Yield: $0.099 \mathrm{~g}, 0.088 \mathrm{mmol}, 87 \%$. ${ }^{1} \mathbf{H}$ NMR (400 MHz, $\mathrm{CD}_{2} \mathrm{Cl}_{2}$ ): $\delta=9.35$ (br. s, $3 \mathrm{H}$ ), 5.39 (br. s), 4.81 (br. s), -1.87 (br. s). CHN Elemental analysis calculated for $\mathrm{C}_{51} \mathrm{H}_{51} \mathrm{~F}_{6} \mathrm{~N}_{6} \mathrm{PU}$ : N 7.43\%; C 54.16\%; H 4.55\%. Found: N 7.25\%; C 54.51\%; H 4.20\%.

\section{Synthesis of $\left[\mathrm{U}\left({ }^{\mathrm{Me}} \mathrm{nacnac}^{\mathrm{Ph}}\right)_{3}\right]\left[\mathrm{BPh}_{4}\right],[1]\left[\mathrm{BPh}_{4}\right]$, (for SC-XRD only).}

To a suspension of [1] $\left(\mathbf{P F}_{\mathbf{6}}\right)(0.064 \mathrm{~g}, 0.057 \mathrm{mmol})$ in THF $(2 \mathrm{~mL})$ a solution of $\mathrm{NaBPh}_{4}(0.018$ g, $0.053 \mathrm{mmol})$ in THF (3 mL) was added dropwise. During addition, the color of the reaction mixture changed to deep red. After the reaction mixture was stirred for $1 \mathrm{~h}$, the solution was filtered and the solvent was removed in vacuo. [1] $\left[\mathbf{B P h}_{4}\right]$ can be recrystallized from a concentraded THF solution at $-35^{\circ} \mathrm{C}$. Yield: $0.066 \mathrm{~g}, 0.050 \mathrm{mmol}, 95 \%$. ${ }^{1} \mathbf{H}$ NMR $(400 \mathrm{MHz}$, $\mathrm{C}_{6} \mathrm{D}_{5} \mathrm{Cl}$ ): $\delta=9.12$ (br. s), 7.99 (m), 7.24 (tr, $J=7.4 \mathrm{~Hz}$ ), 7.04 (m), 5.12 (br. s), 4.60 (br. s), 2.07 (br. s).

\section{Synthesis of [U( $\left.\left(^{\mathrm{Me}} \text { nacnac }^{\mathrm{Ph}}\right)_{3}\right]\left[\mathrm{Al}\left\{\mathrm{OC}\left(\mathrm{CF}_{3}\right)_{3}\right\}_{4}\right],[1]\left[\mathrm{Al}\left\{\mathrm{OC}\left(\mathrm{CF}_{3}\right)_{3}\right\}_{4}\right]$, (for SC-XRD only).}

To a solution of $\mathbf{1}(0.400 \mathrm{~g}, 0.404 \mathrm{mmol})$ in $\mathrm{Et}_{2} \mathrm{O}(10 \mathrm{~mL})$ a solution of $\mathbf{F c}\left[\mathbf{A l}\left\{\mathbf{O C}\left(\mathbf{C F}_{3}\right)_{3}\right\}_{4}\right]$ $(0.698 \mathrm{~g}, 0.606 \mathrm{mmol})$ in $\mathrm{Et}_{2} \mathrm{O}(3 \mathrm{~mL})$ was added dropwise. During the addition, the color of the reaction mixture changed to deep red. After the reaction mixture was stirred for $1 \mathrm{~h}$, the solvent was removed in vacuo until a pale-red solid was obtained. This material was washed with toluene $(3 \times 4 \mathrm{~mL})$ and hexanes $(3 \times 4 \mathrm{~mL})$ and dried in in vacuo. [1] [AI $\left.\left\{\mathbf{O C}\left(\mathbf{C F}_{3}\right)_{3}\right\}_{4}\right]$ can be recrystallized from a concentrated $\mathrm{Et}_{2} \mathrm{O}$ solution at $-24{ }^{\circ} \mathrm{C}$. Yield: $0.550 \mathrm{~g}, 0.280 \mathrm{mmol}$, 69\%. ${ }^{1} \mathbf{H}$ NMR (400 MHz, $\mathrm{CD}_{2} \mathrm{Cl}_{2}$ ): $\delta=9.03$ (br. s), 5.07 (br. s), -2.18 (br. s). ${ }^{19} \mathbf{F}$ NMR (376 $\left.\mathrm{MHz}, \mathrm{CD}_{2} \mathrm{Cl}_{2}\right): \delta=-12.45(\mathrm{~s})$. 


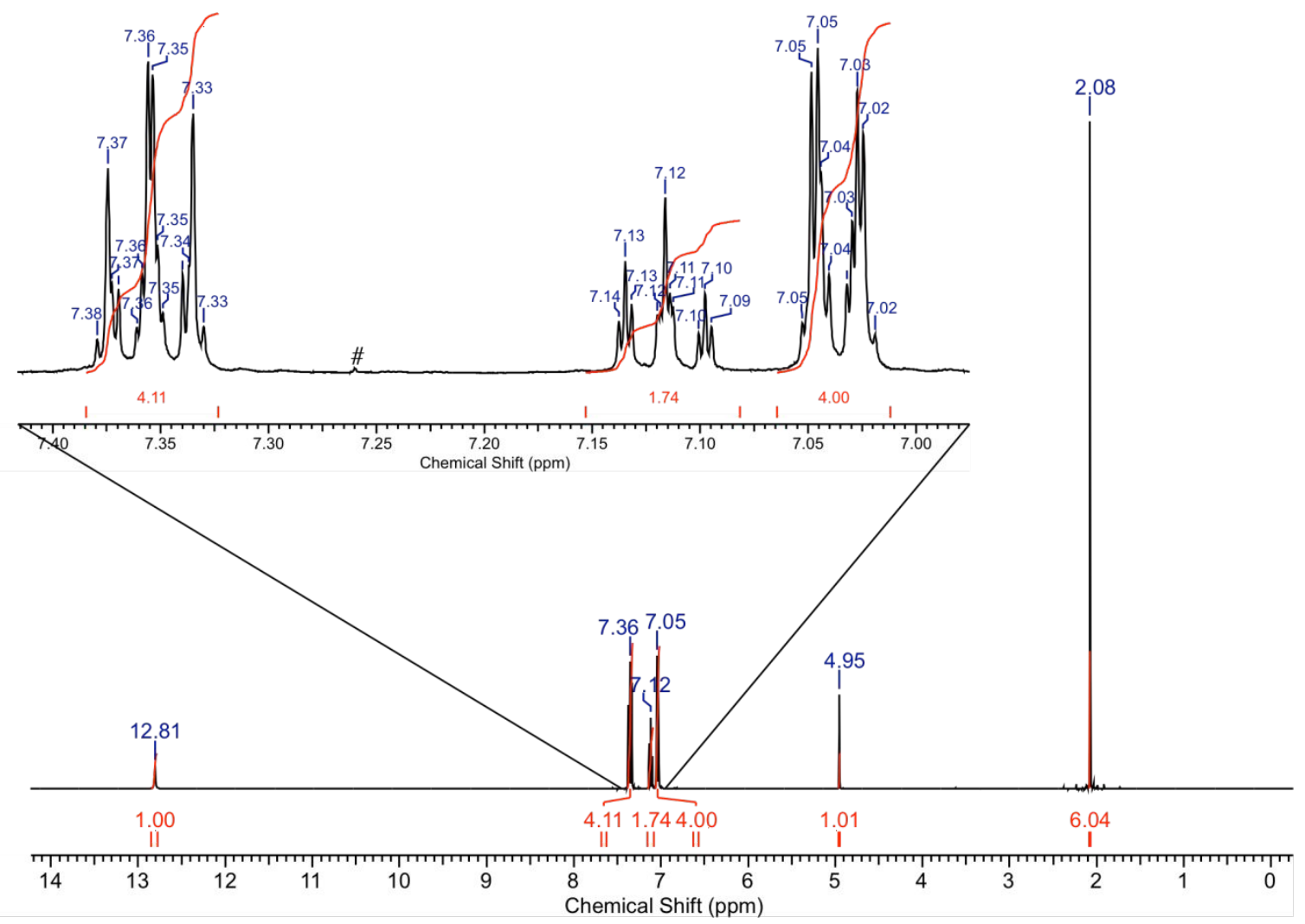

Figure S1: ${ }^{1} \mathrm{H}$ NMR spectrum of ${ }^{\mathrm{Me}}$ nacnac ${ }^{\mathrm{Ph}} \mathbf{H}$ in $\mathrm{CDCl}_{3}$ (\#).

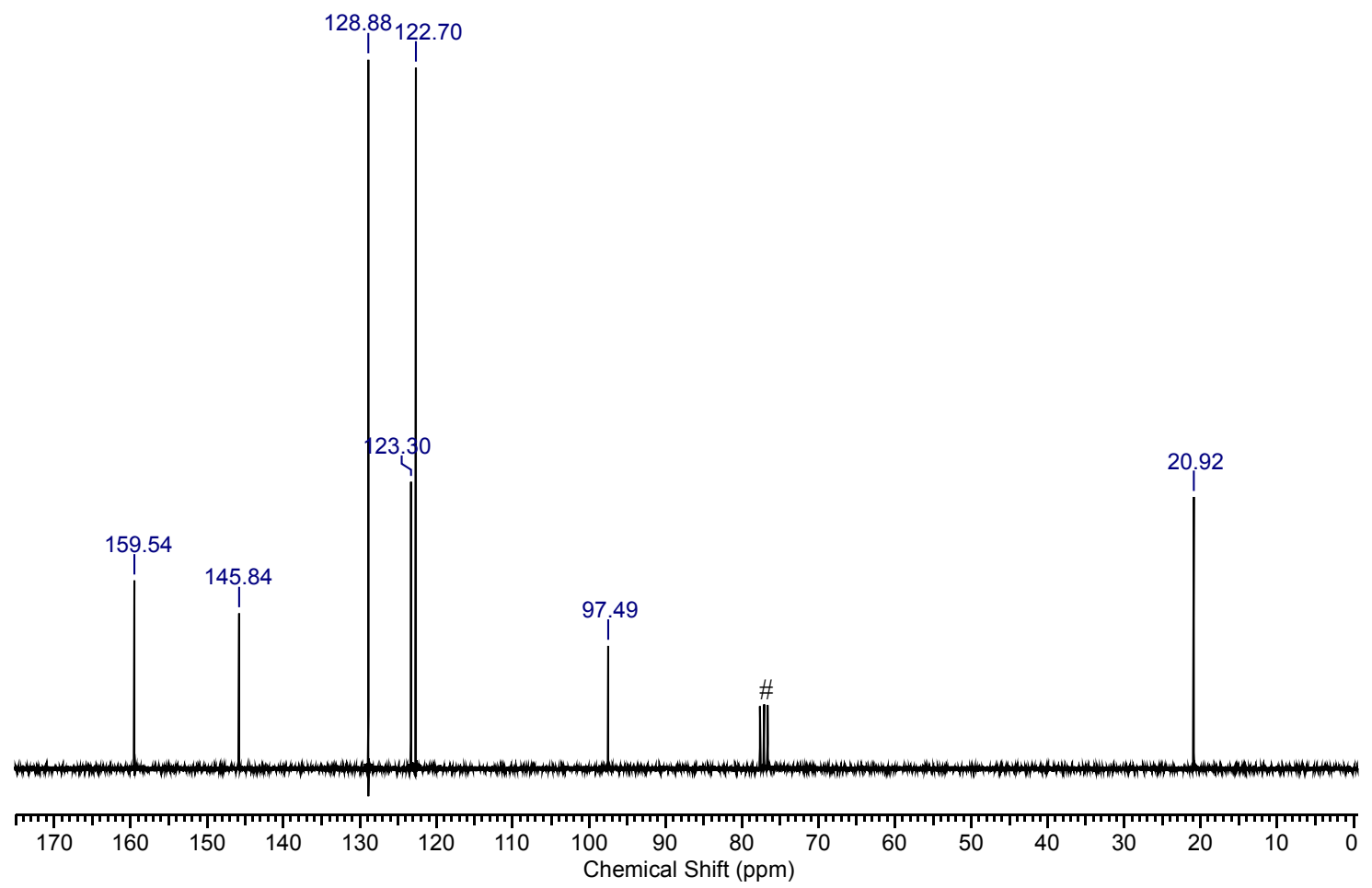

Figure S2: ${ }^{13} \mathrm{C}\left\{{ }^{1} \mathrm{H}\right\}$ NMR spectrum of ${ }^{\mathrm{Me}}$ nacnac ${ }^{\mathrm{Ph}} \mathbf{H}$ in $\mathrm{CDCl}_{3}(\#)$. 


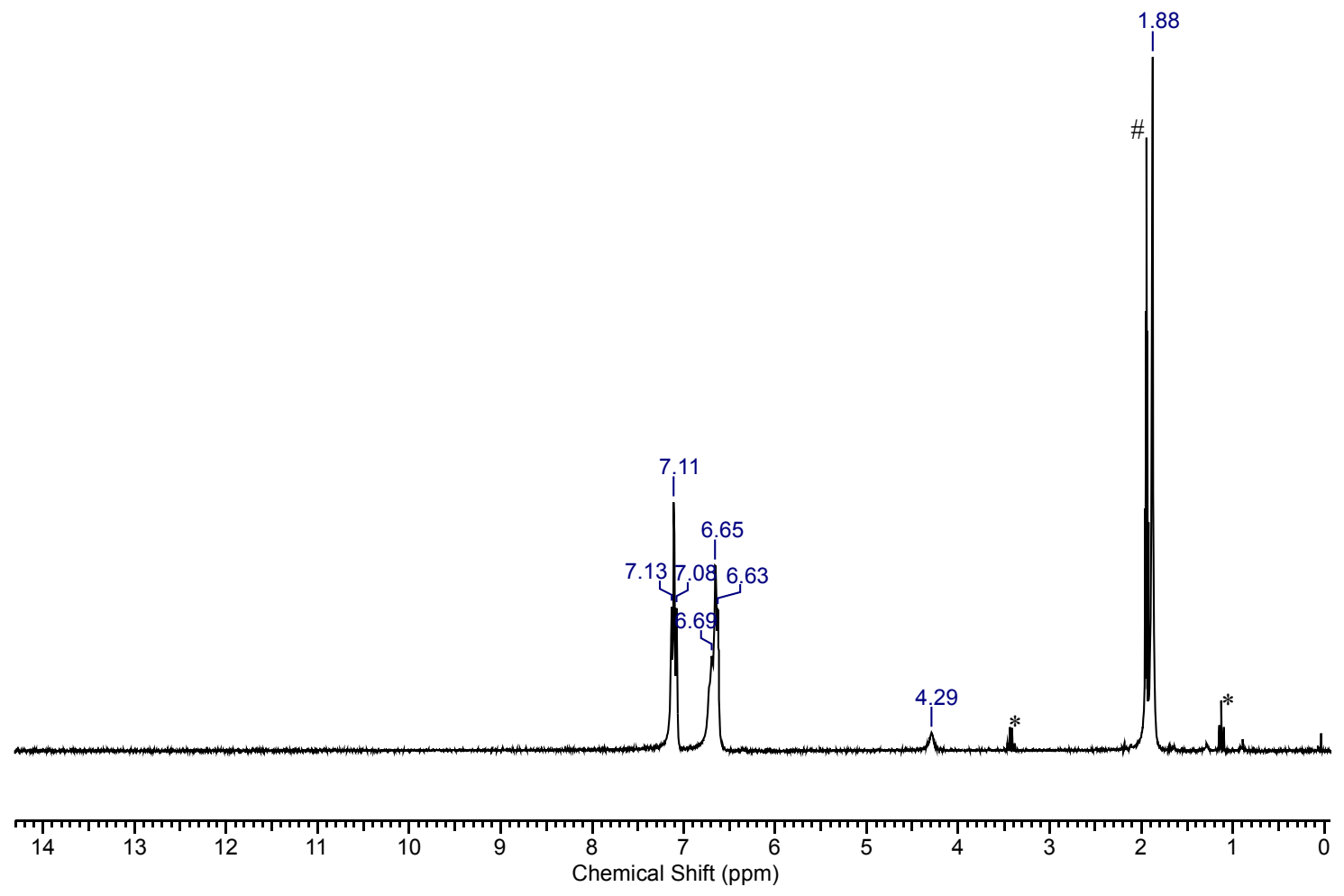

Figure S3: ${ }^{1} \mathrm{H}$ NMR spectrum of $[\mathrm{K}]\left[{ }^{\mathrm{Me}}\right.$ nacnac $\left.{ }^{\mathrm{Ph}}\right]$ in $\mathrm{CD}_{3} \mathrm{CN}(\#)$ with small remains of $\mathrm{Et}_{2} \mathrm{O}$ (*).

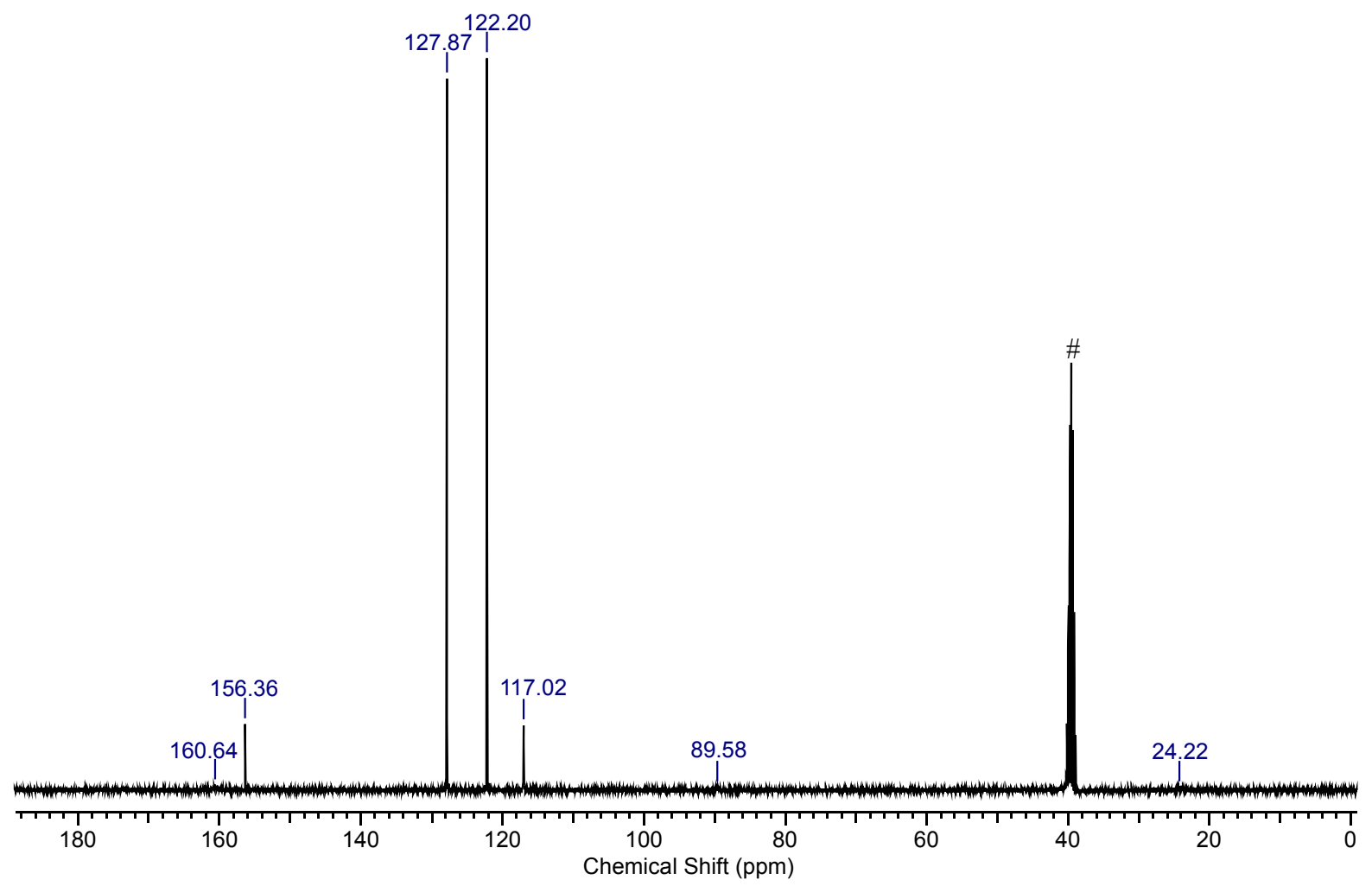

Figure S4: ${ }^{13} \mathrm{C}\left\{{ }^{1} \mathrm{H}\right\}$ NMR spectrum of $[\mathbf{K}]\left[{ }^{\mathrm{Me}}\right.$ nacnac $\left.^{\mathrm{Ph}}\right]$ in $\left(\mathrm{CD}_{3}\right)_{2} \mathrm{SO}(\#)$. 


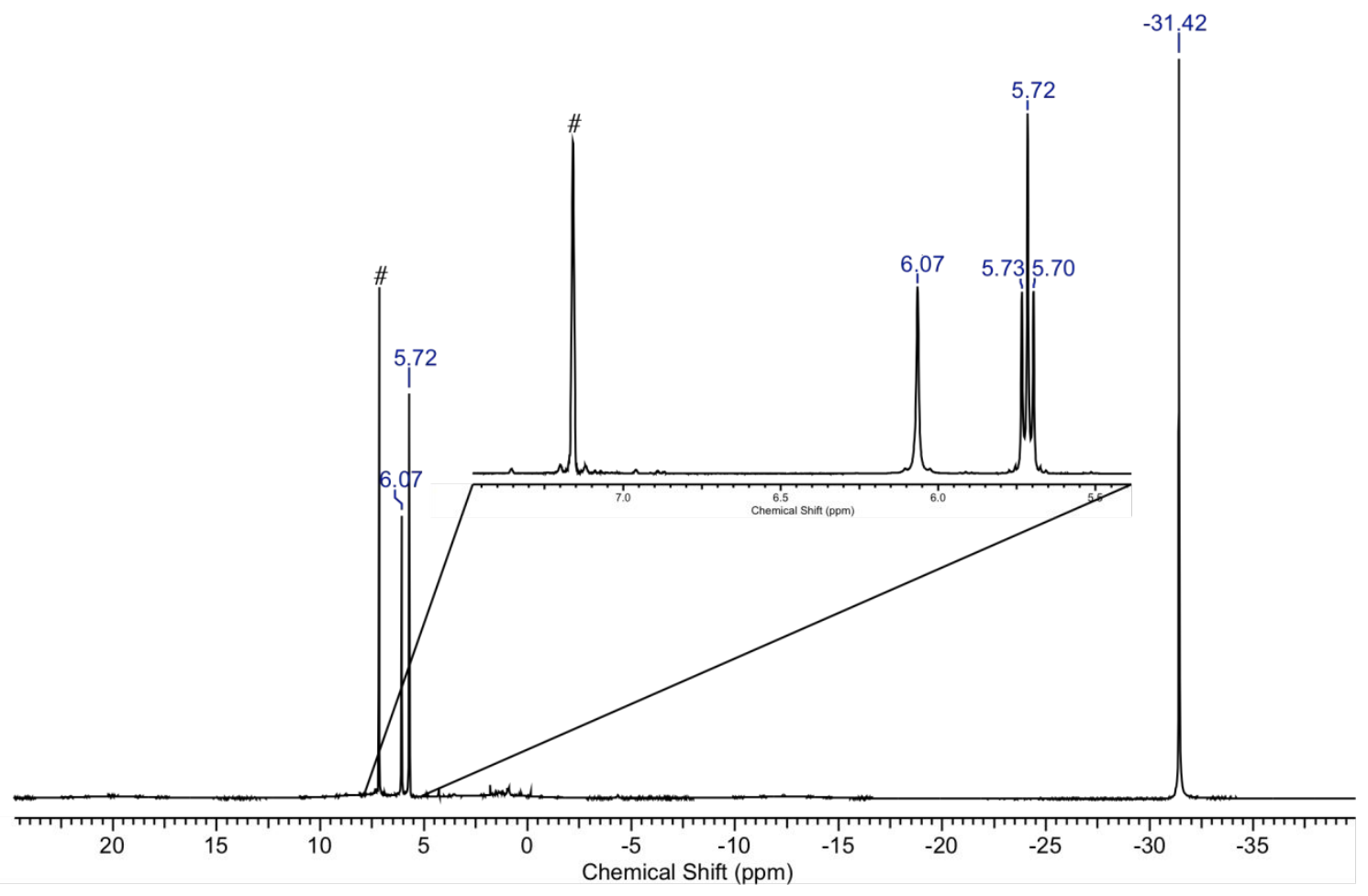

Figure S5: ${ }^{1} \mathrm{H}$ NMR spectrum of 1 in $\mathrm{C}_{6} \mathrm{D}_{6}(\#)$. Peak widths at half heights are $15 \mathrm{~Hz}$ for $\beta$ $\mathrm{CH}_{3}(-31.42 \mathrm{ppm})$ and ranging from 2 to $3 \mathrm{~Hz}$ for $\mathrm{Ar}-\mathrm{H}$.

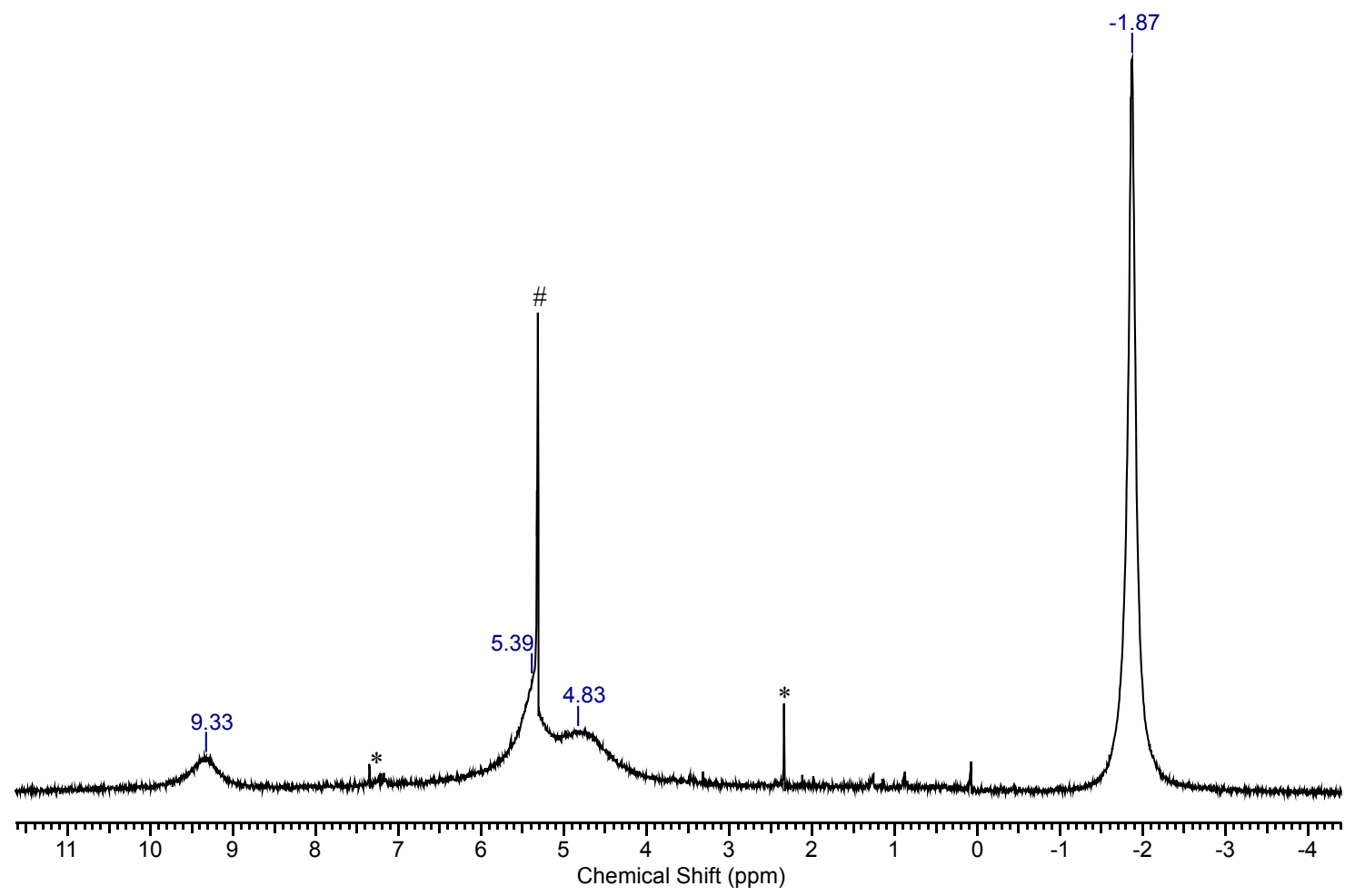

Figure S6: ${ }^{1} \mathrm{H}$ NMR spectrum of $[1]\left[\mathrm{PF}_{\mathbf{6}}\right]$ in $\mathrm{CD}_{2} \mathrm{Cl}_{2}(\#)$ with minor impurities of toluene (*). Peak widths at half heights are $32 \mathrm{~Hz}$ for $\beta-\mathrm{CH}_{3}(-1.87 \mathrm{ppm})$ and ranging from 105 to $230 \mathrm{~Hz}$ for Ar-H. 


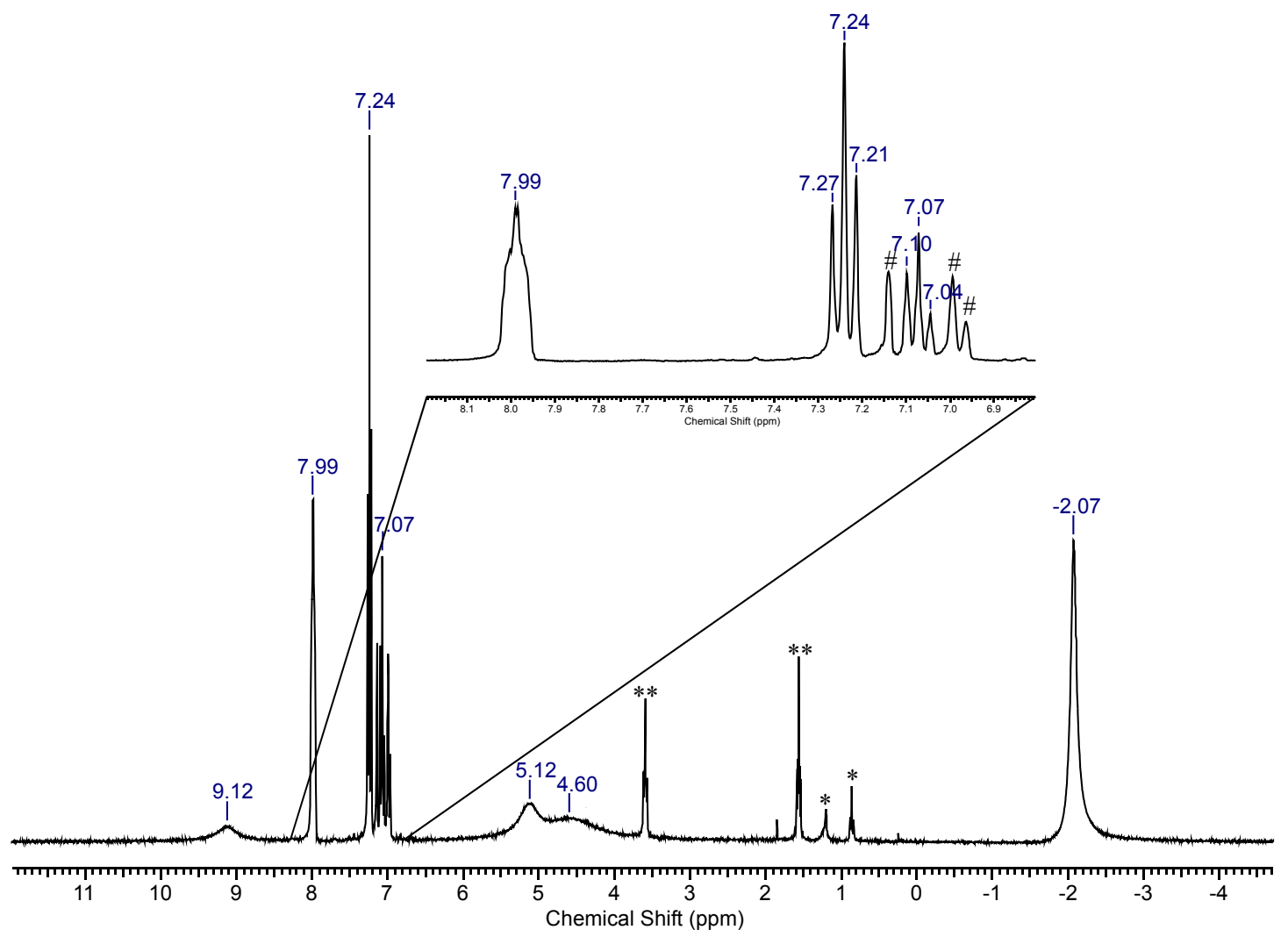

Figure S7: ${ }^{1} \mathrm{H}$ NMR spectrum of [1][BPh $\mathbf{B h}_{4}$ in $\mathrm{C}_{6} \mathrm{D}_{5} \mathrm{Cl}(\#)$ with minor impurities of pentane (*) and THF (**). Peak widths at half heights are $62 \mathrm{~Hz}$ for $\beta-\mathrm{CH}_{3}(-2.07 \mathrm{ppm})$ and ranging from 145 to $260 \mathrm{~Hz}$ for Ar-H.
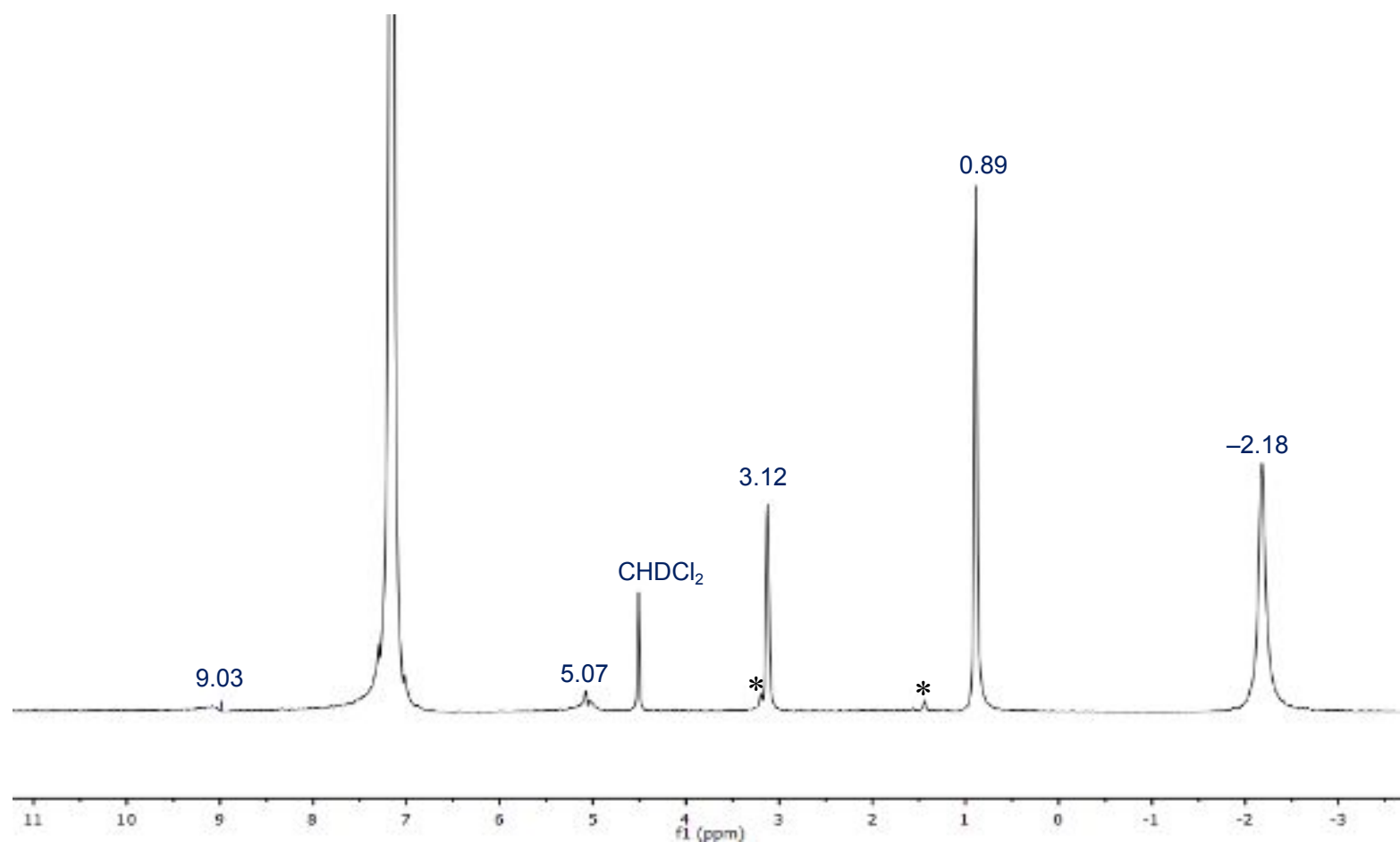

Figure S8: ${ }^{1} \mathrm{H}$ NMR spectrum of [1] $\left[\mathrm{Al}\left\{\mathbf{O C}\left(\mathbf{C F}_{3}\right)_{3}\right\}_{4}\right]$ in $\mathrm{C}_{6} \mathrm{D}_{6} / \mathrm{CD}_{2} \mathrm{Cl}_{2}$ with residuals of $\mathrm{Et}_{2} \mathrm{O}$ (*). Peak widths at half heights are $48 \mathrm{~Hz}$ for $\beta-\mathrm{CH}_{3}(-2.18 \mathrm{ppm})$ and ranging from 108 to $320 \mathrm{~Hz}$ for Ar-H. 


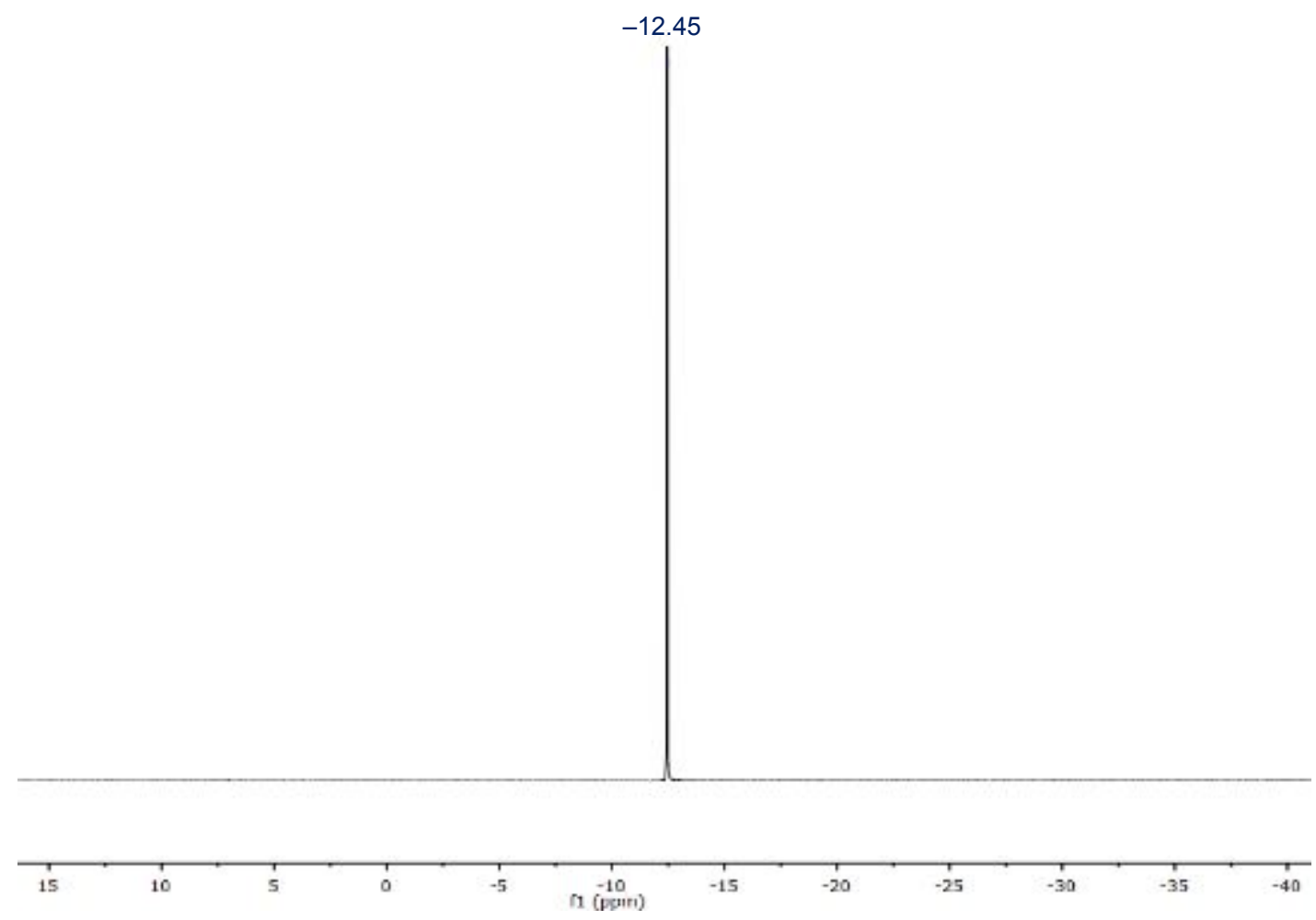

Figure S9: ${ }^{19} \mathrm{~F}\left\{{ }^{1} \mathrm{H}\right\}$ NMR spectrum of [1][AI $\left.\left\{\mathbf{O C}\left(\mathbf{C F}_{3}\right)_{3}\right\}_{4}\right]$ in $\mathrm{C}_{6} \mathrm{D}_{6} / \mathrm{CD}_{2} \mathrm{Cl}_{2}$.

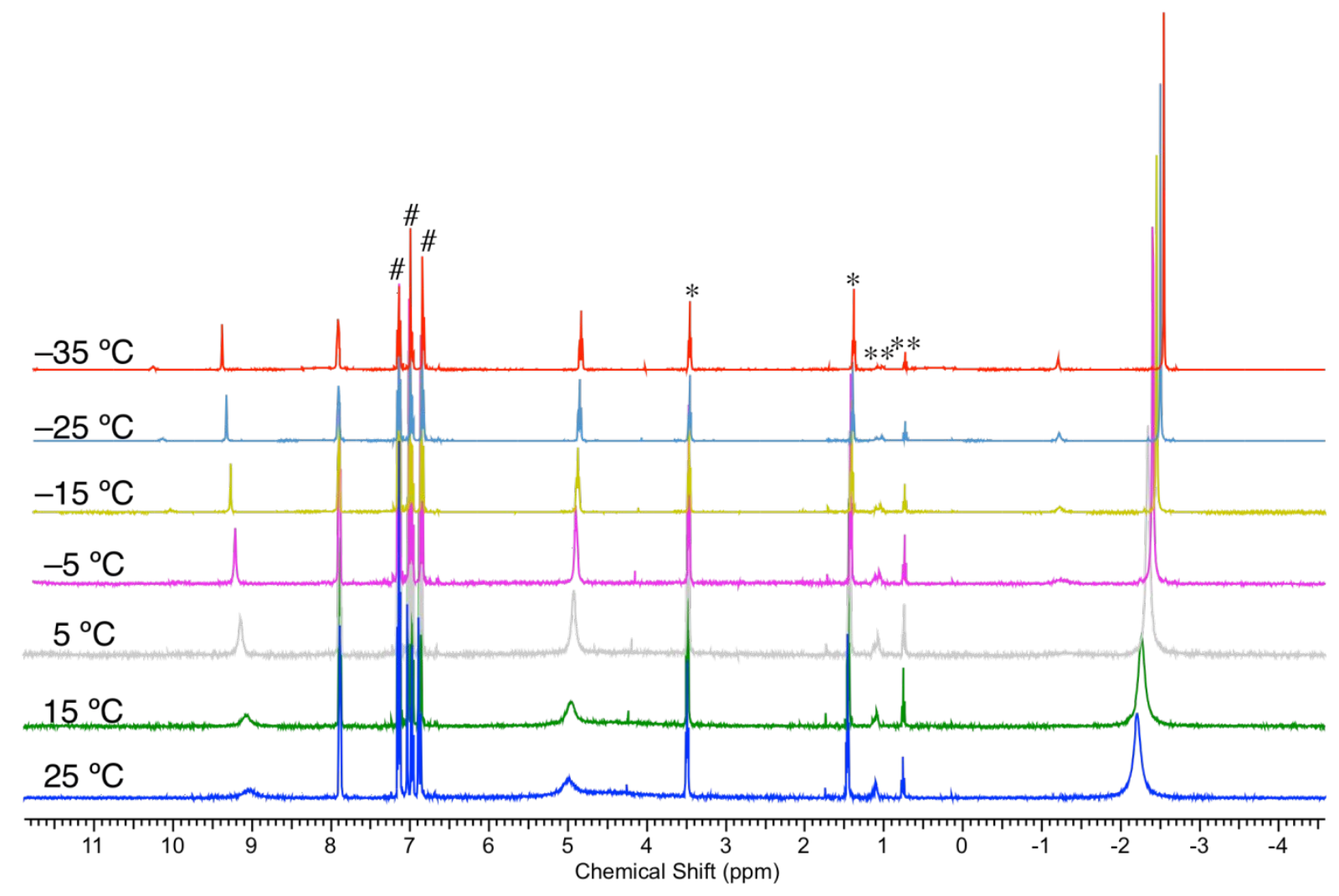

Figure S10: Low temperature ${ }^{1} \mathrm{H}$ NMR spectrum of [1][BPh $]$ in $\mathrm{C}_{6} \mathrm{D}_{5} \mathrm{Cl}$ (\#) with residual solvents THF $(*)$ and pentane $(* *)$ (overview). 


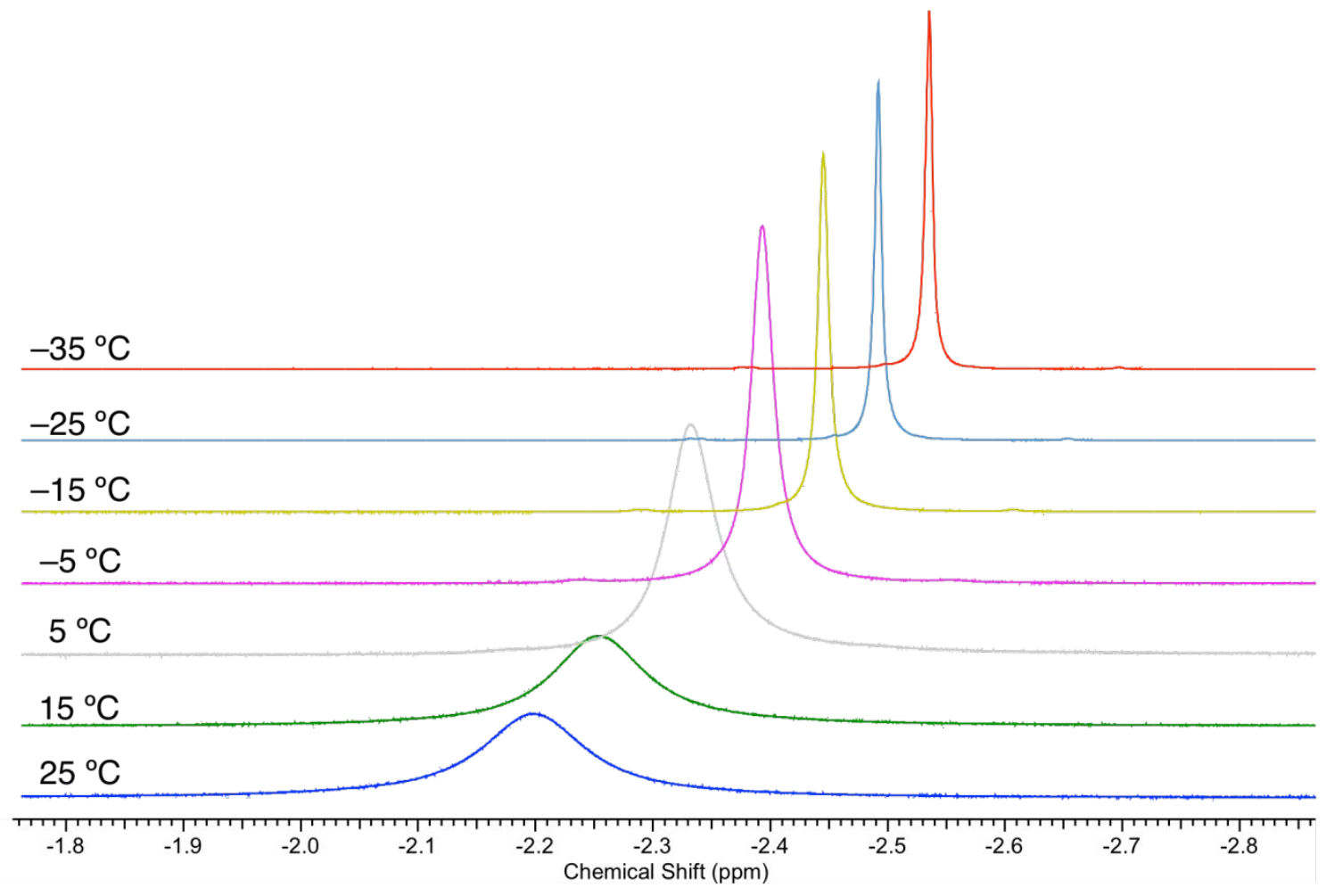

Figure S11: Zoom of the low temperature ${ }^{1} \mathrm{H}$ NMR spectrum of [1] [BPh $\left.\mathbf{B}_{\mathbf{4}}\right]$ at $-2.2 \mathrm{ppm}$.

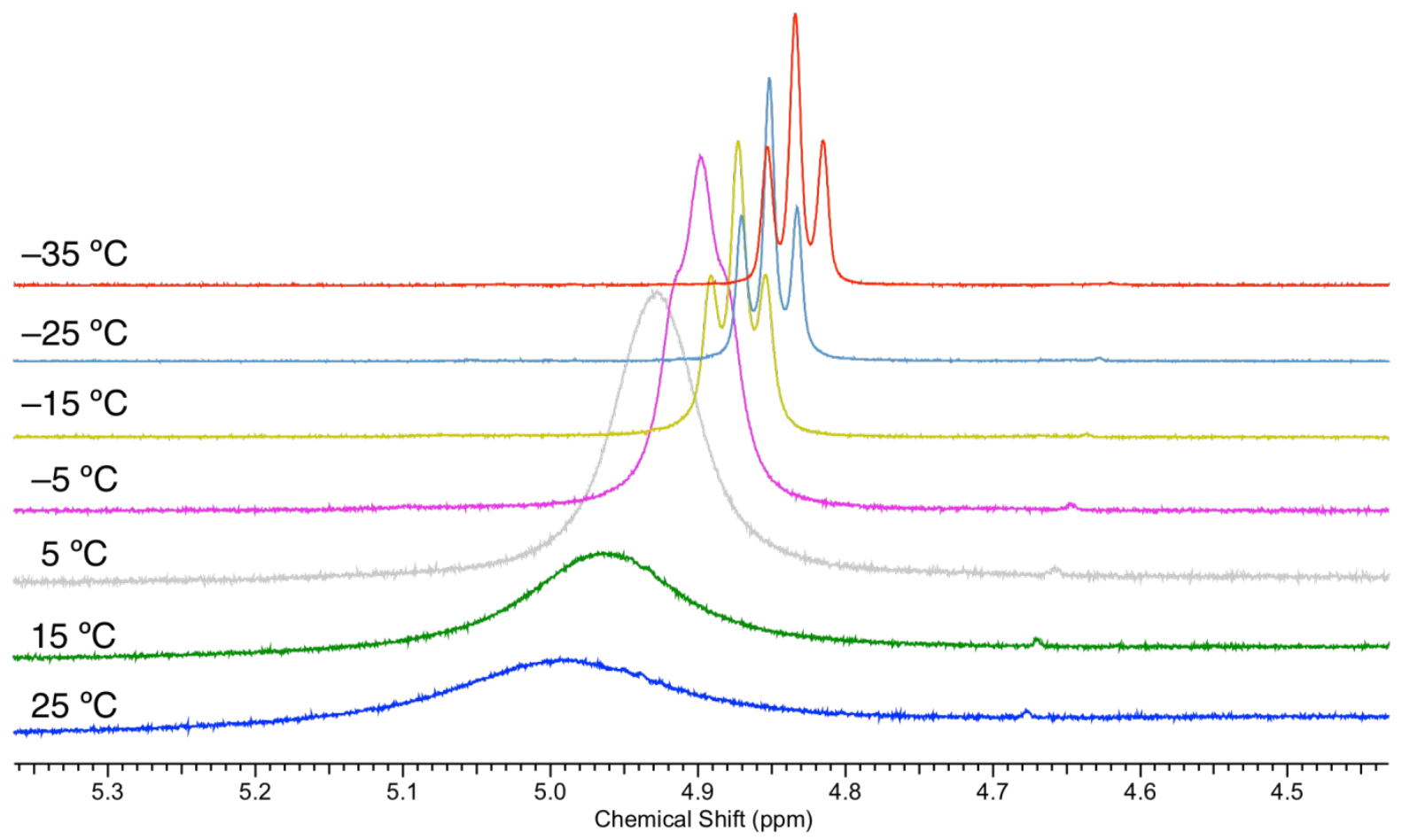

Figure S12: Zoom of the low temperature ${ }^{1} \mathrm{H}$ NMR spectrum of [1]][BPh $\left.\mathbf{h}_{\mathbf{4}}\right]$ at $5.0 \mathrm{ppm}$. 


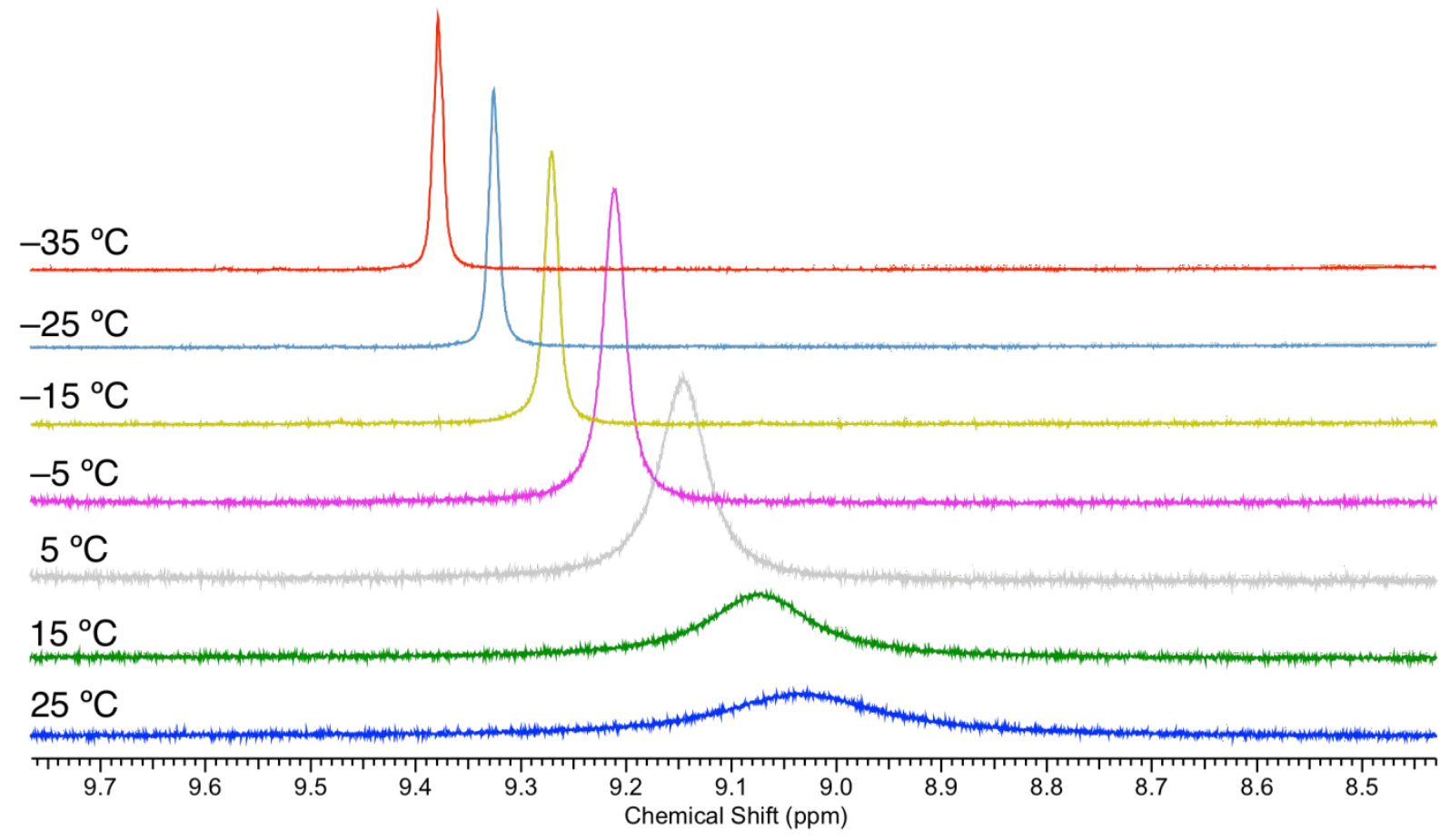

Figure S13: Zoom of the low temperature ${ }^{1} \mathrm{H}$ NMR spectrum of [1][BPh $\left.\mathbf{h}_{\mathbf{4}}\right]$ at $9.0 \mathrm{ppm}$.

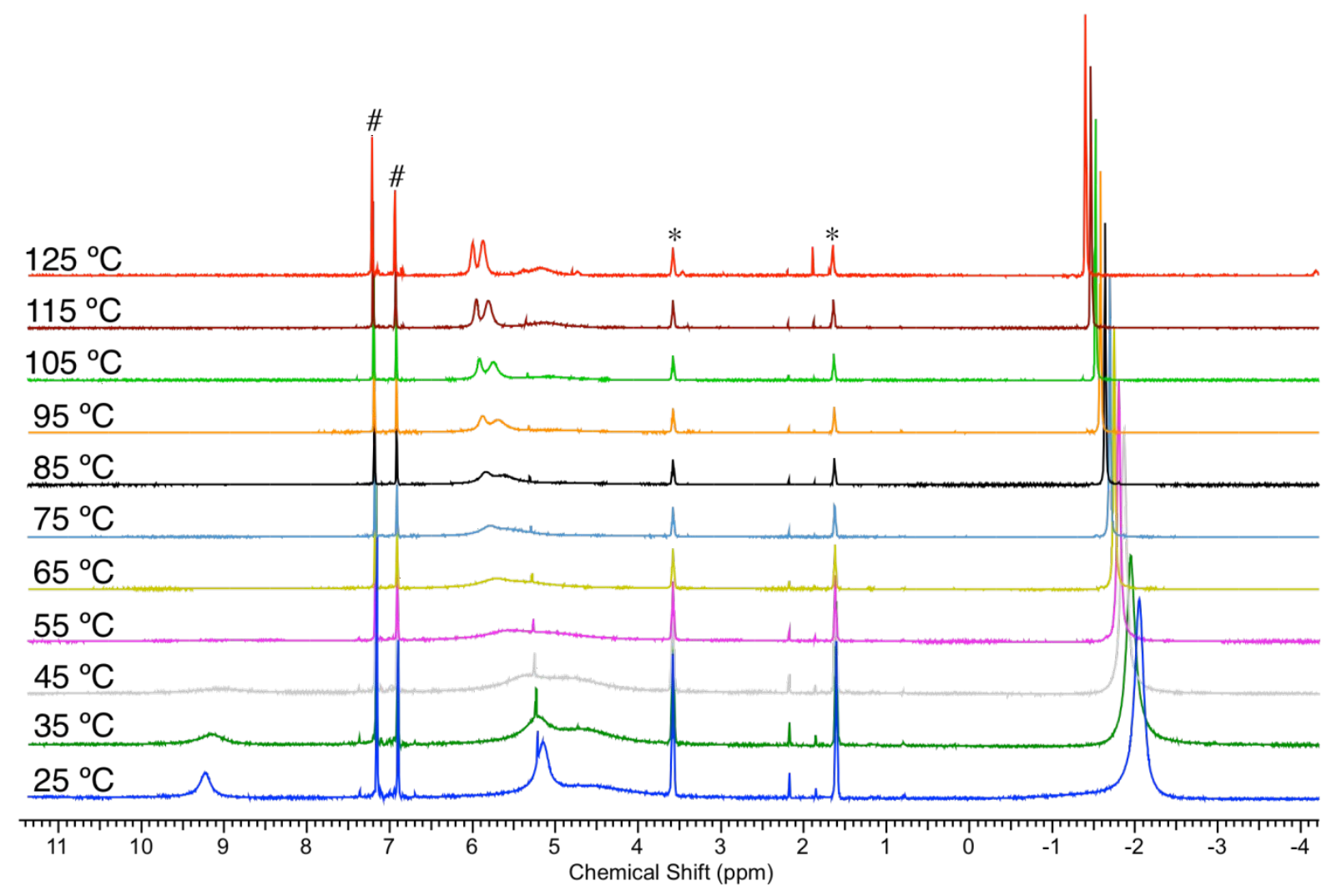

Figure S14: Low temperature ${ }^{1} \mathrm{H}$ NMR spectrum of [1][PF $\mathbf{P F}_{\mathbf{6}}$ in $\mathrm{C}_{6} \mathrm{D}_{4} \mathrm{Cl}_{2}$ (\#) with minor impurities of THF $(*)$ (overview). 


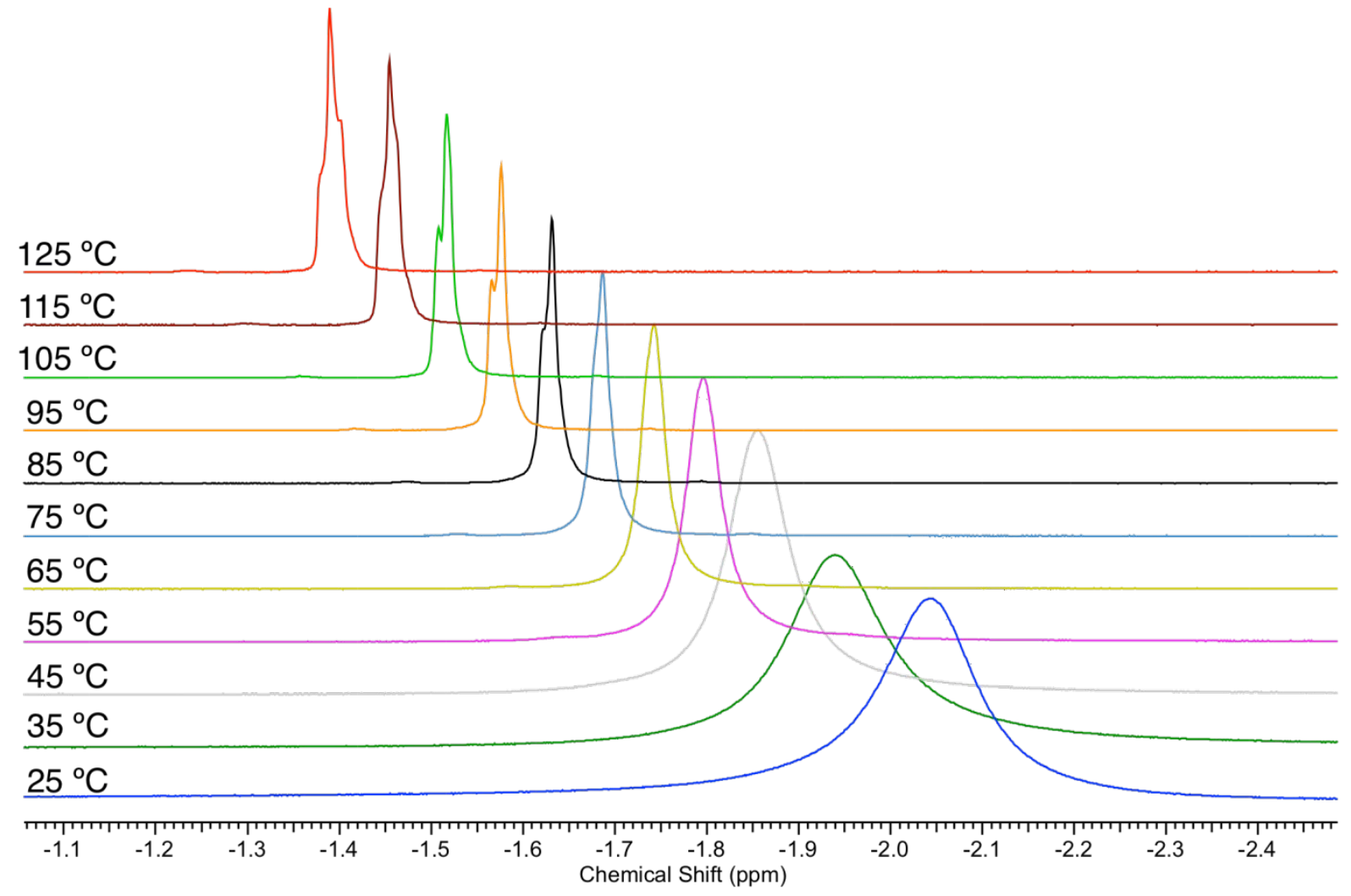

Figure S15: Zoom of the high temperature ${ }^{1} \mathrm{H}$ NMR spectrum of [1][PF $\mathbf{f}$ at $-2.0 \mathrm{ppm}$.

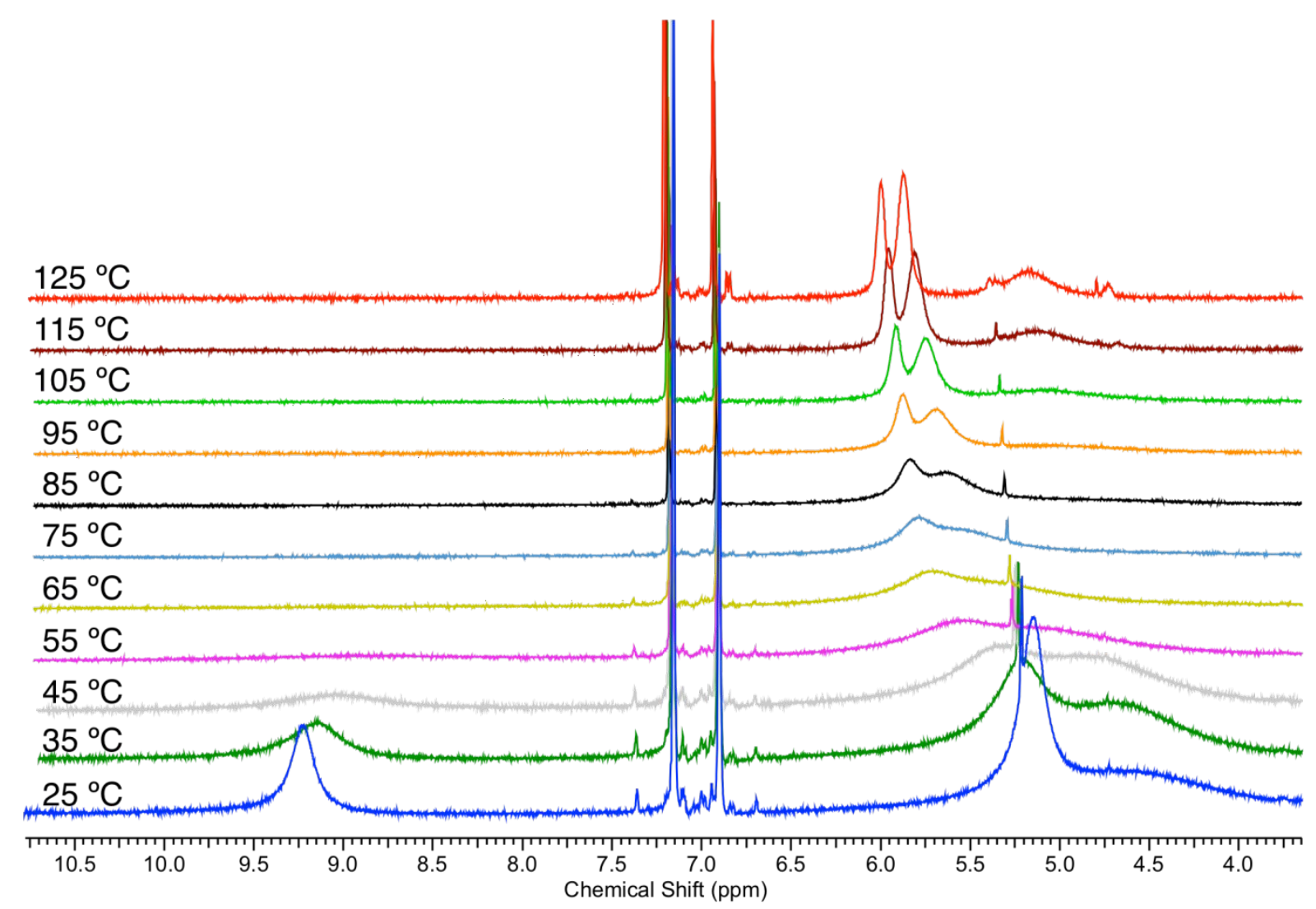

Figure S16: Zoom of the high temperature ${ }^{1} \mathrm{H}$ NMR spectrum of $[1]\left[\mathbf{P F}_{\mathbf{6}}\right]$ at $7.0 \mathrm{ppm}$. 


\section{Attempts to synthesize $\left[\mathrm{U}^{\mathrm{V}}\left({ }^{\mathrm{Me}} \text { nacnac }^{\mathrm{Ph}}\right)_{3}\right]^{2+}$ :}

The oxidation of [1] with two equiv. of $\mathrm{AgBPh}_{4}$ in $\mathrm{THF}$ or $\mathrm{AgPF}_{6}$ in pyridine led always to [1] ${ }^{+}$ and free ligand $\mathrm{H}^{\mathrm{Me}}$ nacnac ${ }^{\mathrm{Ph}}$, which can be observed in the ${ }^{1} \mathrm{H}$ NMR spectrum at $\delta=7.19,6.93$, 4.87 and $1.97 \mathrm{ppm}$. For the oxidation with very strong oxidation reagents, e.g. $\mathrm{WCl}_{6}$, mostly free ligand was observed in addition to a sharp signal at $0.03 \mathrm{ppm}$.

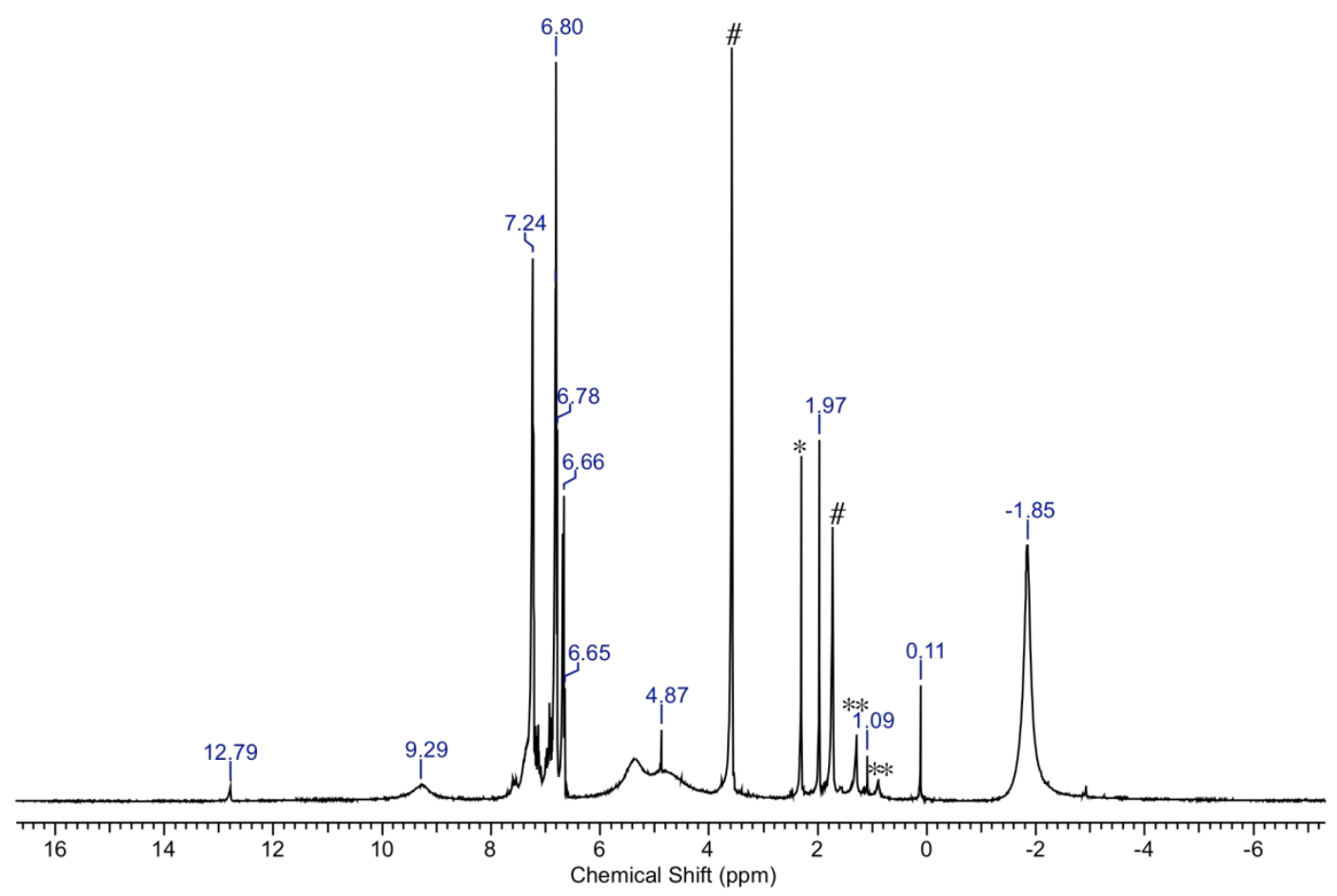

Figure S17: ${ }^{1} \mathrm{H}$ NMR spectrum of the reaction of 1 with two equiv. of $A g B P h$ in $\mathrm{THF}-d_{8}(\#)$ with residuals of tolunede $(*)$ and hexane $(* *)$. 


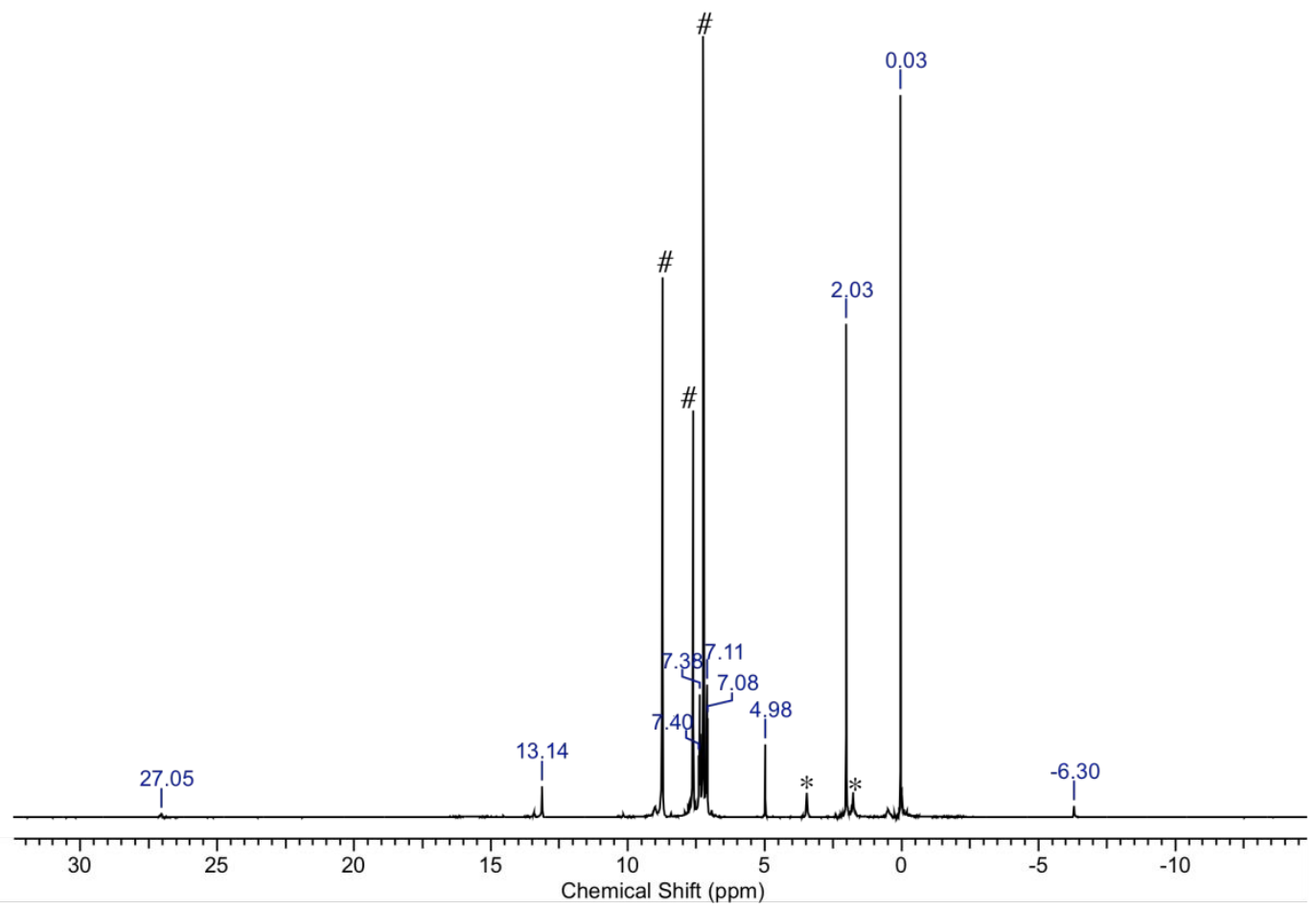

Figure S18: ${ }^{1} \mathrm{H}$ NMR spectrum of the reaction of 1 with two equiv. of $\mathrm{WCl}_{6}$ in pyridine- $\mathrm{d}_{5}$ with minor impurities of THF (*). 


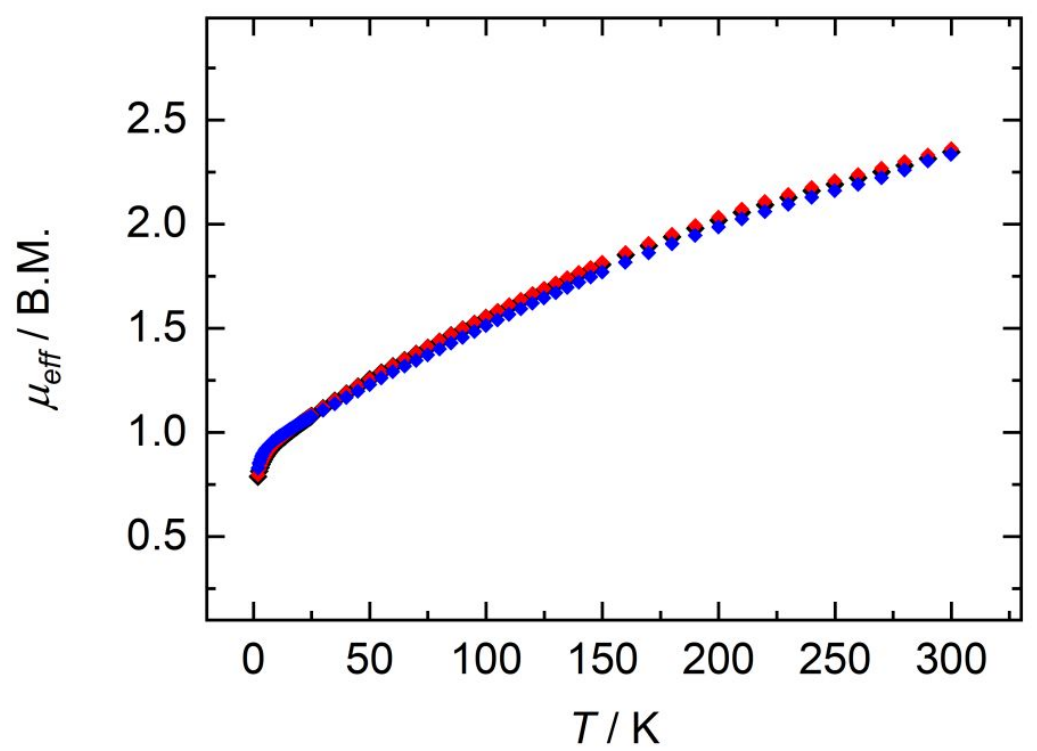

Figure S19: Temperature-dependent SQUID magnetization measurements of 1, recorded from three independently synthesized, microcrystalline solid samples, in the temperature range from $2-300 \mathrm{~K}$, with an applied field of $1 \mathrm{~T}$.

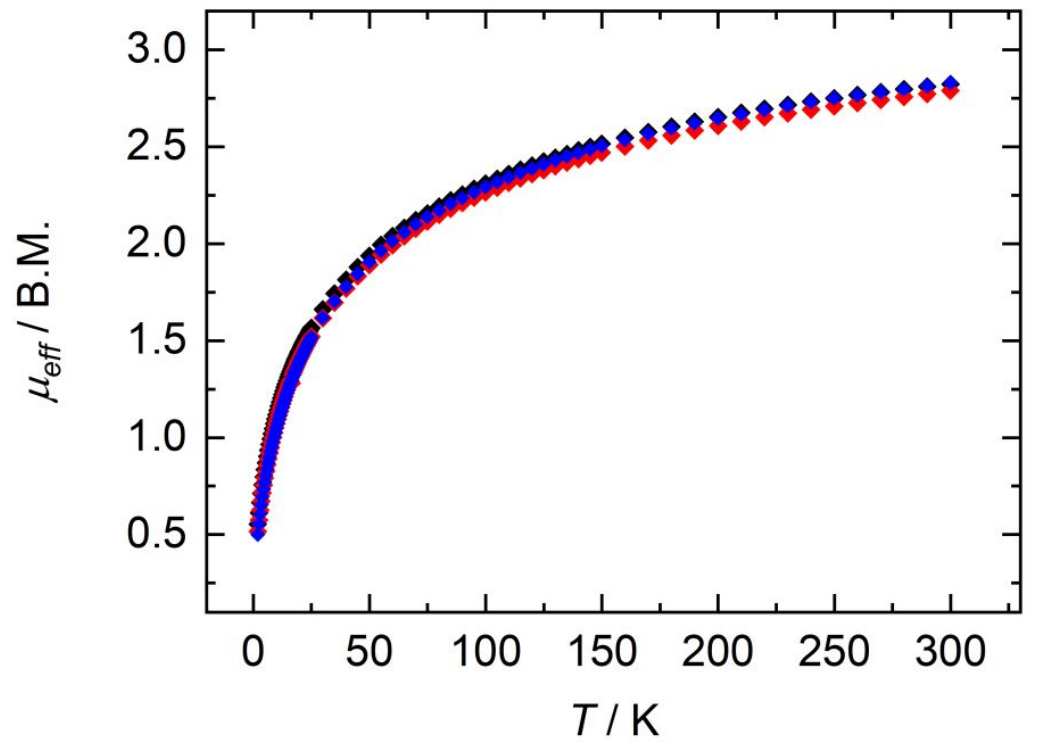

Figure S20: Temperature-dependent SQUID magnetization measurements of [1][ $\left.\mathbf{P F}_{\mathbf{6}}\right]$, recorded from three independently synthesized, microcrystalline solid samples, in the temperature range from $2-300 \mathrm{~K}$ with an applied field of $1 \mathrm{~T}$. 


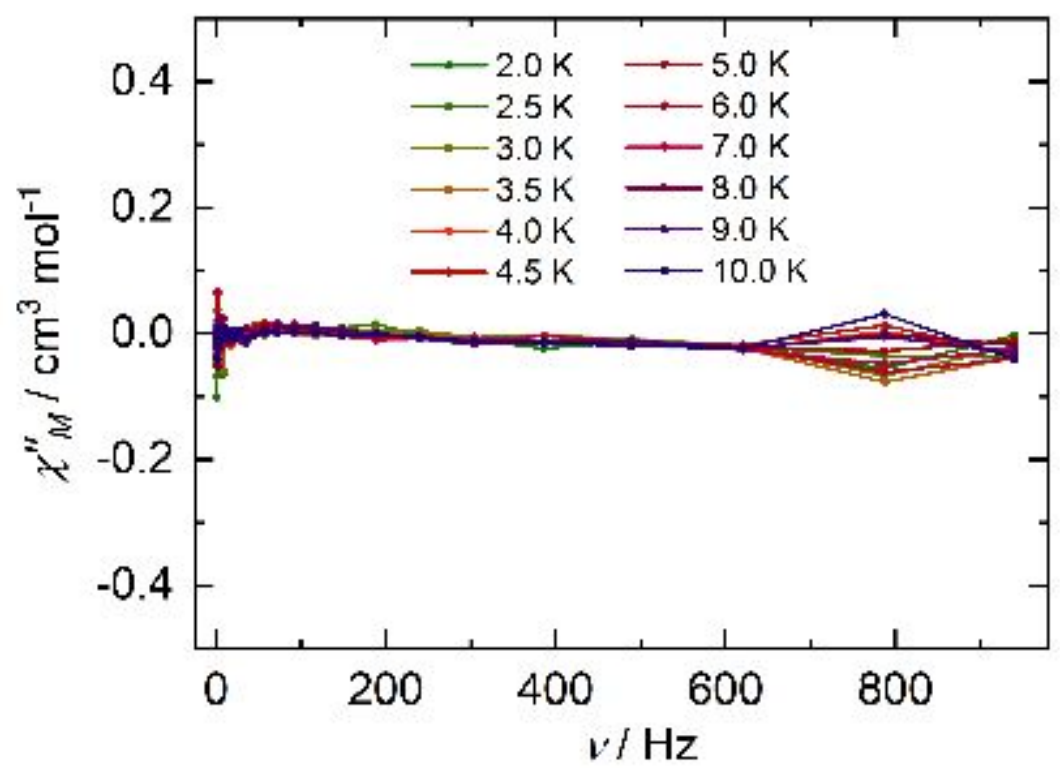

Figure S21: Frequency-dependence of the out-of-phase susceptibility $\chi{ }^{\prime}$ for 1 collected under a magnetic field of $\mathrm{H}_{\mathrm{dc}}=2 \mathrm{kOe}$ at ac frequencies of $v=1-950 \mathrm{~Hz}$ from 2-10 K.

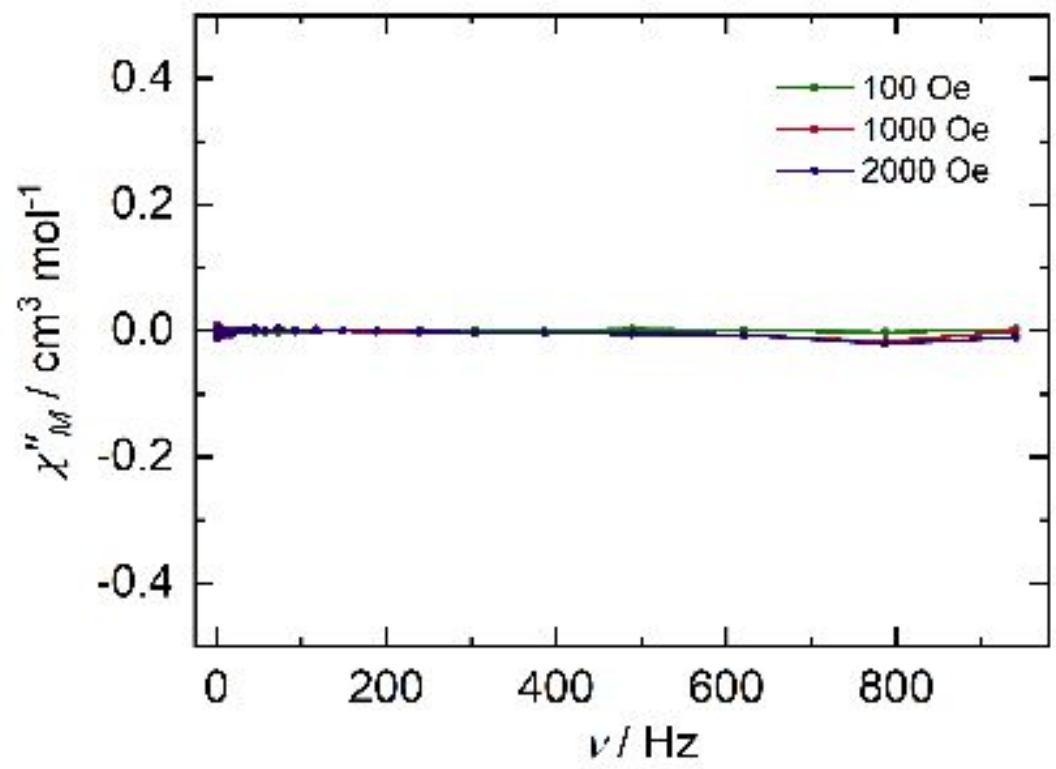

Figure S22: Frequency-dependence of the out-of-phase susceptibility $\chi{ }^{\prime}$ for 1 collected under a magnetic field of $\mathrm{H}_{\mathrm{dc}}=0.1 \mathrm{kOe}, 1 \mathrm{kOe}$ and $2 \mathrm{kOe}$ at ac frequencies of $v=1-950 \mathrm{~Hz}$ at $2 \mathrm{~K}$. 


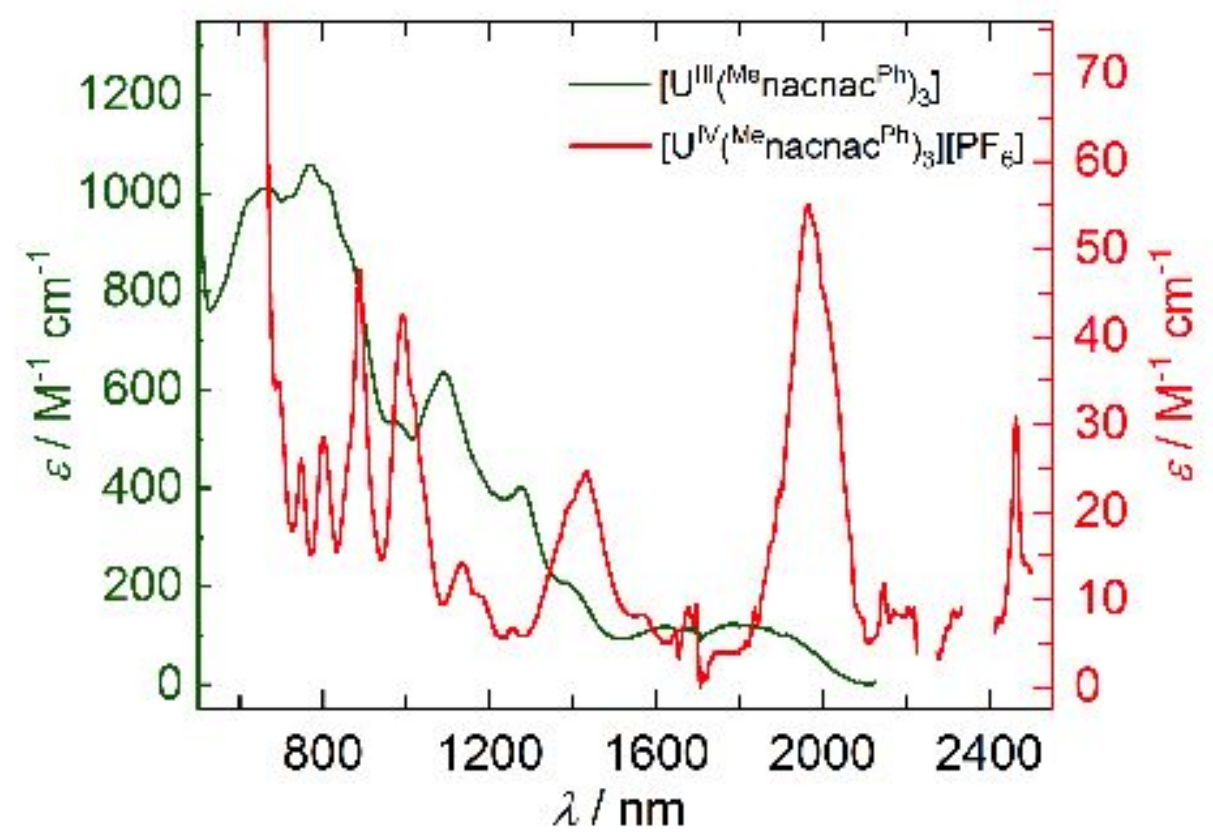

Figure S23: (Vis-) NIR electronic absorption spectra of 1 recorded in toluene with $c=500 \mu \mathrm{M}$ (green trace) and $[\mathbf{1}]\left[\mathbf{P F}_{\mathbf{6}}\right]$, recorded in DCM with $\mathrm{c}=3 \mathrm{mM}$ (red trace).

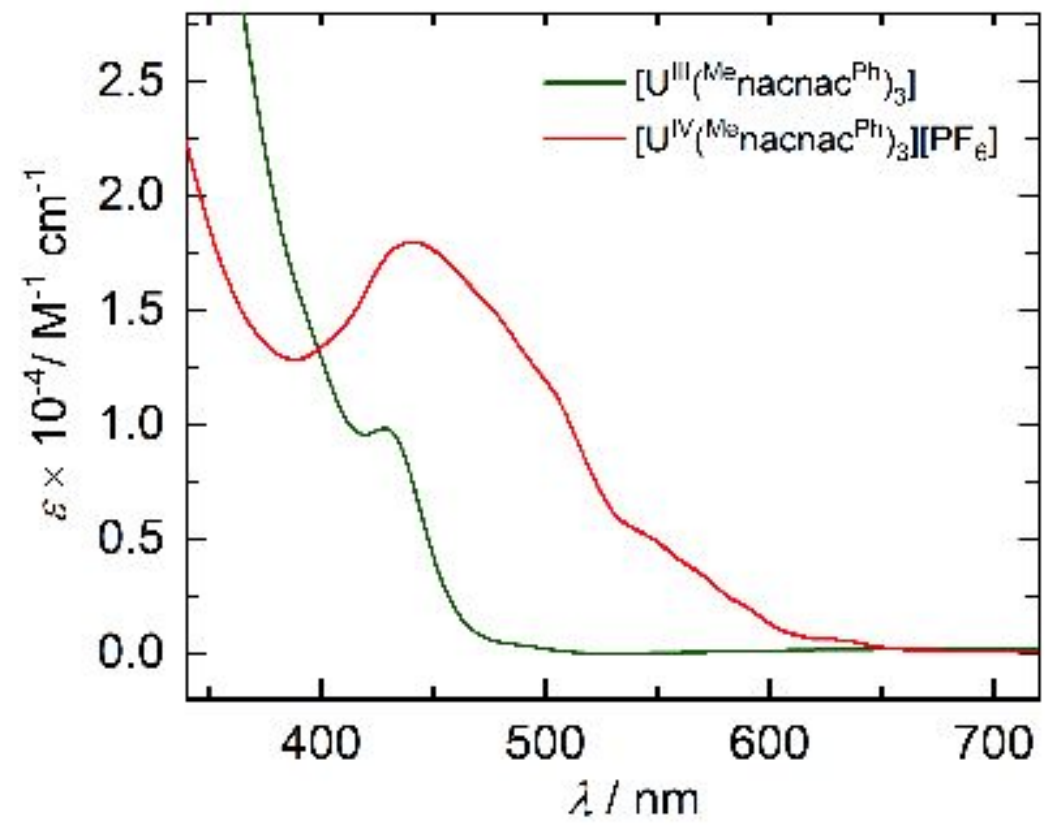

Figure S24: UV/Vis electronic absorption spectra of 1 recorded in toluene with $c=20 \mu \mathrm{M}$ (green trace) and $[\mathbf{1}]\left[\mathbf{P F}_{\mathbf{6}}\right]$, recorded in DCM with $\mathrm{c}=20 \mu \mathrm{M}$ (red trace). 


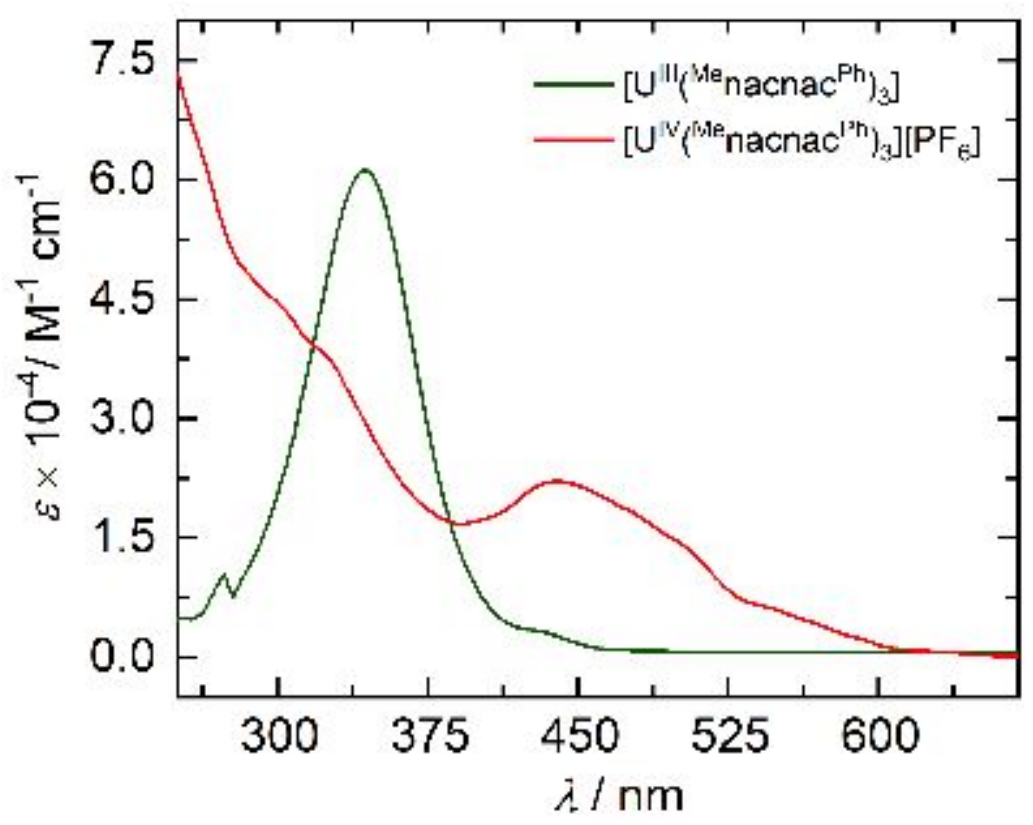

Figure S25: UV/Vis electronic absorption spectra of 1 recorded in toluene with $c=10 \mu \mathrm{M}$ (green trace) and [1] $\left[\mathbf{P F}_{\mathbf{6}}\right]$, recorded in DCM with $\mathrm{c}=10 \mu \mathrm{M}$ (red trace).

\section{EPR Spectroscopic Measurements}

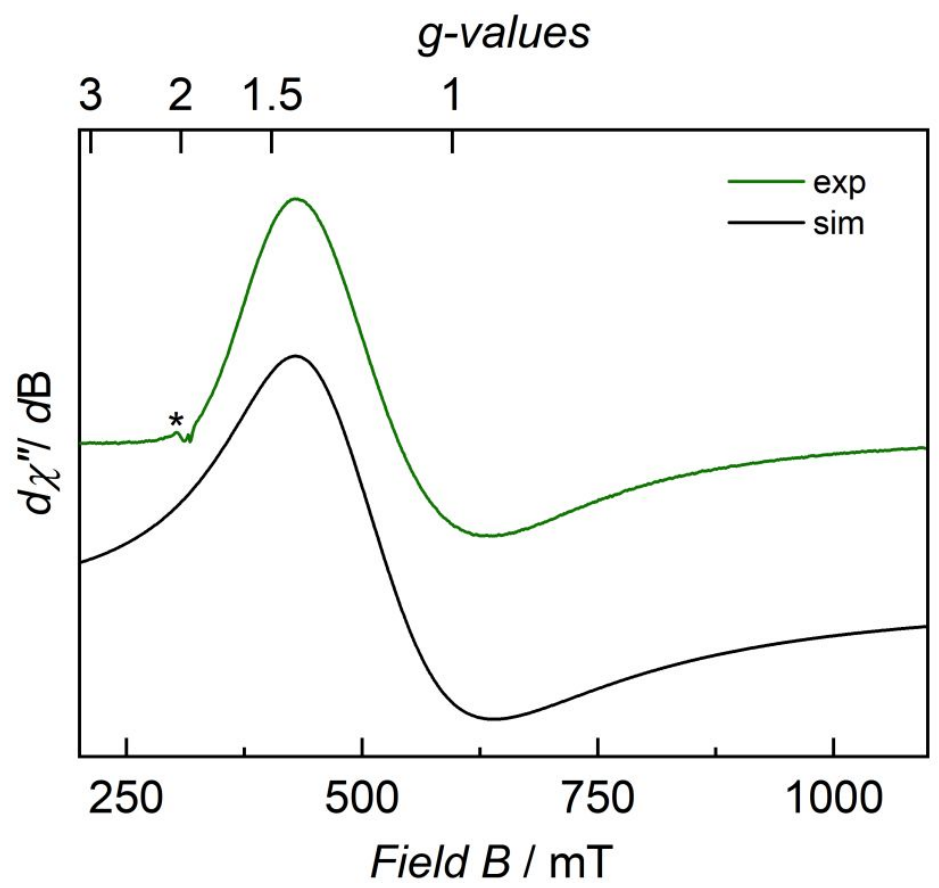

Figure S26: X-band EPR spectrum of 1 recorded in frozen toluene solution at $9 \mathrm{~K}$ (black trace) and its simulation (red trace). Experimental conditions: $\mathrm{c}=40 \mathrm{mM}$, microwave frequency $v=8.954 \mathrm{GHz}$, modulation width $=1.0 \mathrm{mT}$, modulation frequency $=100 \mathrm{kHz}$, microwave power $=1 \mathrm{~mW}$, time constant $=0.1 \mathrm{~s}$. Simulation parameters: $\mathrm{g}_{1}=0.37, \mathrm{~g}_{2}=$ $1.45, \mathrm{~g}_{3}=1.20, \mathrm{~W}_{\mathrm{x}}=130 \mathrm{mT}, \mathrm{W}_{\mathrm{y}}=120 \mathrm{mT}, \mathrm{W}_{\mathrm{z}}=140 \mathrm{mT}$. The cavity is marked with an asterisk. 


\section{Electrochemical Details}

The electrochemistry of $\mathbf{1}$ was invesitaged using a three-electrode setup with rotating gassy carbon working electrode and platinum rods as counter- and reference electrode. The potentiostat was an $\mu$ Autolab Type-III. The electrochemical cell was placed inside an inert-gas glovebox under nitrogen atmosphere and the samples were measured in $0.1 \mathrm{M}$ electrolyte solution of $\left[\mathrm{N}(n-\mathrm{Bu})_{4}\right]\left[\mathrm{PF}_{6}\right]$ (purchased from Sigma Aldrich and used without further purification) in THF and DCM. The reported half-wave potentials are referenced to the $\mathrm{Fc}^{+} / \mathrm{Fc}$ redox couple, which was measured by adding ferrocene to the sample solution. All data were referenced by square wave measurements by the addition of ferrocene to the sample solution. Unless otherwise noted, cyclic voltammograms were scanned with a scan rate of $200 \mathrm{mV} / \mathrm{s}$. In the legends scanreates were shortened with SR and are given in V/s. During linear sweep measurements the speed of the rotating disk electrode was $1000 \mathrm{rpm}$.

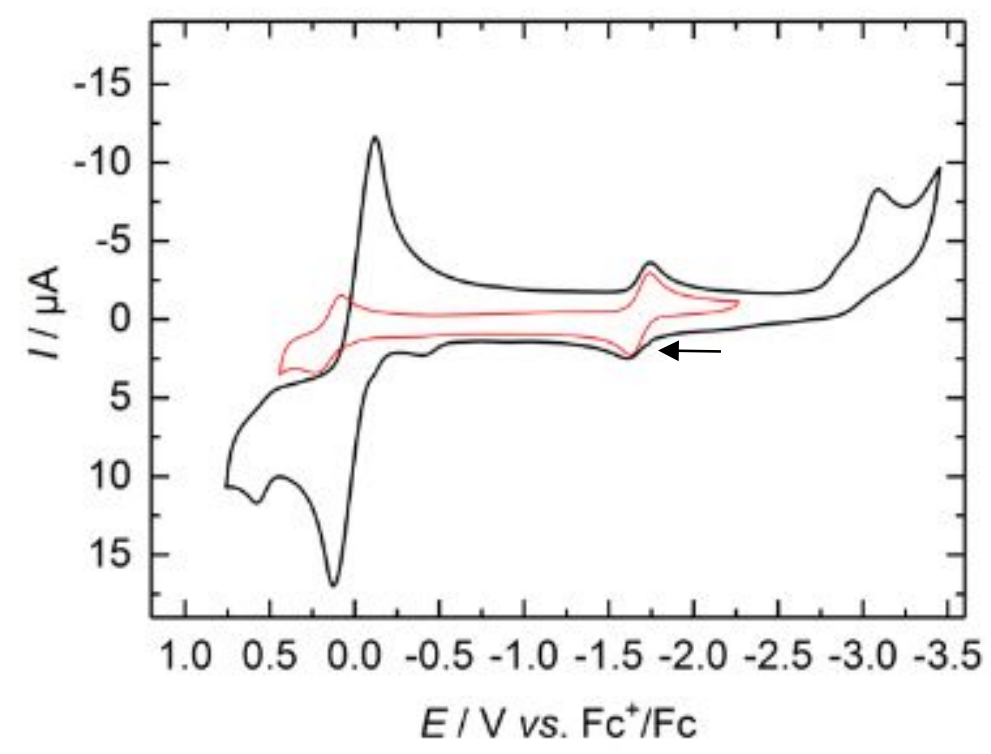

Figure S27: Cyclic voltammograms of 1 measured in a THF solution with $\sim 0.1 \mathrm{M}[\mathrm{N}(n-$ $\left.\mathrm{Bu})_{4}\right]\left[\mathrm{PF}_{6}\right]$ as electrolyte. Overview, including the $\mathrm{Fc}^{+} / \mathrm{Fc}$ redox wave (back trace) and scanning only both oxidations of $\mathbf{1}$ (red trace). 


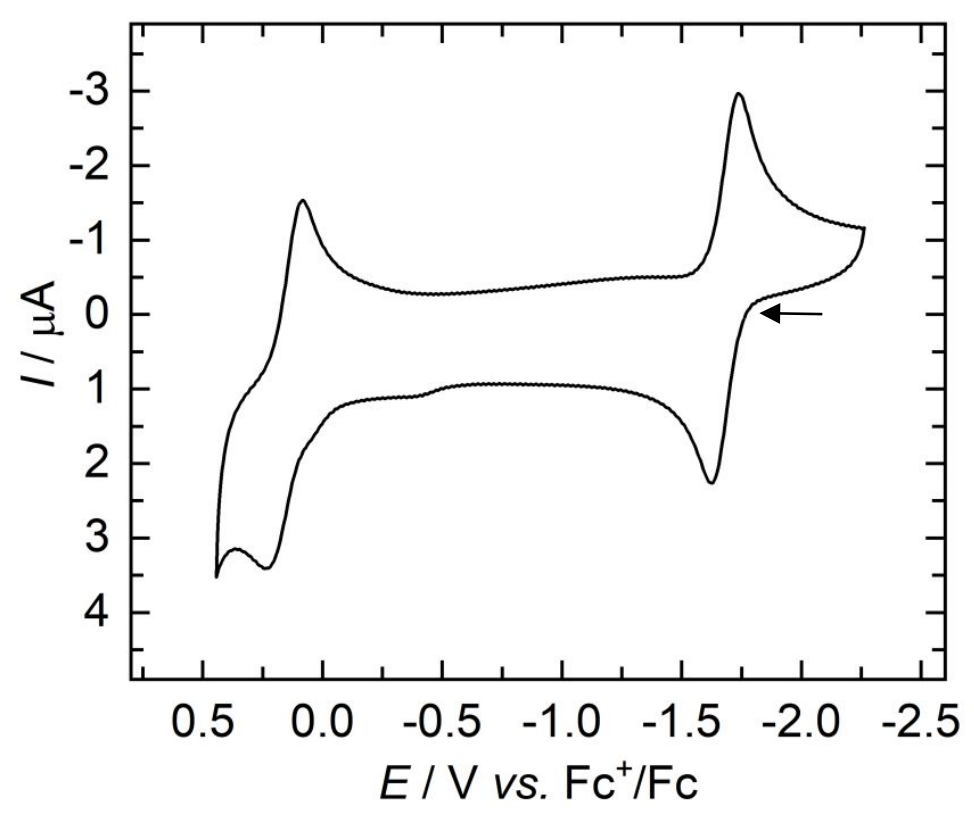

Figure S28: Cyclic voltammogram of 1 measured in a THF solution with $\sim 0.1 \mathrm{M}[\mathrm{N}(n-$ $\left.\mathrm{Bu})_{4}\right]\left[\mathrm{PF}_{6}\right]$ as electrolyte showing the oxidation to $\mathrm{U}(\mathrm{IV})$ at $\mathrm{E}_{1 / 2}=0.15 \mathrm{~V}$ and to $\mathrm{U}(\mathrm{V})$ at $\mathrm{E}_{1 / 2}=$ $-1.69 \mathrm{~V}$.

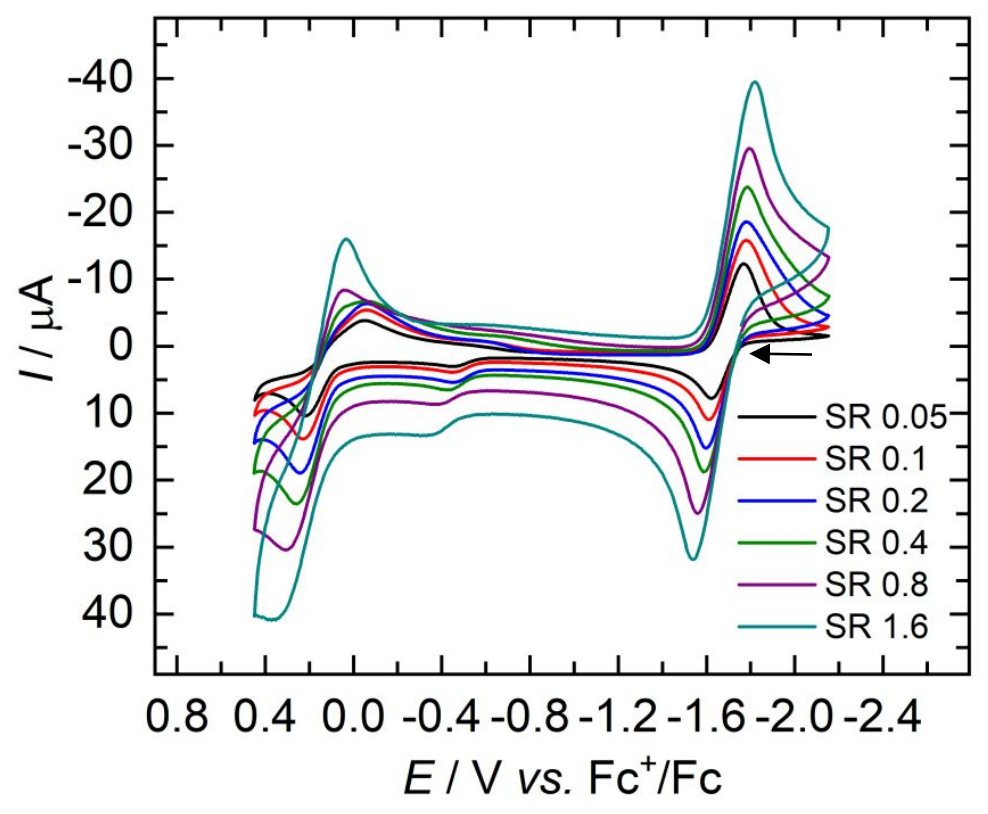

Figure S29: Cyclic voltammograms of 1 scanned with scan rates started from $50 \mathrm{mV} / \mathrm{s}$ and ended with $1600 \mathrm{mV} / \mathrm{s}$ measured in a THF solution with $\sim 0.1 \mathrm{M}\left[\mathrm{N}(n-\mathrm{Bu})_{4}\right]\left[\mathrm{PF}_{6}\right]$ as electrolyte. 


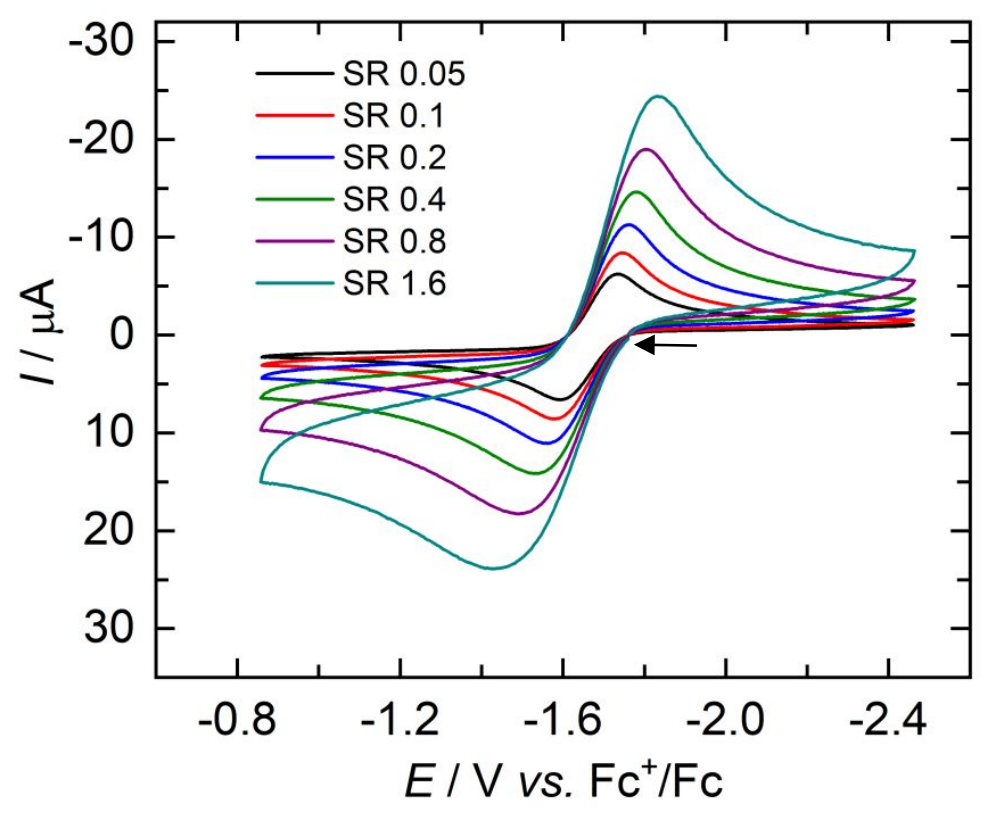

Figure S30: Cyclic voltammograms of 1 showing the scan rate dependence of the oxidation to $\mathrm{U}(\mathrm{IV})$ at $\mathrm{E}_{1 / 2}=0.15 \mathrm{~V}$ measured in a THF solution with $\sim 0.1 \mathrm{M}\left[\mathrm{N}(n-\mathrm{Bu})_{4}\right]\left[\mathrm{PF}_{6}\right]$ as electrolyte.

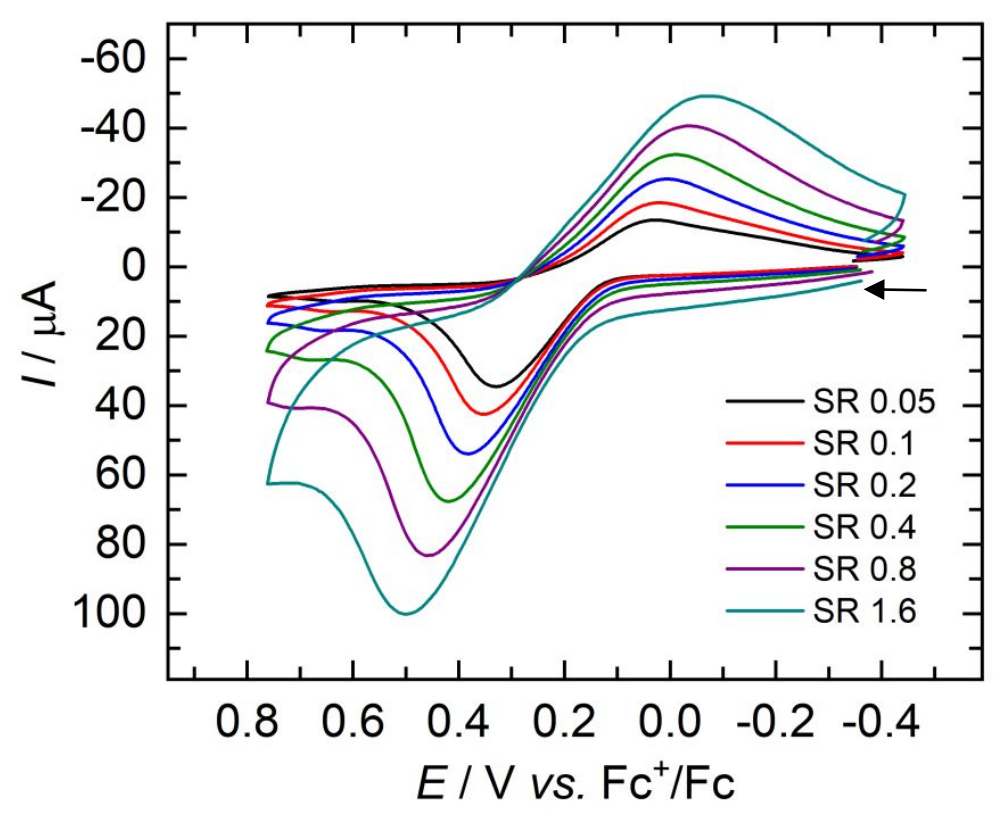

Figure S31: Cyclic voltammograms of 1 showing the scan rate dependence of the oxidation to $\mathrm{U}(\mathrm{V})$ at $\mathrm{E}_{1 / 2}=0.15 \mathrm{~V}$ measured in a THF solution with $\sim 0.1 \mathrm{M}\left[\mathrm{N}(n-\mathrm{Bu})_{4}\right]\left[\mathrm{PF}_{6}\right]$ as electrolyte. 

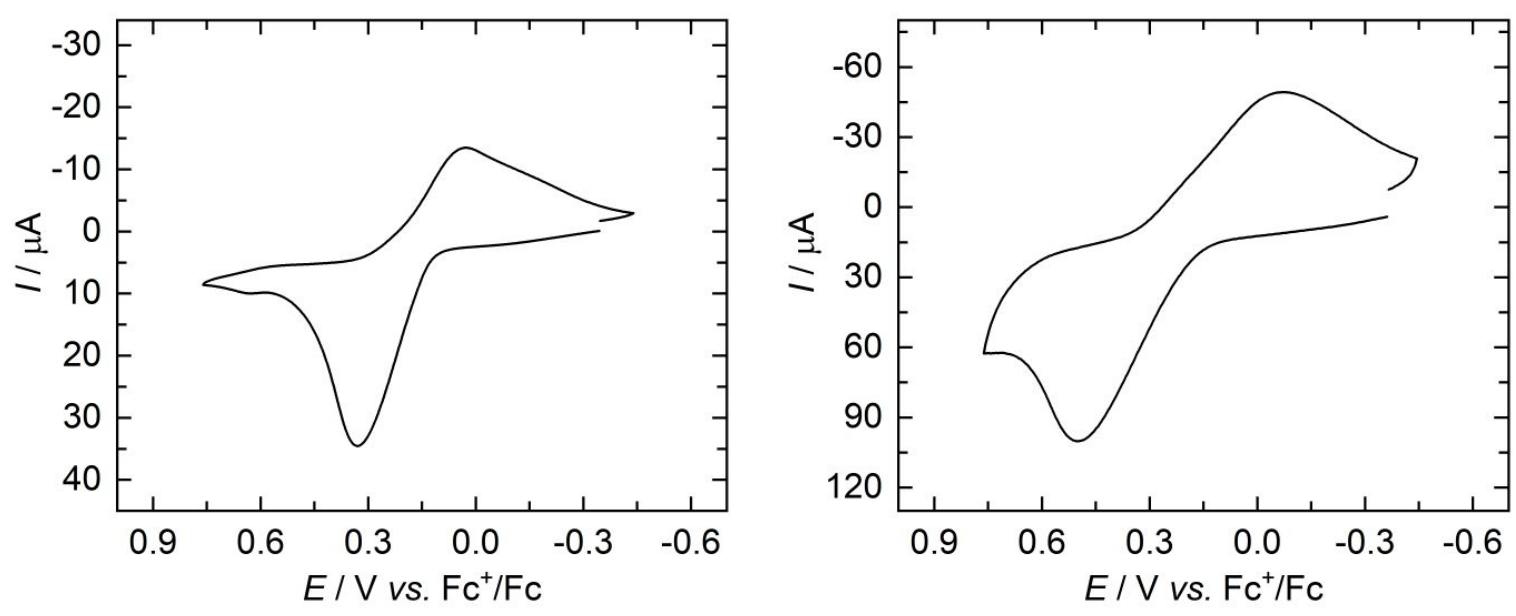

Figure S32: Cyclic voltammograms of 1 showing the oxidation of U(IV)/(V) with a scan rate of $50 \mathrm{mV} / \mathrm{s}$ (left) and $1600 \mathrm{mV} / \mathrm{s}$ (right). At high scan rates quasi reversible behavior can be found in the cyclic voltammogram. At small scan rates the $\mathrm{CV}$ is showing irreversible behavior (ratio of peak areas 2:1 (oxidation : readuction)).

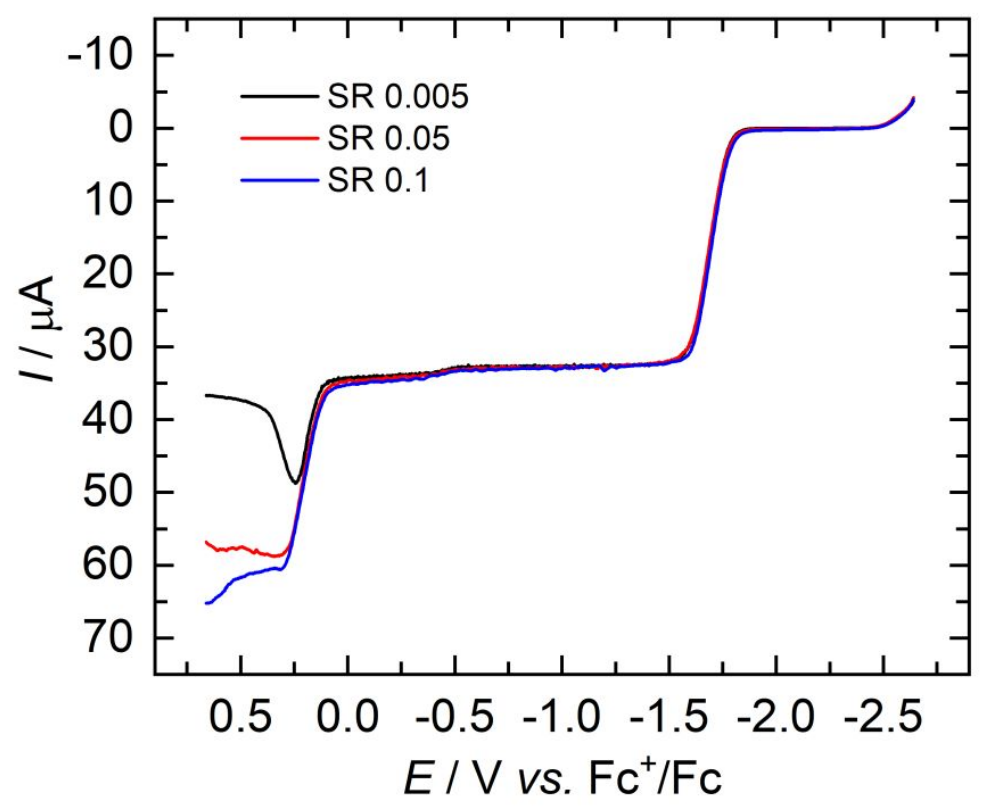

Figure S33: Linear sweep of 1 measured in a THF solution with $\sim 0.1 \mathrm{M}\left[\mathrm{N}(n-\mathrm{Bu})_{4}\right]\left[\mathrm{PF}_{6}\right]$ as electrolyte, confirming two oxidations. 


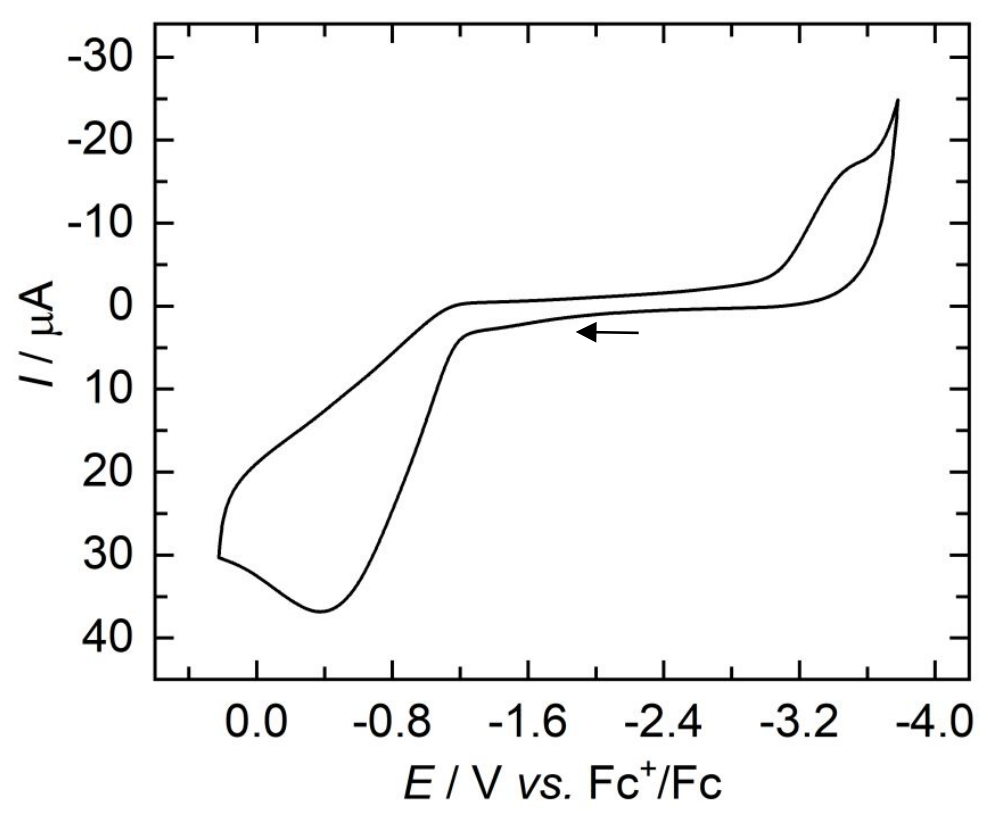

Figure S34: Cyclic voltammogram of $[\mathrm{K}]\left[\mathrm{Me}^{\mathrm{Macnac}}{ }^{\mathrm{Ph}}\right]$ measured in a THF solution with $\sim 0.1$ $\mathrm{M}\left[\mathrm{N}(n-\mathrm{Bu})_{4}\right]\left[\mathrm{PF}_{6}\right]$ as electrolyte showing the ligand oxidation starting at $\sim-1 \mathrm{~V}$.

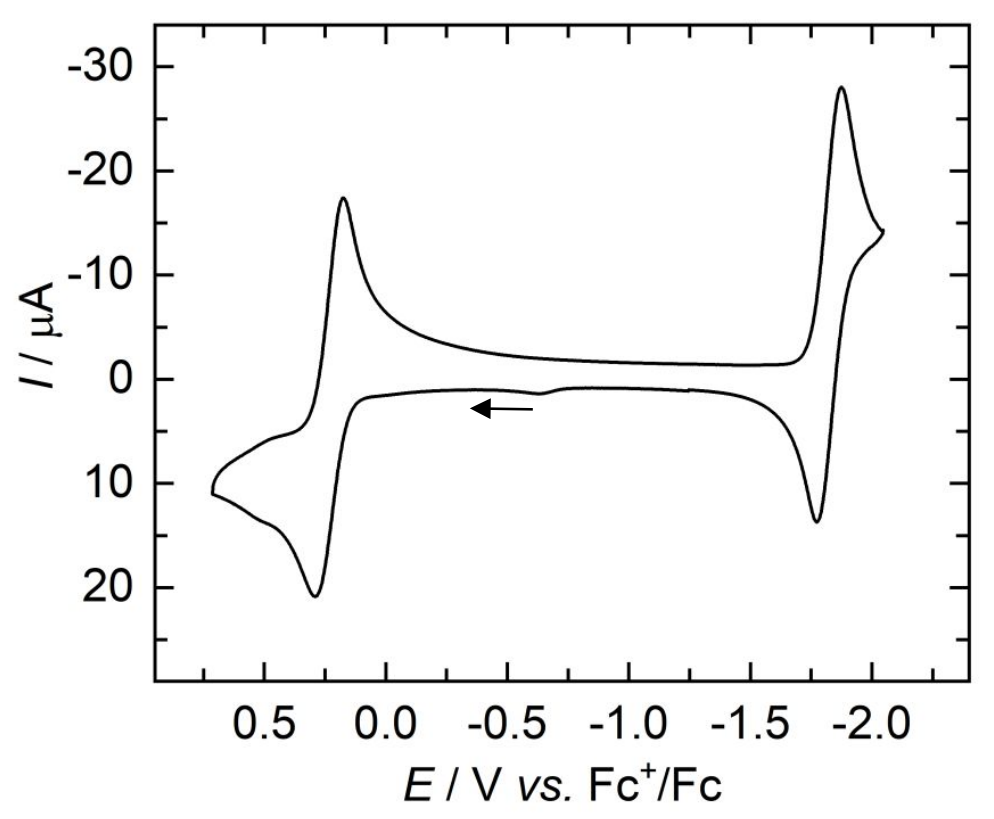

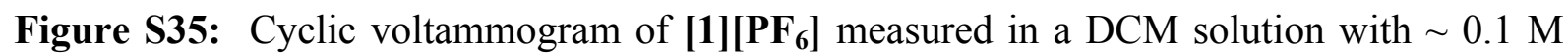
$\left[\mathrm{N}(n-\mathrm{Bu})_{4}\right]\left[\mathrm{PF}_{6}\right]$ as electrolyte showing the oxidation to $\mathrm{U}(\mathrm{IV})$ at $\mathrm{E}_{1 / 2}=0.23 \mathrm{~V}$ and to $\mathrm{U}(\mathrm{V})$ at $\mathrm{E}_{1 / 2}=-1.82 \mathrm{~V}$. 


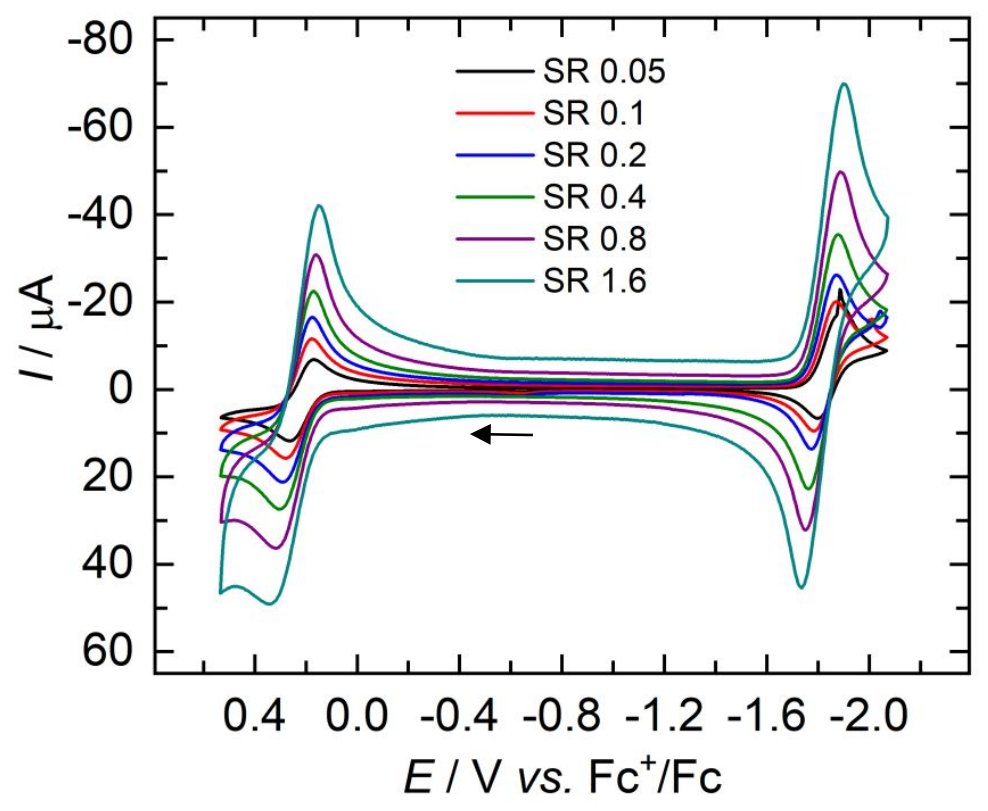

Figure S36: Cyclic voltammograms of [1][PF $\left.\mathbf{P F}_{\mathbf{6}}\right]$ scanned with scan rates started from $50 \mathrm{mV} / \mathrm{s}$ and ended with $1600 \mathrm{mV} / \mathrm{s}$ measured in a DCM solution with $\sim 0.1 \mathrm{M}\left[\mathrm{N}(n-\mathrm{Bu})_{4}\right]\left[\mathrm{PF}_{6}\right]$ as electrolyte.

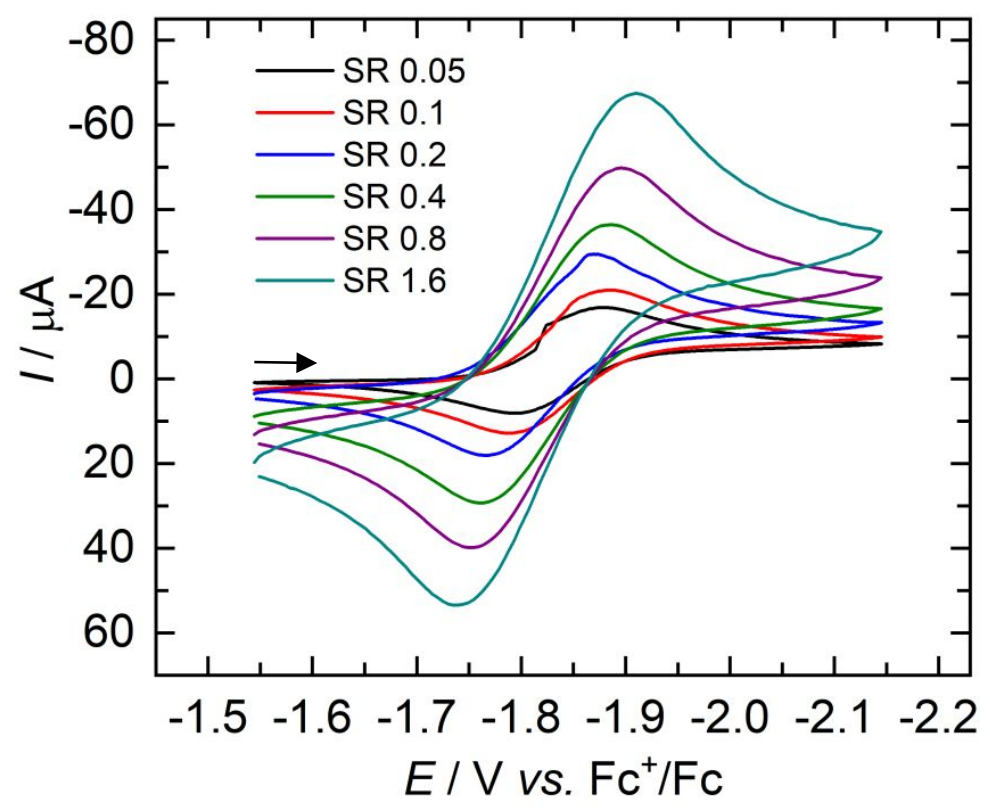

Figure S37: Cyclic voltammograms of $[1]\left[\mathbf{P F}_{\mathbf{6}}\right]$ showing the scan rate dependence of the reduction to $\mathrm{U}(\mathrm{III})$ at $\mathrm{E}_{1 / 2}=0.23 \mathrm{~V}$ measured in a DCM solution with $\sim 0.1 \mathrm{M}\left[\mathrm{N}(n-\mathrm{Bu})_{4}\right]\left[\mathrm{PF}_{6}\right]$ as electrolyte. 


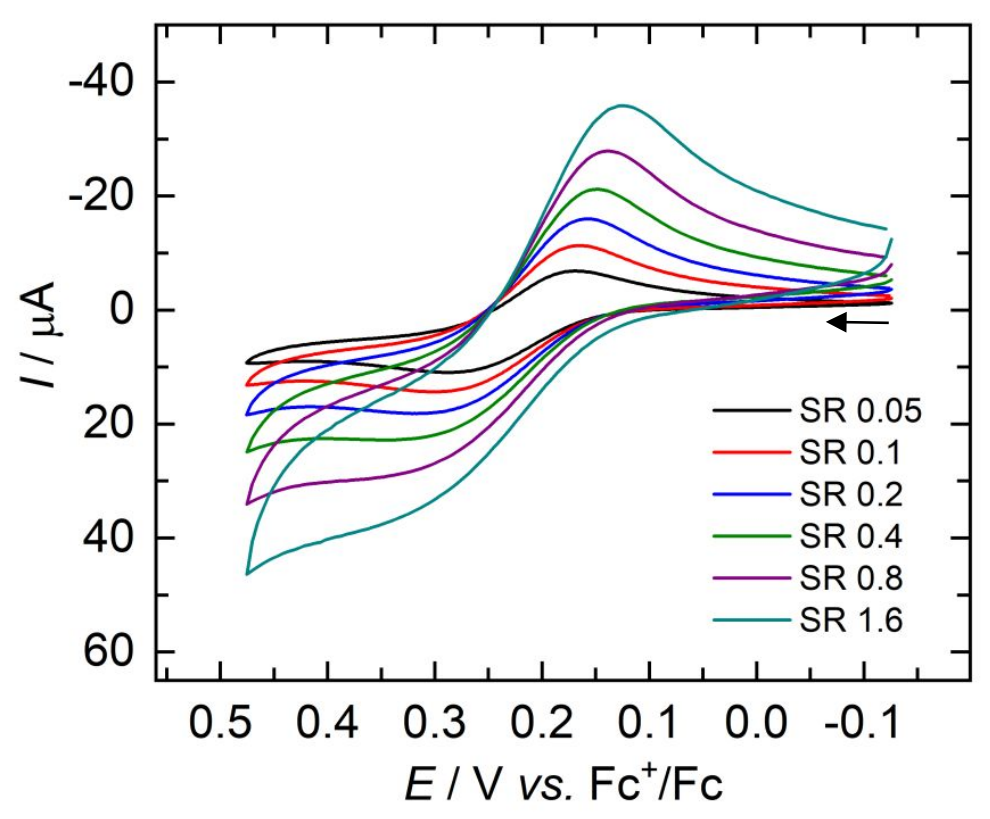

Figure S38: Cyclic voltammograms of $[1]\left[\mathbf{P F}_{\mathbf{6}}\right]$ showing the scan rate dependence of the oxidation to $\mathrm{U}(\mathrm{V})$ at $\mathrm{E}_{1 / 2}=-1.82 \mathrm{~V}$ measured in a DCM solution with $\sim 0.1 \mathrm{M}\left[\mathrm{N}(n-\mathrm{Bu})_{4}\right]\left[\mathrm{PF}_{6}\right]$ as electrolyte.

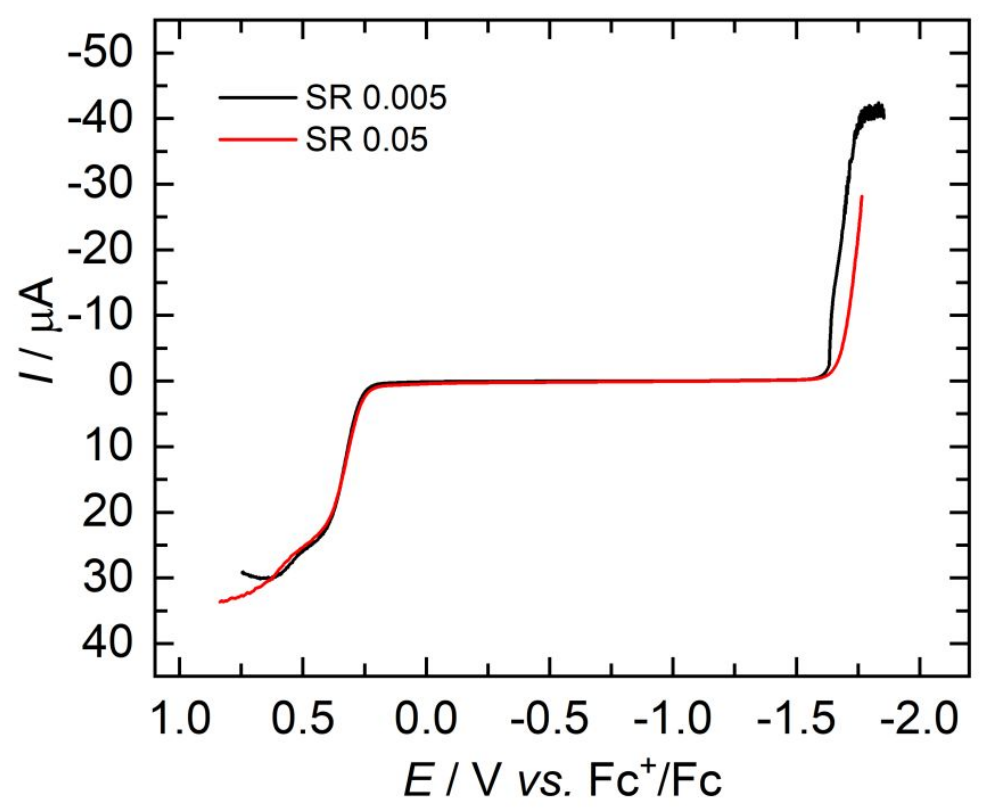

Figure S39: Linear sweep of $[1]\left[\mathbf{P F}_{6}\right]$ measured in a DCM solution with $\sim 0.1 \mathrm{M}[\mathrm{N}(n-$ $\left.\mathrm{Bu})_{4}\right]\left[\mathrm{PF}_{6}\right]$ as electrolyte, confirming one reduction and one oxidation. 


\section{Reference}

(1) Monreal, M. J.; Thomson, R. K.; Cantat, T.; Travia, N. E.; Scott, B. L.; Kiplinger, J. L. $\mathrm{UI}_{4}(1,4 \text {-dioxane })_{2}, \quad\left[\mathrm{UCl}_{4}(1,4 \text {-dioxane })\right]_{2}$, and $\mathrm{UI}_{3}(1,4$-dioxane $) 1.5$ : Stable and Versatile Starting Materials for Low- and High-Valent Uranium Chemistry. Organometallics 2011, 30, 2031-2038.

(2) Clark, D. L.; Sattelberger, A. P.; Bott, S. G.; Vrtis, R. N. Lewis base adducts of uranium triiodide: a new class of synthetically useful precursors for trivalent uranium chemistry. Inorg. Chem. 1989, 28, 1771-1773.

(3) Krossing, I. The Facile Preparation of Weakly Coordinating Anions: Structure and Characterisation of Silverpolyfluoroalkoxyaluminates $\operatorname{AgAl}\left(\mathrm{OR}_{\mathrm{F}}\right)_{4}$, Calculation of the Alkoxide Ion Affinity. Chem. Eur. J. 2011, 7, 490-502.

(4) Fulmer, G. R.; Miller, A. J. M.; Sherden, N. H.; Gottlieb, H. E.; Nudelman, A.; Stoltz, B. M.; Bercaw, J. E.; Goldberg, K. I. NMR Chemical Shifts of Trace Impurities: Common Laboratory Solvents, Organics, and Gases in Deuterated Solvents Relevant to the Organometallic Chemist. Organometallics 2010, 29, 2176-2179.

(5) SADABS 2014/5, Bruker AXS area detector scaling and absorption correction. Bruker AXS, Inc., 2014, Madison WI., USA.

(6) Vicente, I.; Bernardo-Gusmão, K.; de Souza, M. O.; de Souza, R. F. Friedel-Crafts alkylation of toluene as a parallel reaction in propylene dimerization catalyzed by nickel $\beta$ diimine complex/EASE in homogeneous phase. J. Braz. Chem. Soc. 2014, 25, 2151-2156. 


\section{X-Ray Crystal Structure Determinations}

CCDC-1943494 for [U( ${ }^{\mathrm{Me}}$ nacnac $\left.\left.^{\mathrm{Ph}}\right)_{3}\right]$ 1, CCDC-1943495 [U( ${ }^{\mathrm{Me}}$ nacnac $\left.\left.^{\mathrm{Ph}}\right)_{3}\right]\left[\mathrm{BPh}_{4}\right][1]\left[\mathrm{BPh}_{4}\right]$ and CCDC-1946325 for $\left[\mathrm{U}\left(\mathrm{Me} \text { nacnac }^{\mathrm{Ph}}\right)_{3}\right]\left[\mathrm{Al}\left\{\mathrm{OC}\left(\mathrm{CF}_{3}\right)_{3}\right\}_{4}\right]$ [1] $\left[\mathbf{A l}\left\{\mathbf{O C}\left(\mathbf{C F}_{3}\right)_{3}\right\}_{4}\right]$, contain the supplementary crystallographic data for this paper. The data can be obtained free of charge from Cambridge Crystallographic Data Centre, 12 Union Road, Cambridge, CB2 1EZ, UK (fax: ++44-1223-336-033; e-mail: deposit@ccdc.cam.ac.uk).

Suitable single crystals of the investigated compounds were embedded in protective perfluoropolyalkyether oil on a microscope slide and a single specimen was selected and subsequently transferred to the cold nitrogen gas stream of the diffractometer. Intensity data were collected using $\mathrm{Mo} K_{\alpha}$ radiation $(\lambda=0.71073 \AA)$ on a Bruker Smart APEX2 diffractometer equipped with a curved graphite monochromator (Triumph) at a temperature of $100 \mathrm{~K}$. Data were corrected for Lorentz and polarization effects, semi-empirical absorption corrections were performed on the basis of multiple scans using $S A D A B S .{ }^{1}$ The structures were solved by direct methods $(S H E L X X T)^{2}$ and refined by full-matrix leastsquares procedures on $F^{2}$ using SHELXL 2018/3. ${ }^{3}$ All non-hydrogen atoms were refined with anisotropic displacement parameters. All hydrogen atoms were placed in positions of optimized geometry, their isotropic displacement parameters were tied to those of the corresponding carrier atoms by a factor of either 1.2 or 1.5 . Olex 2 was used to prepare material for publication. ${ }^{4}$ Crystallographic data, data collection, and structure refinement details are given in Table S1. 
Table S1: Crystallographic data, data collection, and refinement details for for $\Lambda \mathbf{- 1}$ and $\Delta \mathbf{- 1}^{+}$.

\begin{tabular}{|c|c|c|c|}
\hline & $\begin{array}{c}1 \\
\text { CCDC-1943494 }\end{array}$ & $\begin{array}{c}{[1]\left[\mathrm{BPh}_{4}\right]} \\
\text { CCDC-1943495 }\end{array}$ & $\begin{array}{c}{[1]\left[\mathrm{Al}\left\{\mathrm{OC}\left(\mathrm{CF}_{3}\right)_{3}\right\}_{4}\right]} \\
\mathrm{CCDC}-1946325\end{array}$ \\
\hline Empirical formula & $\mathrm{C}_{51} \mathrm{H}_{51} \mathrm{~N}_{6} \mathrm{U}$ & $\mathrm{C}_{75} \mathrm{H}_{71} \mathrm{BN}_{6} \mathrm{U}$ & $\mathrm{C}_{67} \mathrm{H}_{51} \mathrm{AlF}_{36} \mathrm{~N}_{6} \mathrm{O}_{4} \mathrm{U}$ \\
\hline Mol. Weight & 986.01 & 1305.21 & 1953.15 \\
\hline Crystal shape, color & block, black & block, brown & block, red \\
\hline Crystal size [mm] & $0.15 \times 0.14 \times 0.07$ & $0.14 \times 0.14 \times 0.11$ & $0.20 \times 0.15 \times 0.05$ \\
\hline Temperature $[\mathrm{K}]$ & 100 & 100 & 100 \\
\hline Crystal system & Monoclinic & Monoclinic & Orthorhombic \\
\hline Space group & $P 2_{1} / c$ & $P 2_{1} / n$ & Pca2 $_{1}$ \\
\hline$a[\AA]$ & $18.564(2)$ & $17.7855(5)$ & $22.7564(6)$ \\
\hline$b[\AA]$ & $10.5127(8)$ & $17.5909(4)$ & $10.5910(3)$ \\
\hline$c[\AA]$ & $22.717(2)$ & $19.5870(5)$ & $29.9959(6)$ \\
\hline$\alpha\left[^{\circ}\right]$ & 90 & 90 & 90 \\
\hline$\beta\left[^{\mathrm{o}}\right]$ & $104.515(4)$ & $101.133(2)$ & 90 \\
\hline$\gamma\left[{ }^{\circ}\right]$ & 90 & 90 & 90 \\
\hline$V\left[\AA^{3}\right]$ & $4291.8(6)$ & $6012.7(3)$ & $7229.4(3)$ \\
\hline$Z^{2-3}$ & 4 & 4 & 4 \\
\hline$\rho\left[\mathrm{g} \mathrm{cm}^{-3}\right]$ (calc. $)$ & 1.526 & 1.442 & 2.219 \\
\hline$\mu\left[\mathrm{mm}^{-1}\right]$ & 3.825 & 2.750 & 9.613 \\
\hline$F(000)$ & 1964 & 2640 & 4323 \\
\hline$T_{\min } ; T_{\max }$ & $0.645 ; 0.746$ & $0.681 ; 0.746$ & $0.645 ; 0.889$ \\
\hline $2 \Theta$ interval $\left[{ }^{\circ}\right]$ & $2.2 \leq 2 \Theta \leq 59.3$ & $2.8 \leq 2 \Theta \leq 59.3$ & $6.6 \leq 2 \Theta \leq 51.2$ \\
\hline Coll. Refl. & 202392 & 238806 & 57751 \\
\hline Indep. Refl.; $R_{\mathrm{int}}$ & $12059,0.042$ & $16823,0.072$ & 16106 \\
\hline Obs. refl. $F_{0} \geq 4 \sigma(F)$ & 8414 & 12618 & 9153 \\
\hline No. ref. param. & 529 & 754 & \\
\hline $\mathrm{wR}_{2}$ (all data) & 0.043 & 0.057 & 0.0518 \\
\hline $\mathrm{R}_{1}\left(F_{0} \geq 4 \sigma(F)\right)$ & 0.022 & 0.035 & 0.0291 \\
\hline GooF on $F^{2}$ & 1.039 & 1.052 & 1.031 \\
\hline$\Delta \rho_{\max / \min }\left[\mathrm{e} \AA^{-3}\right]$ & $0.91 ;-0.61$ & $1.58 ;-1.44$ & $0.50 ;-1.11$ \\
\hline
\end{tabular}




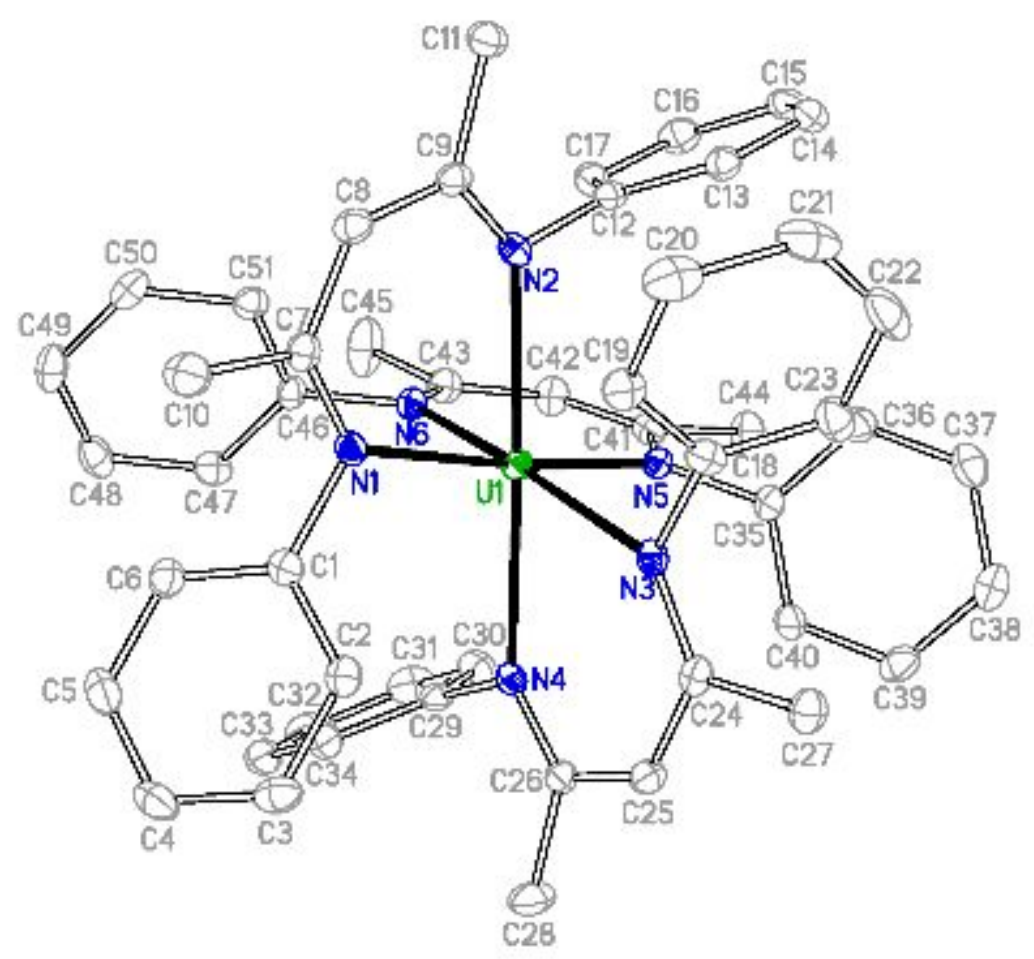

Figure S40: Solid-state molecular structure with applied numbering scheme of $\mathbf{1}$. Hydrogen atoms are omitted for clarity. Thermal ellipsoids are drawn at the $50 \%$ probability level.

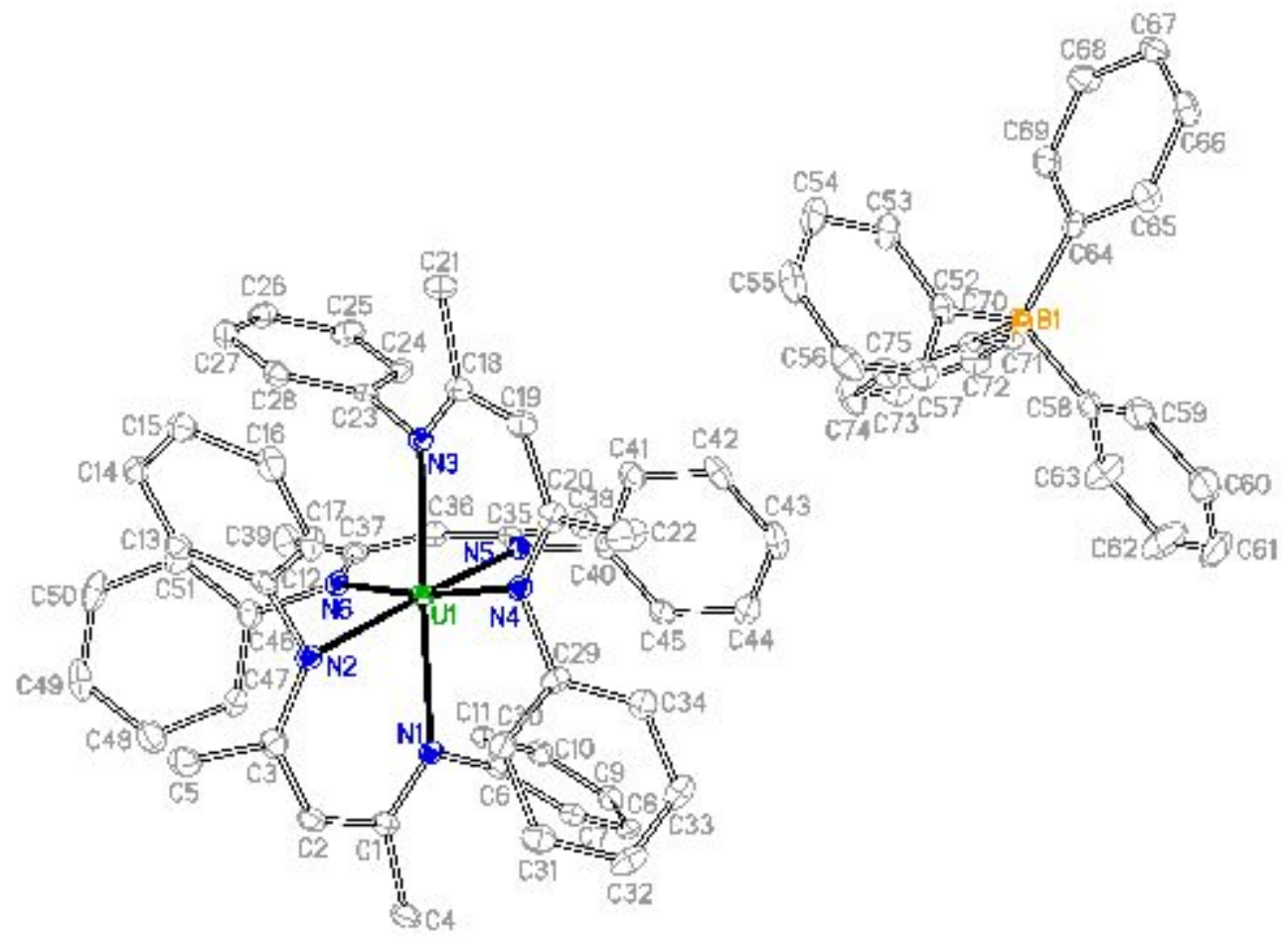

Figure S41: Solid-state molecular structure with applied numbering scheme of [1][BPh $\left.\mathbf{P h}_{4}\right]$. Hydrogen atoms are omitted for clarity. Thermal ellipsoids are drawn at the $50 \%$ probability level. 

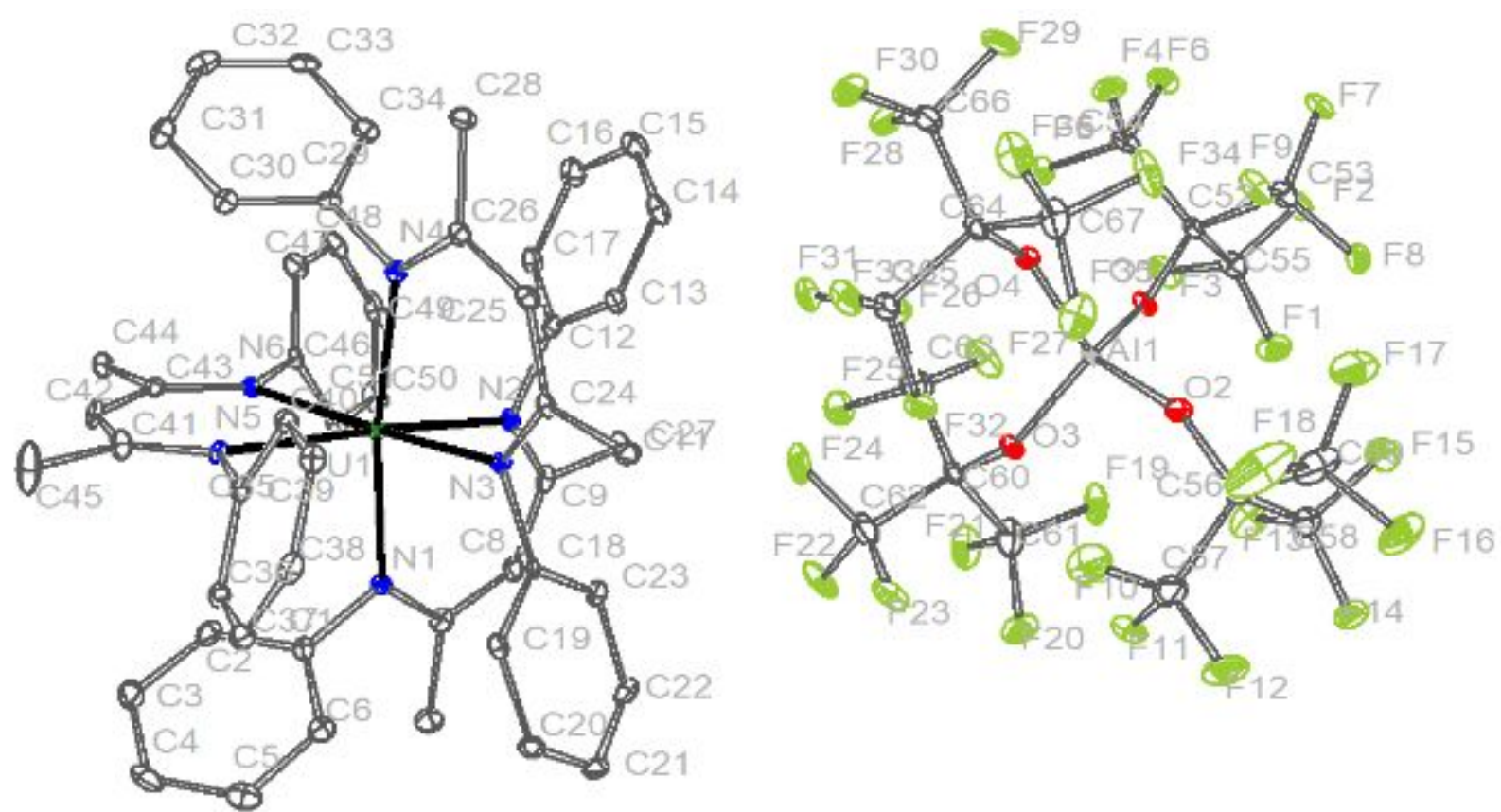

Figure S42: Solid-state molecular structure with applied numbering scheme of [1] $\left[\mathbf{A l}\left\{\mathbf{O}\left(\mathbf{C C F}_{3}\right)_{3}\right\}_{4}\right]$. Hydrogen atoms are omitted for clarity. Thermal ellipsoids are drawn at the $50 \%$ probability level.

\section{References for $\mathrm{X}$-ray structure determination of 1 and $[1]\left[\mathrm{BPh}_{4}\right]$}

(1) SADABS 2014/5, Bruker AXS area detector scaling and absorption correction. Bruker AXS, Inc., 2014, Madison WI., USA.

(2) Sheldrick, G. M. A short history of SHELX. Acta Cryst. A 2008, 64, 112-122.

(3) Sheldrick, G.M. SHELXT - Integrated space-group and crystal-structure determination Acta Cryst. C 2015, 71, 3-8.

(4) Dolomanov, O. V.; Bourhis, L. J.; Gildea, J. R.; Howard, J. A. K.; Puschmann, H. OLEX2: a complete structure solution, refinement and analysis program. J. Appl. Cryst. 2009, 42, 339-341. 


\section{Computational Details}

All calculations were performed with ORCA v. 4.0.1., 2 The molecular structure of complex 1 was optimized using the functionals $\mathrm{BP}^{3} 6^{3,4}$ and $\mathrm{BLYP}^{5}$ each with and without dispersion correction D3(BJ) ${ }^{6,7}$ and the relativistically recontracted DKH-def2-SVP (all-electron SARCdef2-TZVP for uranium, respectively) basis set. ${ }^{8,9}$ Scalar relativistic effects were modeled with the Douglas-Kroll-Hess method (DKH2), ${ }^{10}$ as implemented in ORCA. ${ }^{11,12}$ Calculations using the Stuttgart-Dresden ECP led to comparable results. ${ }^{13}, 14$ The RI approximation and the related relativistically recontracted auxiliary basis set (" $S A R C / J$ ') $)^{15}$ were used to speed up the calculations. Tighter than default scf ("tightscf") and optimization criteria ("tightopt") were chosen in conjunction with finer than default grid values ("grid6"; "finalgrid6"). The optimization with the BP86 functional and without inclusion of dispersion effects showed the best agreement with the structural parameters as obtained from the solid-state, single-crystal XRD structure. All reported optimized structures were verified as true minima by the absence of negative eigenvalues in the harmonic vibrational frequency analysis.

For clarity, optimization of the structural parameters were subsequently performed, where the aryl substituents were truncated by methyl groups (BP86/DKH-def2-SVP). The obtained U-N bond lengths as well as the nacnac N-U-N bond angles were in good agreement with the structural parameters from the solid state structure. (mean deviation from the solid-state, singlecrystal XRD structure: $0.006 \AA ; 2.2^{\circ}$ ). Molecular orbitals were then obtained from single-point calculations at the B3PW91/DKH-def2-TZVPP//BP86/DKH-def2-SVP level of theory. ${ }^{16}$ Note that the B3PW91 functional proved an excellent choice in our recent investigations on U(III) and U(IV) compounds. ${ }^{17,18}$ The molecular orbitals obtained from the truncated model system were essentially equivalent to the ones obtained without truncation.

For the U(IV) compound $\mathbf{1}^{+}$, the B3PW91/DKH-def2-TZVPP//BP86/def2-SVP(U: DKH-def2TZVP) level of theory was used and the phenyl groups were NOT truncated (mean deviation from the solid-state, single-crystal XRD structure: $0.02 \AA ; 0.4^{\circ}$ ).

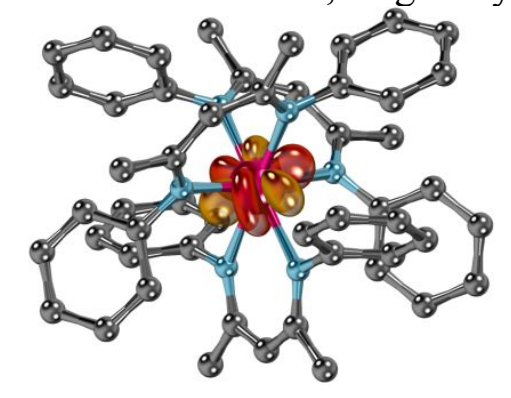

SOMO 1: $f(\mathrm{yz})^{2}$ (very few spin density on nacnac)

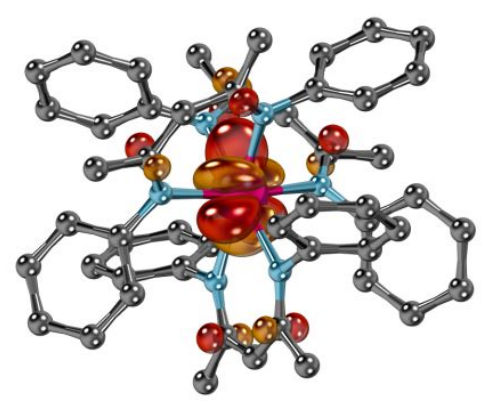

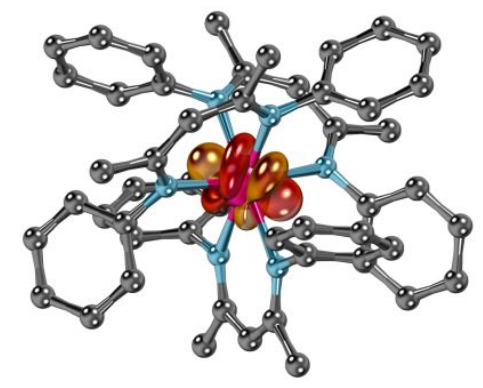

SOMO 2: $f\left(\mathrm{xz}^{2}\right)$ (very few spin density on nacnac)

SOMO 3: $f\left[y\left(3 \mathrm{x}^{2}-\mathrm{y}^{2}\right)\right]$ (some spin density on nacnac)

Figure S43: Singly occupied molecular orbitals for U(III) compound 1 as obtained from the B3PW91/DKH-def2-TZVPP//BP86/DKH-def2-SVP level of theory without truncation. Molecular orbitals obtained from the BP86/DKH-def2-SVP level of theory are very similar. 


\begin{tabular}{|c|c|l|c|l|}
\hline & $\begin{array}{l}\text { BP86-D3/DKH- } \\
\text { def2-TZVPP/BP86- } \\
\text { D3/DKH-def2-SVP }\end{array}$ & $\begin{array}{l}\text { BP6/DKH-def2- } \\
\text { TZVP//BP86/DKH- } \\
\text { def2-SVP }\end{array}$ & $\begin{array}{l}\text { B3PW91-D3/DKH- } \\
\text { def2-TZVPP//B3PW91- } \\
\text { D3/DKH-def2-SVP }\end{array}$ & $\begin{array}{l}\text { B3PW91/DKH-def2- } \\
\text { TZVPP//B3PW91/DKH- } \\
\text { def2-SVP }\end{array}$ \\
\hline $\begin{array}{c}\text { Truncated Model } \\
\text { System }\end{array}$ & 2.4 & 2.5 & 2.4 & 2.6 \\
\hline No Truncation & 2.5 & 2.6 & 2.6 & 2.8 \\
\hline
\end{tabular}

Table S2. Spin population (values given in [electrons]) at uranium for U(III) compound $\mathbf{1}$ as obtained at various levels of theory.

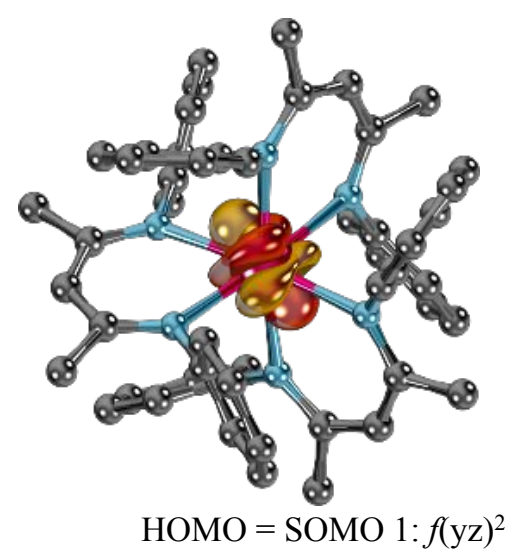

few ligand contribution

BP86/def2-SVP

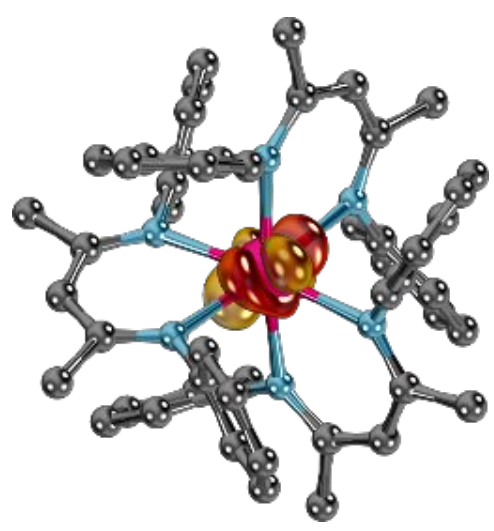

SOMO 2: $f(\mathrm{xz})^{2}$

few ligand contribution

BP86/def2-SVP

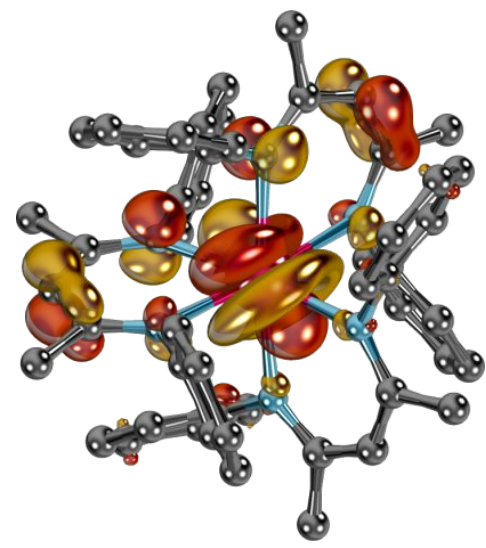

SOMO 1: $f(\mathrm{yz})^{2}+$ ligand

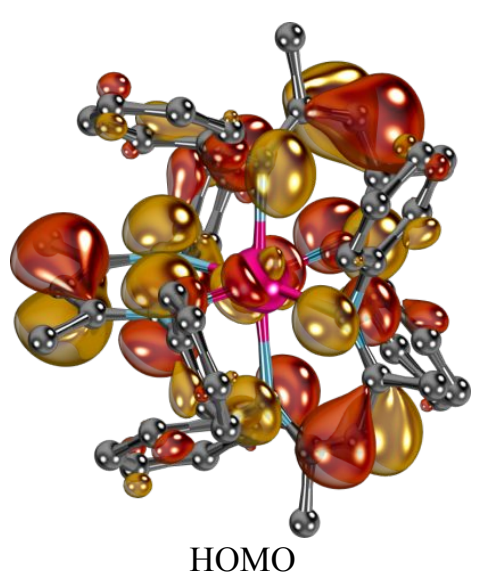

HOMO $\neq$ SOMO, $f(y z)^{2}$ mixes with ligand

B3PW91/DKH-def2-TZVPP//BP86/DKH-def2-SVP

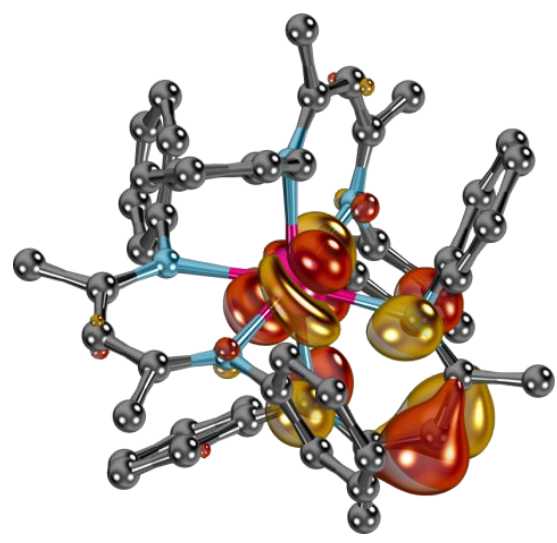

SOMO 2: $f(\mathrm{xz})^{2}+$ ligand

considerable ligand contribution

SOMO 2 (B3PW91/DKH-def2-TZVPP//BP86/DKH-def2-SVP)

Figure S44: Singly occupied molecular orbitals for U(IV) cation $[1]^{+}$as obtained from the BP86/DKH-def2-SVP and B3PW91/DKH-def2-TZVPP//BP86/DKH-def2-SVP levels of theory. The GGA functional (left) predicts few ligand contribution (some in the SOMO 2), whereas the hybrid functional (right) suggests considerable ligand contribution for both MOs. In case of the B3PW91/DKH-def2-TZVPP//BP86/DKH-def2-SVP level of theory, a ligand centered orbitals was predicted to be the highest occupied molecular orbital (HOMO). 
XYZ Coordinates and Electronic Energies
for U(III) compound 1

No truncation: BP86-D3BJ/DKH-def2-SVP $E=-30262.794974503 \mathrm{H}$

\begin{tabular}{|c|c|c|c|}
\hline $\mathrm{U}$ & 9.79006 & 5.20108 & 15.64538 \\
\hline $\mathrm{N}$ & 8.57358 & 7.13396 & 16.46704 \\
\hline $\mathrm{N}$ & 7.65892 & 5.07424 & 14.51639 \\
\hline $\mathrm{N}$ & 8.90416 & 3.52510 & 17.15858 \\
\hline $\mathrm{N}$ & 10.80272 & 3.13813 & 14.88775 \\
\hline $\mathrm{N}$ & 10.93289 & 6.76226 & 14.19087 \\
\hline $\mathrm{N}$ & 11.90586 & 5.60661 & 16.76920 \\
\hline $\mathrm{C}$ & 10.50736 & 8.53679 & 17.04393 \\
\hline $\mathrm{C}$ & 11.30687 & 9.18620 & 17.99729 \\
\hline $\mathrm{C}$ & 10.97873 & 9.12115 & 19.36366 \\
\hline $\mathrm{C}$ & 9.85200 & 8.38043 & 19.76956 \\
\hline $\mathrm{C}$ & 9.06494 & 7.70985 & 18.82348 \\
\hline $\mathrm{C}$ & 9.37380 & 7.79472 & 17.44573 \\
\hline $\mathrm{C}$ & 6.82561 & 8.81530 & 16.99723 \\
\hline $\mathrm{C}$ & 5.40797 & 5.53967 & 13.58225 \\
\hline $\mathrm{C}$ & 7.32022 & 7.59184 & 16.24830 \\
\hline $\mathrm{C}$ & 6.42343 & 7.01224 & 15.32230 \\
\hline $\mathrm{C}$ & 6.56875 & 5.87336 & 14.49952 \\
\hline $\mathrm{C}$ & 7.66662 & 2.64811 & 14.13792 \\
\hline $\mathrm{C}$ & 7.73445 & 1.54487 & 13.27312 \\
\hline $\mathrm{C}$ & 7.83011 & 1.73642 & 11.88295 \\
\hline $\mathrm{C}$ & 7.87850 & 3.04574 & 11.36629 \\
\hline $\mathrm{C}$ & 7.83533 & 4.15048 & 12.22720 \\
\hline $\mathrm{C}$ & 7.71137 & 3.96424 & 13.62423 \\
\hline $\mathrm{C}$ & 8.56918 & 4.32327 & 19.47747 \\
\hline $\mathrm{C}$ & 7.77078 & 4.95802 & 20.43841 \\
\hline $\mathrm{C}$ & 6.51593 & 5.48997 & 20.08419 \\
\hline $\mathrm{C}$ & 6.06832 & 5.37736 & 18.75534 \\
\hline $\mathrm{C}$ & 6.85444 & 4.72230 & 17.79460 \\
\hline $\mathrm{C}$ & 8.11221 & 4.18178 & 18.14608 \\
\hline $\mathrm{C}$ & 8.44852 & 1.42904 & 18.40947 \\
\hline $\mathrm{C}$ & 11.40154 & 0.76024 & 14.50919 \\
\hline $\mathrm{C}$ & 9.11230 & 2.19440 & 17.27988 \\
\hline $\mathrm{C}$ & 9.90478 & 1.43949 & 16.38620 \\
\hline $\mathrm{C}$ & 10.67120 & 1.84903 & 15.27229 \\
\hline $\mathrm{C}$ & 11.15264 & 3.06439 & 12.43920 \\
\hline $\mathrm{C}$ & 11.94429 & 3.34885 & 11.31836 \\
\hline $\mathrm{C}$ & 13.16848 & 4.02967 & 11.46404 \\
\hline $\mathrm{C}$ & 13.59430 & 4.41900 & 12.74689 \\
\hline $\mathrm{C}$ & 12.81703 & 4.11424 & 13.87503 \\
\hline $\mathrm{C}$ & 11.58865 & 3.42957 & 13.73448 \\
\hline $\mathrm{C}$ & 8.93439 & 7.74460 & 13.15455 \\
\hline $\mathrm{C}$ & 8.11359 & 7.95384 & 12.03548 \\
\hline $\mathrm{C}$ & 8.46532 & 7.41425 & 10.78496 \\
\hline $\mathrm{C}$ & 9.63854 & 6.64384 & 10.66926 \\
\hline $\mathrm{C}$ & 10.44900 & 6.41256 & 11.78882 \\
\hline $\mathrm{C}$ & 10.11510 & 6.97552 & 13.04302 \\
\hline $\mathrm{C}$ & 12.61036 & 8.21713 & 13.08127 \\
\hline $\mathrm{C}$ & 14.12413 & 6.49233 & 17.44983 \\
\hline $\mathrm{C}$ & 12.15967 & 7.32918 & 14.22580 \\
\hline $\mathrm{C}$ & 13.06398 & 7.17166 & 15.29929 \\
\hline
\end{tabular}

12.95700

$$
11.77783
$$

11.81136

\subsection{5}

\subsection{8}

12.04654

11.91287

10.75214

12.18726

11.59861

9.59357

8.20438

7.59690

5.91806

6.58061

5.17898

4.50660

5.64518

5.46282

7.58382

7.70753

7.87327

7.96986

7.89880

9.55396

8.14023

5.89620

5.09875

6.50688

7.39984

8.47162

8.96550

12.43964

11.41948

10.90919

9.93483

10.18913

11.59273

13.78197

14.53986

13.14739

8.67056

7.19778

7.82825

9.91635

11.34680

11.80288

13.48700

12.89008

14.40366

15.00084

13.86740

13.99870

11.64791

11.71164

11.96640
6.40794

5.58858

4.88477

3.48337

2.79402

3.49713

4.90385

8.59155

9.74945

9.63751

8.30741

7.11330

9.60521

9.22150

8.56711

4.45929

6.10180

5.79553

7.52887

2.50628

0.53212

0.87338

3.20919

5.16796

3.93025

5.05326

5.99364

5.79611

4.62482

1.74612

0.34564

1.61045

1.05933

$-0.17663$

0.55389

0.36504

2.55924

3.05314

4.25917

4.95928

4.40563

8.16923

8.54724

7.58692

6.20349

5.79343

8.89810

8.81600

7.61475

5.49443

6.94668

7.10867

7.73266

6.67420

5.43413

2.93356
16.48345

19.24070

20.45216

20.45884

19.23713

18.02235

18.01050

15.97915

17.66446

20.10682

20.83344

19.13837

17.03086

16.52288

18.04688

13.60115

13.87417

12.53260

15.22736

15.21959

13.69338

11.20738

10.28520

11.83140

19.74438

21.46719

20.83613

18.45924

16.76179

18.54901

18.21091

19.37032

14.27894

15.08849

13.54048

16.59444

12.32737

10.32191

10.58420

12.87756

14.87635

14.12763

12.14615

9.90893

9.70344

11.70826

12.75849

13.37552

12.19675

17.83178

16.96134

18.33164

15.19799

19.23153

21.39675

21.40782 


\begin{tabular}{|c|c|c|c|c|c|c|c|}
\hline \multirow{3}{*}{$\begin{array}{l}\mathrm{H} \\
\mathrm{H}\end{array}$} & 12.15264 & 1.70156 & 19.22343 & $\mathrm{C}$ & 12.99836 & 6.38633 & 16.46858 \\
\hline & 12.14008 & 2.96773 & 17.06959 & $\mathrm{C}$ & 11.87015 & 5.61859 & 19.27787 \\
\hline & & & & $\mathrm{C}$ & 11.98072 & 4.94067 & 20.50184 \\
\hline \multicolumn{4}{|c|}{ No truncation: BP86/DKH-def2-SVP } & $\mathrm{C}$ & 12.20469 & 3.55133 & 20.53084 \\
\hline \multicolumn{4}{|c|}{$E=-30262.427050084127 \mathrm{H}$} & $\mathrm{C}$ & 12.31286 & 2.84623 & 19.31860 \\
\hline U & 9.79600 & 5.20170 & 15.64221 & $\mathrm{C}$ & 12.21607 & 3.52221 & 18.09067 \\
\hline $\mathrm{N}$ & 8.56501 & 7.16254 & 16.49604 & $\mathrm{C}$ & 12.00318 & 4.92025 & 18.05252 \\
\hline $\mathrm{N}$ & 7.63708 & 5.06128 & 14.48360 & $\mathrm{H}$ & 10.66547 & 8.76258 & 16.01499 \\
\hline $\mathrm{N}$ & 8.88999 & 3.51013 & 17.19062 & $\mathrm{H}$ & 11.97897 & 10.05444 & 17.70164 \\
\hline $\mathrm{N}$ & 10.81965 & 3.10982 & 14.85565 & $\mathrm{H}$ & 11.37785 & 9.92293 & 20.13818 \\
\hline $\mathrm{N}$ & 10.94783 & 6.78256 & 14.15313 & $\mathrm{H}$ & 9.47492 & 8.44985 & 20.86107 \\
\hline $\mathrm{N}$ & 11.93855 & 5.61053 & 16.80086 & $\mathrm{H}$ & 8.19184 & 7.13615 & 19.16943 \\
\hline $\mathrm{C}$ & 10.41106 & 8.69698 & 17.07818 & $\mathrm{H}$ & 7.58397 & 9.69861 & 16.84895 \\
\hline $\mathrm{C}$ & 11.14540 & 9.42166 & 18.03185 & $\mathrm{H}$ & 5.90157 & 9.25820 & 16.41351 \\
\hline $\mathrm{C}$ & 10.81081 & 9.34708 & 19.39593 & $\mathrm{H}$ & 6.60701 & 8.73568 & 17.96848 \\
\hline $\mathrm{C}$ & 9.74207 & 8.52447 & 19.79894 & $\mathrm{H}$ & 5.06441 & 4.41829 & 13.78871 \\
\hline $\mathrm{C}$ & 9.01415 & 7.78752 & 18.85180 & $\mathrm{H}$ & 4.44539 & 6.08905 & 13.98836 \\
\hline $\mathrm{C}$ & 9.32864 & 7.87622 & 17.47334 & $\mathrm{H}$ & 5.49848 & 5.66610 & 12.60941 \\
\hline $\mathrm{C}$ & 6.82396 & 8.89773 & 16.89642 & $\mathrm{H}$ & 5.45464 & 7.52410 & 15.23219 \\
\hline $\mathrm{C}$ & 5.31853 & 5.48894 & 13.68594 & $\mathrm{H}$ & 7.39694 & 2.47511 & 15.15286 \\
\hline $\mathrm{C}$ & 7.31967 & 7.62298 & 16.22703 & $\mathrm{H}$ & 7.33951 & 0.52531 & 13.59183 \\
\hline $\mathrm{C}$ & 6.41709 & 7.00988 & 15.32522 & $\mathrm{H}$ & 7.51750 & 0.89036 & 11.11195 \\
\hline $\mathrm{C}$ & 6.53716 & 5.85065 & 14.52326 & $\mathrm{H}$ & 7.79224 & 3.22487 & 10.22487 \\
\hline $\mathrm{C}$ & 7.48353 & 2.63185 & 14.07238 & $\mathrm{H}$ & 7.88174 & 5.16305 & 11.79750 \\
\hline $\mathrm{C}$ & 7.45188 & 1.53990 & 13.18908 & $\mathrm{H}$ & 9.55579 & 3.92162 & 19.77317 \\
\hline $\mathrm{C}$ & 7.55351 & 1.74340 & 11.80117 & $\mathrm{H}$ & 8.09635 & 4.90125 & 21.54579 \\
\hline $\mathrm{C}$ & 7.70371 & 3.05231 & 11.30532 & $\mathrm{H}$ & 5.77740 & 5.68736 & 20.98091 \\
\hline $\mathrm{C}$ & 7.74947 & 4.14578 & 12.18397 & $\mathrm{H}$ & 4.94801 & 5.48473 & 18.61741 \\
\hline $\mathrm{C}$ & 7.62425 & 3.95157 & 13.58186 & $\mathrm{H}$ & 6.40552 & 4.47349 & 16.85948 \\
\hline $\mathrm{C}$ & 8.54064 & 4.25417 & 19.52801 & $\mathrm{H}$ & 7.28597 & 1.64657 & 18.39534 \\
\hline $\mathrm{C}$ & 7.71741 & 4.80986 & 20.51959 & $\mathrm{H}$ & 8.41509 & 0.28323 & 18.11004 \\
\hline $\mathrm{C}$ & 6.41962 & 5.25413 & 20.20378 & $\mathrm{H}$ & 8.78431 & 1.53109 & 19.33213 \\
\hline $\mathrm{C}$ & 5.95546 & 5.13864 & 18.88110 & $\mathrm{H}$ & 12.54659 & 1.01639 & 14.45198 \\
\hline $\mathrm{C}$ & 6.77063 & 4.57098 & 17.88745 & $\mathrm{H}$ & 11.45737 & -0.20331 & 15.18669 \\
\hline $\mathrm{C}$ & 8.07223 & 4.11203 & 18.19851 & $\mathrm{H}$ & 11.08515 & 0.50783 & 13.59117 \\
\hline $\mathrm{C}$ & 8.35143 & 1.36124 & 18.32887 & $\mathrm{H}$ & 9.92971 & 0.35448 & 16.58982 \\
\hline $\mathrm{C}$ & 11.48992 & 0.72655 & 14.59660 & $\mathrm{H}$ & 10.19933 & 2.53827 & 12.29204 \\
\hline $\mathrm{C}$ & 9.07701 & 2.17027 & 17.26212 & $\mathrm{H}$ & 11.66135 & 2.88684 & 10.29754 \\
\hline $\mathrm{C}$ & 9.90234 & 1.42956 & 16.38277 & $\mathrm{H}$ & 13.93190 & 3.92948 & 10.56279 \\
\hline $\mathrm{C}$ & 10.70335 & 1.83148 & 15.28787 & $\mathrm{H}$ & 14.71266 & 4.62099 & 12.84906 \\
\hline $\mathrm{C}$ & 11.19455 & 2.98244 & 12.40968 & $\mathrm{H}$ & 13.25535 & 4.23603 & 14.84064 \\
\hline $\mathrm{C}$ & 12.01847 & 3.18535 & 11.29169 & $\mathrm{H}$ & 8.75206 & 8.31882 & 14.03525 \\
\hline $\mathrm{C}$ & 13.28931 & 3.77269 & 11.43830 & $\mathrm{H}$ & 7.38677 & 8.82335 & 12.00549 \\
\hline $\mathrm{C}$ & 13.72653 & 4.15758 & 12.71842 & $\mathrm{H}$ & 8.02861 & 7.84871 & 9.77973 \\
\hline $\mathrm{C}$ & 12.91156 & 3.94423 & 13.84266 & $\mathrm{H}$ & 10.02762 & 6.33439 & 9.62646 \\
\hline $\mathrm{C}$ & 11.63680 & 3.34575 & 13.70566 & $\mathrm{H}$ & 11.36505 & 5.81040 & 11.66908 \\
\hline $\mathrm{C}$ & 9.02557 & 7.88687 & 13.06673 & $\mathrm{H}$ & 11.80865 & 9.06447 & 12.90212 \\
\hline $\mathrm{C}$ & 8.26196 & 8.16673 & 11.92114 & $\mathrm{H}$ & 13.50322 & 8.89977 & 13.46380 \\
\hline $\mathrm{C}$ & 8.61940 & 7.61995 & 10.67563 & $\mathrm{H}$ & 12.85086 & 7.81336 & 12.20590 \\
\hline $\mathrm{C}$ & 9.74188 & 6.77472 & 10.59055 & $\mathrm{H}$ & 14.52425 & 5.40628 & 17.68452 \\
\hline $\mathrm{C}$ & 10.50044 & 6.48110 & 11.73424 & $\mathrm{H}$ & 15.07246 & 6.90024 & 16.85876 \\
\hline $\mathrm{C}$ & 10.16156 & 7.04699 & 12.98827 & $\mathrm{H}$ & 14.02592 & 6.98910 & 18.30236 \\
\hline $\mathrm{C}$ & 12.60793 & 8.34142 & 13.14653 & $\mathrm{H}$ & 14.01304 & 7.73612 & 15.19457 \\
\hline $\mathrm{C}$ & 14.22308 & 6.42291 & 17.37328 & $\mathrm{H}$ & 11.68208 & 6.69818 & 19.25737 \\
\hline $\mathrm{C}$ & 12.16429 & 7.37279 & 14.23411 & $\mathrm{H}$ & 11.88572 & 5.50282 & 21.43993 \\
\hline $\mathrm{C}$ & 13.07760 & 7.17575 & 15.29635 & $\mathrm{H}$ & 12.29242 & 3.02365 & 21.48892 \\
\hline
\end{tabular}




\begin{tabular}{lccccccc}
$\mathrm{H}$ & 12.48252 & 1.76203 & 19.32385 & $\mathrm{H}$ & 12.70463 & 5.53592 & 18.73823 \\
$\mathrm{H}$ & 12.30957 & 2.97458 & 17.14684 & $\mathrm{C}$ & 7.48568 & 3.85499 & 13.71931 \\
& & & & $\mathrm{H}$ & 8.44557 & 3.51749 & 13.31211 \\
\multicolumn{2}{l}{$\begin{array}{l}\text { Truncated Model } \\
\text { D3BJ/DKH-def2-SVP }\end{array}$ System: } & BP86- & $\mathrm{H}$ & 7.07701 & 3.03645 & 14.32271 \\
$\mathrm{E}=-29112.458225211252 \mathrm{H}$ & & & $\mathrm{H}$ & 6.80602 & 4.01330 & 12.87426 \\
$\mathrm{U}$ & 9.82690 & 5.24940 & 15.63220 & $\mathrm{C}$ & 8.02462 & 4.03355 & 18.14522 \\
$\mathrm{~N}$ & 8.51500 & 7.14620 & 16.48050 & $\mathrm{H}$ & 7.01357 & 4.16564 & 17.74343 \\
$\mathrm{~N}$ & 7.64340 & 5.08020 & 14.51610 & $\mathrm{H}$ & 7.95368 & 3.35075 & 18.99954 \\
$\mathrm{~N}$ & 8.94400 & 3.51620 & 17.12150 & $\mathrm{H}$ & 8.35793 & 5.00554 & 18.52632 \\
$\mathrm{~N}$ & 10.80820 & 3.13840 & 14.81000 & $\mathrm{C}$ & 11.82871 & 3.32554 & 13.76864 \\
$\mathrm{~N}$ & 11.02570 & 6.86020 & 14.21550 & $\mathrm{H}$ & 12.83551 & 3.36750 & 14.19956 \\
$\mathrm{~N}$ & 11.97970 & 5.67110 & 16.74040 & $\mathrm{H}$ & 11.81408 & 2.50400 & 13.04340 \\
$\mathrm{C}$ & 6.78210 & 8.86960 & 16.87410 & $\mathrm{H}$ & 11.66757 & 4.25751 & 13.21494 \\
$\mathrm{C}$ & 5.40330 & 5.52860 & 13.58540 & $\mathrm{C}$ & 9.22698 & 7.94106 & 17.49153 \\
$\mathrm{C}$ & 7.28650 & 7.60590 & 16.21300 & $\mathrm{H}$ & 8.58849 & 8.14932 & 18.35759 \\
$\mathrm{C}$ & 6.41760 & 7.02560 & 15.27570 & $\mathrm{H}$ & 10.11763 & 7.41698 & 17.85650 \\
$\mathrm{C}$ & 6.56500 & 5.88080 & 14.48690 & $\mathrm{H}$ & 9.55462 & 8.90414 & 17.08381
\end{tabular}

Truncated Model System: BP86/DKH-def2SVP

$E=-29112.292678878424 \mathrm{H}$

$\begin{array}{llll}\mathrm{U} & 9.79890 & 5.20705 & 15.58189\end{array}$

$\begin{array}{llll}\mathrm{N} & 8.63513 & 7.17046 & 16.37037\end{array}$

$\begin{array}{llll}\mathrm{N} & 7.63183 & 5.09807 & 14.53019\end{array}$

$\begin{array}{llll}\mathrm{N} & 8.84551 & 3.52120 & 17.03995\end{array}$

$\begin{array}{llll}\text { C } & 12.25400 & 7.38660 & 14.22650\end{array}$

$\begin{array}{llll}\text { C } & 13.16290 & 7.19070 & 15.27400\end{array}$

$\begin{array}{llll}\mathrm{C} & 13.05010 & 6.40960 & 16.43560\end{array}$

$\begin{array}{llll}\mathrm{H} & 7.42960 & 9.59180 & 16.73360\end{array}$

$\begin{array}{llll}\mathrm{H} & 5.92090 & 9.12190 & 16.48070\end{array}$

$\begin{array}{llll}\mathrm{H} & 6.66910 & 8.71290 & 17.83540\end{array}$

$\begin{array}{llll}\mathrm{H} & 5.09800 & 4.61930 & 13.78670\end{array}$

$\begin{array}{llll}\mathrm{H} & 4.66930 & 6.16040 & 13.73610\end{array}$

$\begin{array}{llll}\mathrm{H} & 5.68940 & 5.57700 & 12.64970\end{array}$

$\begin{array}{llll}\mathrm{H} & 5.59480 & 7.48610 & 15.15900\end{array}$

$\begin{array}{llll}\mathrm{H} & 7.54510 & 1.57590 & 18.34560\end{array}$

$\begin{array}{llll}\mathrm{H} & 8.66160 & 0.44360 & 18.16300\end{array}$

$\begin{array}{llll}\mathrm{H} & 8.91620 & 1.66420 & 19.16590\end{array}$

$\begin{array}{llll}\mathrm{H} & 12.01180 & 1.00400 & 13.89880\end{array}$

$\begin{array}{llll}\mathrm{H} & 11.29370 & -0.06200 & 14.85110\end{array}$

$\begin{array}{llll}\mathrm{H} & 10.52670 & 0.50880 & 13.56900\end{array}$

$\begin{array}{llll}\mathrm{H} & 9.84330 & 0.51090 & 16.39490\end{array}$

$\begin{array}{llll}\mathrm{H} & 11.99850 & 8.80960 & 12.75970\end{array}$

$\begin{array}{llll}\mathrm{H} & 13.47340 & 8.81380 & 13.37980\end{array}$

$\begin{array}{llll}\mathrm{H} & 13.04490 & 7.67010 & 12.34620\end{array}$

$\begin{array}{llll}\mathrm{H} & 14.45470 & 5.46350 & 17.61330\end{array}$

$\begin{array}{llll}\mathrm{H} & 15.04450 & 6.74070 & 16.84790\end{array}$

$\begin{array}{llll}\mathrm{H} & 14.10430 & 6.93730 & 18.12790\end{array}$

$\begin{array}{llll}\mathrm{H} & 13.98430 & 7.66060 & 15.18540\end{array}$

$\begin{array}{llll}\text { C } & 10.20472 & 7.35816 & 13.10243\end{array}$

$\begin{array}{llll}\mathrm{H} & 10.80151 & 7.48494 & 12.19200\end{array}$

$\begin{array}{llll}\mathrm{H} & 9.38811 & 6.66583 & 12.86804\end{array}$

$\begin{array}{llll}\mathrm{H} & 9.75600 & 8.32920 & 13.34083\end{array}$

$\begin{array}{llll}\mathrm{C} & 12.11974 & 4.95465 & 18.01633\end{array}$

$\begin{array}{llll}\mathrm{H} & 11.14269 & 4.75240 & 18.46972\end{array}$

$\begin{array}{llll}\mathrm{H} & 12.62596 & 3.99222 & 17.88006\end{array}$

$\begin{array}{llll}\mathrm{N} & 10.83249 & 3.14507 & 14.88771\end{array}$

$\begin{array}{llll}\mathrm{N} & 10.93969 & 6.85116 & 14.21744\end{array}$

$\begin{array}{llll}\mathrm{N} & 11.95806 & 5.51282 & 16.64412\end{array}$

$\begin{array}{llll}\mathrm{C} & 7.01393 & 9.00027 & 16.80831\end{array}$

$\begin{array}{llll}\text { C } & 5.26038 & 5.40931 & 13.85986\end{array}$

$\begin{array}{llll}\text { C } & 7.40153 & 7.68093 & 16.16033\end{array}$

$\begin{array}{llll}\mathrm{C} & 6.41923 & 7.04342 & 15.36206\end{array}$

$\begin{array}{llll}\text { C } & 6.50960 & 5.84631 & 14.60895\end{array}$

$\begin{array}{llll}\mathrm{C} & 8.18540 & 1.41395 & 18.17712\end{array}$

$\begin{array}{llll}\text { C } & 11.66362 & 0.81355 & 14.68596\end{array}$

$\begin{array}{llll}\text { C } & 9.00519 & 2.18362 & 17.15351\end{array}$

$\begin{array}{llll}\text { C } & 9.91499 & 1.43518 & 16.36642\end{array}$

$\begin{array}{llll}\mathrm{C} & 10.77154 & 1.86699 & 15.32463\end{array}$

$\begin{array}{llll}\text { C } & 12.48983 & 8.55401 & 13.28581\end{array}$

$\begin{array}{llll}\text { C } & 14.28670 & 6.14159 & 17.23300\end{array}$

$\begin{array}{llll}\text { C } & 12.13870 & 7.47125 & 14.29332\end{array}$

$\begin{array}{llll}\text { C } & 13.10944 & 7.17532 & 15.28059\end{array}$

$\begin{array}{llll}\text { C } & 13.04737 & 6.25928 & 16.35960\end{array}$

$\begin{array}{llll}\mathrm{H} & 7.67785 & 9.82339 & 16.47920\end{array}$

$\begin{array}{llll}\mathrm{H} & 5.97912 & 9.27930 & 16.55364\end{array}$

$\begin{array}{llll}\mathrm{H} & 7.09320 & 8.95572 & 17.91230\end{array}$

$\begin{array}{llll}\mathrm{H} & 4.90287 & 4.41974 & 14.20486\end{array}$

$\begin{array}{llll}\mathrm{H} & 4.44018 & 6.13176 & 13.99962\end{array}$

$\begin{array}{llll}\mathrm{H} & 5.44887 & 5.31418 & 12.77287\end{array}$

$\begin{array}{llll}\mathrm{H} & 5.45255 & 7.55682 & 15.31059\end{array}$

$\begin{array}{llll}\mathrm{H} & 7.09936 & 1.50803 & 17.98170\end{array}$

$\begin{array}{llll}\mathrm{H} & 8.43874 & 0.34196 & 18.16436\end{array}$

$\begin{array}{llll}\mathrm{H} & 8.35314 & 1.79173 & 19.20476\end{array}$

$\begin{array}{llll}\mathrm{H} & 12.73623 & 1.06101 & 14.80910\end{array}$

$\begin{array}{llll}\mathrm{H} & 11.49258 & -0.17737 & 15.13587\end{array}$ 


$\begin{array}{cccc}\mathrm{H} & 11.48379 & 0.72896 & 13.59656 \\ \mathrm{H} & 9.96121 & 0.36497 & 16.59636 \\ \mathrm{H} & 11.77779 & 9.40067 & 13.33454 \\ \mathrm{H} & 13.50067 & 8.95293 & 13.46842 \\ \mathrm{H} & 12.45657 & 8.17442 & 12.24607 \\ \mathrm{H} & 14.69316 & 5.11134 & 17.22641 \\ \mathrm{H} & 15.08329 & 6.81965 & 16.88689 \\ \mathrm{H} & 14.06684 & 6.38533 & 18.29061 \\ \mathrm{H} & 14.04377 & 7.74275 & 15.20273 \\ \mathrm{C} & 10.01233 & 7.25093 & 13.16089 \\ \mathrm{H} & 10.40023 & 7.04609 & 12.13996 \\ \mathrm{H} & 9.06359 & 6.68651 & 13.26970 \\ \mathrm{H} & 9.73795 & 8.32519 & 13.20653 \\ \mathrm{C} & 12.02990 & 4.59753 & 17.78182 \\ \mathrm{H} & 11.08404 & 4.02714 & 17.85928 \\ \mathrm{H} & 12.83906 & 3.84424 & 17.68291 \\ \mathrm{H} & 12.17544 & 5.12125 & 18.75095 \\ \mathrm{C} & 7.60756 & 3.87655 & 13.72765 \\ \mathrm{H} & 8.58299 & 3.35497 & 13.81887 \\ \mathrm{H} & 6.83999 & 3.14989 & 14.06523 \\ \mathrm{H} & 7.43701 & 4.06779 & 12.64655 \\ \mathrm{C} & 7.85895 & 4.17704 & 17.89740 \\ \mathrm{H} & 6.82992 & 3.78961 & 17.74771 \\ \mathrm{H} & 8.09683 & 4.08673 & 18.97929 \\ \mathrm{H} & 7.82264 & 5.25892 & 17.66137 \\ \mathrm{C} & 11.76287 & 3.47177 & 13.80914 \\ \mathrm{H} & 12.81996 & 3.25259 & 14.06616 \\ \mathrm{H} & 11.53095 & 2.94558 & 12.85859 \\ \mathrm{H} & 11.71809 & 4.56102 & 13.60096 \\ \mathrm{C} & 9.57423 & 7.93798 & 17.18823 \\ \mathrm{H} & 9.22885 & 8.07358 & 18.23565 \\ \mathrm{H} & 10.54687 & 7.40823 & 17.23273 \\ \mathrm{H} & 9.78623 & 8.94460 & 16.77152 \\ & & & \\ & & & \end{array}$

XYZ Coordinates XYZ Coordinates and Electronic Energies for U(IV) compound $[1]\left(\mathrm{BPh}_{4}\right)$

\begin{tabular}{|c|c|c|c|}
\hline & $\begin{array}{l}\text { ncation: } \\
262.2707\end{array}$ & $\begin{array}{l}\text { 6-D3BJ// } \\
23057 \mathrm{H}\end{array}$ & \\
\hline $\mathrm{U}$ & 4.92447 & 6.46384 & 1.74907 \\
\hline $\mathrm{N}$ & 6.14188 & 8.24393 & 0.62271 \\
\hline $\mathrm{N}$ & 5.67474 & 7.85064 & 3.60434 \\
\hline $\mathrm{N}$ & 3.61496 & 4.88123 & 3.01567 \\
\hline $\mathrm{N}$ & 2.79731 & 7.61154 & 2.06561 \\
\hline $\mathrm{N}$ & 4.41426 & 5.11382 & -0.18425 \\
\hline $\mathrm{N}$ & 6.96271 & 5.17341 & 1.40133 \\
\hline $\mathrm{C}$ & 5.22596 & 8.90537 & -1.58071 \\
\hline $\mathrm{C}$ & 5.22266 & 8.80342 & -2.98097 \\
\hline $\mathrm{C}$ & 6.06580 & 7.88267 & -3.62990 \\
\hline $\mathrm{C}$ & 6.91762 & 7.06545 & -2.86562 \\
\hline $\mathrm{C}$ & 6.93626 & 7.17355 & -1.46489 \\
\hline $\mathrm{C}$ & 6.09242 & 8.09737 & -0.80806 \\
\hline $\mathrm{C}$ & 6.22376 & 6.61558 & 5.67943 \\
\hline $\mathrm{C}$ & 5.85539 & 6.13128 & 6.94473 \\
\hline $\mathrm{C}$ & 4.54125 & 6.30186 & 7.41761 \\
\hline
\end{tabular}

\begin{tabular}{|c|c|c|c|}
\hline $\mathrm{C}$ & 3.59712 & 6.96637 & 6.61477 \\
\hline $\mathrm{C}$ & 3.96398 & 7.46664 & 5.35414 \\
\hline $\mathrm{C}$ & 5.28259 & 7.29892 & 4.87453 \\
\hline $\mathrm{C}$ & 7.48955 & 10.27569 & 0.14934 \\
\hline $\mathrm{C}$ & 6.72046 & 9.65150 & 4.95784 \\
\hline $\mathrm{C}$ & 6.79626 & 9.32367 & 1.10807 \\
\hline $\mathrm{C}$ & 6.90633 & 9.64270 & 2.48019 \\
\hline $\mathrm{C}$ & 6.40638 & 8.98798 & 3.62842 \\
\hline $\mathrm{C}$ & 4.92292 & 3.50563 & 4.60721 \\
\hline $\mathrm{C}$ & 5.63774 & 2.33554 & 4.90667 \\
\hline $\mathrm{C}$ & 5.86720 & 1.36677 & 3.91199 \\
\hline $\mathrm{C}$ & 5.37174 & 1.57679 & 2.61302 \\
\hline $\mathrm{C}$ & 4.64070 & 2.73827 & 2.31154 \\
\hline $\mathrm{C}$ & 4.40383 & 3.71385 & 3.30699 \\
\hline $\mathrm{C}$ & 2.11655 & 9.05238 & 0.16875 \\
\hline $\mathrm{C}$ & 2.06670 & 10.31181 & -0.44992 \\
\hline $\mathrm{C}$ & 2.70766 & 11.41902 & 0.13569 \\
\hline $\mathrm{C}$ & 3.39798 & 11.25681 & 1.35008 \\
\hline $\mathrm{C}$ & 3.43933 & 10.00196 & 1.98062 \\
\hline $\mathrm{C}$ & 2.79574 & 8.88621 & 1.39845 \\
\hline $\mathrm{C}$ & 1.80804 & 3.72409 & 4.27263 \\
\hline $\mathrm{C}$ & 0.47691 & 8.20413 & 2.73372 \\
\hline $\mathrm{C}$ & 2.35508 & 4.91906 & 3.51183 \\
\hline $\mathrm{C}$ & 1.47561 & 6.01055 & 3.35219 \\
\hline $\mathrm{C}$ & 1.65700 & 7.24865 & 2.69316 \\
\hline $\mathrm{C}$ & 1.94936 & 4.93374 & -0.00849 \\
\hline $\mathrm{C}$ & 0.66585 & 5.20768 & -0.51032 \\
\hline $\mathrm{C}$ & 0.50901 & 5.97199 & -1.68001 \\
\hline $\mathrm{C}$ & 1.64713 & 6.47339 & -2.33867 \\
\hline $\mathrm{C}$ & 2.93098 & 6.21738 & -1.83275 \\
\hline $\mathrm{C}$ & 3.09692 & 5.43170 & -0.66720 \\
\hline $\mathrm{C}$ & 8.71588 & 6.63099 & 2.36858 \\
\hline $\mathrm{C}$ & 9.69273 & 6.88361 & 3.34628 \\
\hline $\mathrm{C}$ & 9.90714 & 5.96558 & 4.38978 \\
\hline $\mathrm{C}$ & 9.12838 & 4.79548 & 4.45400 \\
\hline $\mathrm{C}$ & 8.14134 & 4.54465 & 3.48746 \\
\hline $\mathrm{C}$ & 7.93136 & 5.45663 & 2.42671 \\
\hline $\mathrm{C}$ & 4.50071 & 3.50575 & -2.07891 \\
\hline $\mathrm{C}$ & 8.68288 & 3.61354 & 0.51316 \\
\hline $\mathrm{C}$ & 5.12903 & 4.20026 & -0.88365 \\
\hline $\mathrm{C}$ & 6.44828 & 3.81656 & -0.56315 \\
\hline $\mathrm{C}$ & 7.30263 & 4.24665 & 0.47859 \\
\hline $\mathrm{H}$ & 4.56601 & 9.61955 & -1.07565 \\
\hline $\mathrm{H}$ & 4.55862 & 9.45001 & -3.56814 \\
\hline $\mathrm{H}$ & 6.06510 & 7.80878 & -4.72419 \\
\hline $\mathrm{H}$ & 7.58576 & 6.35032 & -3.36100 \\
\hline $\mathrm{H}$ & 7.61767 & 6.55621 & -0.87114 \\
\hline $\mathrm{H}$ & 7.24613 & 6.47819 & 5.30995 \\
\hline $\mathrm{H}$ & 6.60149 & 5.61965 & 7.56554 \\
\hline $\mathrm{H}$ & 4.25741 & 5.92702 & 8.40851 \\
\hline $\mathrm{H}$ & 2.57203 & 7.11311 & 6.97656 \\
\hline $\mathrm{H}$ & 3.23656 & 8.00647 & 4.73987 \\
\hline $\mathrm{H}$ & 6.75244 & 10.87956 & -0.41029 \\
\hline $\mathrm{H}$ & 8.15327 & 10.96544 & 0.69284 \\
\hline $\mathrm{H}$ & 8.08169 & 9.72717 & -0.60429 \\
\hline $\mathrm{H}$ & 7.46801 & 9.06735 & 5.52448 \\
\hline
\end{tabular}




$\begin{array}{lrlllllr}\mathrm{H} & 7.12330 & 10.66446 & 4.80530 & \mathrm{H} & 0.49155 & 5.87632 & 3.81120 \\ \mathrm{H} & 5.82256 & 9.71511 & 5.59753 & \mathrm{H} & 2.07227 & 4.31525 & 0.88607 \\ \mathrm{H} & 7.47562 & 10.55306 & 2.68950 & \mathrm{H} & -0.21341 & 4.80526 & 0.00740 \\ \mathrm{H} & 4.75029 & 4.26228 & 5.38064 & \mathrm{H} & -0.49281 & 6.16973 & -2.08028 \\ \mathrm{H} & 6.01664 & 2.17944 & 5.92443 & \mathrm{H} & 1.53579 & 7.06743 & -3.25435 \\ \mathrm{H} & 6.42217 & 0.45120 & 4.15007 & \mathrm{H} & 3.81633 & 6.61326 & -2.34262 \\ \mathrm{H} & 5.53780 & 0.82544 & 1.83136 & \mathrm{H} & 8.56803 & 7.33206 & 1.54110 \\ \mathrm{H} & 4.23150 & 2.88798 & 1.30754 & \mathrm{H} & 10.30025 & 7.79457 & 3.28023 \\ \mathrm{H} & 1.61952 & 8.19011 & -0.28950 & \mathrm{H} & 10.68153 & 6.15621 & 5.14274 \\ \mathrm{H} & 1.52047 & 10.42863 & -1.39427 & \mathrm{H} & 9.29165 & 4.06969 & 5.26045 \\ \mathrm{H} & 2.66218 & 12.40301 & -0.34665 & \mathrm{H} & 7.53355 & 3.63444 & 3.53946 \\ \mathrm{H} & 3.89357 & 12.11459 & 1.82115 & \mathrm{H} & 4.42455 & 4.19039 & -2.94308 \\ \mathrm{H} & 3.95356 & 9.88226 & 2.93941 & \mathrm{H} & 5.10359 & 2.63739 & -2.38636 \\ \mathrm{H} & 2.25975 & 3.65077 & 5.27853 & \mathrm{H} & 3.47409 & 3.16630 & -1.85468 \\ \mathrm{H} & 0.71721 & 3.80701 & 4.39612 & \mathrm{H} & 8.77475 & 2.90472 & 1.35598 \\ \mathrm{H} & 2.03775 & 2.77635 & 3.75448 & \mathrm{H} & 8.88399 & 3.06206 & -0.41819 \\ \mathrm{H} & -0.01441 & 8.27205 & 1.74618 & \mathrm{H} & 9.47129 & 4.37365 & 0.65555 \\ \mathrm{H} & -0.27441 & 7.86711 & 3.46444 & \mathrm{H} & 6.87968 & 3.06129 & -1.22688 \\ \mathrm{H} & 0.79630 & 9.22817 & 2.99621 & & & & \end{array}$

\section{References for Computations}

(1) Neese, F. Software update: the ORCA program system, version 4.0. Wiley Interdiscip. Rev.: Comput. Mol. Sci. 2018, 8, 1327.

(2) Neese, F. The ORCA program system. Wiley Interdiscip. Rev.: Comput. Mol. Sci. 2012, 2, 73-78.

(3) Becke, A. D. Density-functional exchange-energy approximation with correct asymptotic behavior. Phys. Rev. A 1988, 38, 3098-3100.

(4) Perdew, J. P. Density-functional approximation for the correlation energy of the inhomogeneous electron gas. Phys. Rev. B 1986, 33, 8822-8824.

(5) Lee, C.; Yang, W.; Parr, R. G. Development of the Colle-Salvetti correlation-energy formula into a functional of the electron density. Phys. Rev. B: Condens. Matter 1988, 37, 785-789.

(6) Grimme, S.; Ehrlich, S.; Goerigk, L. Effect of the damping function in dispersion corrected density functional theory. J. Comput. Chem. 2011, 32, 1456-1465.

(7) Grimme, S.; Antony, J.; Ehrlich, S.; Krieg, H. A consistent and accurate ab initio parametrization of density functional dispersion correction (DFT-D) for the 94 elements HPu. J. Chem. Phys. 2010, 132, 154104.

(8) Weigend, F.; Ahlrichs, R. Balanced basis sets of split valence, triple zeta valence and quadruple zeta valence quality for $\mathrm{H}$ to Rn: Design and assessment of accuracy. Phys. Chem. Chem. Phys. 2005, 7, 3297-3305.

(9) Pantazis, D. A.; Nesse, F. All-Electron Scalar Relativistic Basis Sets for the Actinides. 
J. Chem. Theory Comput. 2011, 7, 677-684.

(10) Wolf, A.; Reiher, M.; Hess, B. A. The generalized Douglas-Kroll transformation. $J$. Chem. Phys. 2002, 117, 9215-9226.

(11) Lenthe, E. v.; Baerends, E. J.; Snijders, J. G. Relativistic regular two-component Hamiltonians. J. Chem. Phys. 1993, 99, 4597-4610.

(12) Wüllen, C. v. Molecular density functional calculations in the regular relativistic approximation: Method, application to coinage metal diatomics, hydrides, fluorides and chlorides, and comparison with first-order relativistic calculations J. Chem. Phys. 1998, 109, 392-399.

(13) Dolg, W. M.; Stoll, H.; Preuss, H. Energy-adjusted pseudopotentials for the actinides. Parameter sets and test calculations for thorium and thorium monoxide. J. Chem. Phys. 1994, $100,7535-7542$.

(14) Cao, X.; Dolg, M.; Stoll, H. Valence basis sets for relativistic energy-consistent smallcore actinide pseudopotentials. J. Chem. Phys. 2003, 118, 487-496.

(15) Weigend F. Accurate Coulomb-fitting basis sets for H to Rn. Phys. Chem. Chem. Phys. 2006, $8,1057-1065$.

(16) Becke, A. D. Density-functional thermochemistry. III. The role of exact exchange $J$. Chem. Phys. 1993, 98, 5648-5652.

(17) Rosenzweig, M.W.; Scheurer, A.; Lamsfus, C. A.; Heinemann, F. W.; Maron, L.; Andrez, J.; Mazzanti, M.; Meyer, K. Uranium(IV) terminal hydrosulfido and sulfido complexes: insights into the nature of the uranium-sulfur bond. Chem. Sci. 2016, 7, 58575866 .

(18) Halter, D. P.; Heinemann, F. W.; Maron, L.; Meyer, K. The role of uranium-arene bonding in $\mathrm{H}_{2} \mathrm{O}$ reduction catalysis. Nat. Chem. 2017, 10, 259. 